Cochrane Database of Systematic Reviews

\title{
Relaxation techniques for pain management in labour (Review)
}

Smith CA, Levett KM, Collins CT, Armour M, Dahlen HG, Suganuma M

Smith CA, Levett KM, Collins CT, Armour M, Dahlen HG, Suganuma M.

Relaxation techniques for pain management in labour.

Cochrane Database of Systematic Reviews 2018, Issue 3. Art. No.: CD009514.

DOI: 10.1002/14651858.CD009514.pub2.

www.cochranelibrary.com 
TABLE OF CONTENTS

ABSTRACT

PLAIN LANGUAGE SUMMARY

SUMMARY OF FINDINGS

BACKGROUND

OBJECTIVES

METHODS

RESULTS

Figure 1.

Figure 2.

Figure 3.

DISCUSSION

AUTHORS' CONCLUSIONS

ACKNOWLEDGEMENTS

REFERENCES

CHARACTERISTICS OF STUDIES

DATA AND ANALYSES

Analysis 1.1. Comparison 1 Relaxation versus usual care, Outcome 1 Pain intensity.

Analysis 1.2. Comparison 1 Relaxation versus usual care, Outcome 2 Pain intensity.

Analysis 1.3. Comparison 1 Relaxation versus usual care, Outcome 3 Satisfaction with pain relief.

Analysis 1.4. Comparison 1 Relaxation versus usual care, Outcome 4 Satisfaction with childbirth experience. ..........................

Analysis 1.5. Comparison 1 Relaxation versus usual care, Outcome 5 Assisted vaginal birth.

Analysis 1.6. Comparison 1 Relaxation versus usual care, Outcome 6 Caesarean section.

Analysis 1.7. Comparison 1 Relaxation versus usual care, Outcome 7 Admission to special care nursery.

Analysis 1.8. Comparison 1 Relaxation versus usual care, Outcome 8 Low Apgar score $<7$ at 5 minutes.

Analysis 1.9. Comparison 1 Relaxation versus usual care, Outcome 9 Use of pharmacological pain relief.

Analysis 1.10. Comparison 1 Relaxation versus usual care, Outcome 10 Length of labour.

Analysis 1.11. Comparison 1 Relaxation versus usual care, Outcome 11 Need for augmentation with oxytocin.

Analysis 1.12. Comparison 1 Relaxation versus usual care, Outcome 12 Anxiety.

Analysis 1.13. Comparison 1 Relaxation versus usual care, Outcome 13 Non-prespecified: vitality.

Analysis 1.14. Comparison 1 Relaxation versus usual care, Outcome 14 Non-prespecified: fatigue in labour.

Analysis 2.1. Comparison 2 Yoga versus control, Outcome 1 Pain intensity.

Analysis 2.2. Comparison 2 Yoga versus control, Outcome 2 Satisfaction with pain relief.

Analysis 2.3. Comparison 2 Yoga versus control, Outcome 3 Satisfaction with childbirth experience.

Analysis 2.4. Comparison 2 Yoga versus control, Outcome 4 Low Apgar score $<7$ at 5 minutes.

Analysis 2.5. Comparison 2 Yoga versus control, Outcome 5 Use of pharmacological pain relief.

Analysis 2.6. Comparison 2 Yoga versus control, Outcome 6 Length of labour.

Analysis 2.7. Comparison 2 Yoga versus control, Outcome 7 Need for augmentation with oxytocin.

Analysis 3.1. Comparison 3 Music versus control, Outcome 1 Pain intensity.

Analysis 3.2. Comparison 3 Music versus control, Outcome 2 Assisted vaginal birth.

Analysis 3.3. Comparison 3 Music versus control, Outcome 3 Caesarean section.

Analysis 3.4. Comparison 3 Music versus control, Outcome 4 Admission to special care nursery.

Analysis 3.5. Comparison 3 Music versus control, Outcome 5 Use of pharmacological pain relief.

Analysis 3.6. Comparison 3 Music versus control, Outcome 6 Length of labour.

Analysis 3.7. Comparison 3 Music versus control, Outcome 7 Anxiety.

Analysis 4.1. Comparison 4 Audio-analgesia versus control, Outcome 1 Satisfaction with pain relief.

Analysis 5.1. Comparison 5 Mindfulness training versus usual care, Outcome 1 Sense of control in labour.

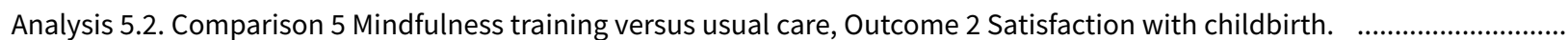

Analysis 5.3. Comparison 5 Mindfulness training versus usual care, Outcome 3 Assisted vaginal birth.

Analysis 5.4. Comparison 5 Mindfulness training versus usual care, Outcome 4 Caesarean section. 
[Intervention Review]

\title{
Relaxation techniques for pain management in labour
}

\author{
Caroline A Smith ${ }^{1}$, Kate M Levett ${ }^{2}$, Carmel T Collins ${ }^{3}$, Mike Armour ${ }^{1}$, Hannah G Dahlen ${ }^{4}$, Machiko Suganuma ${ }^{3}$
}

${ }^{1}$ National Institute of Complementary Medicine (NICM), Western Sydney University, Penrith, Australia. ${ }^{2}$ School of Medicine, The University of Notre Dame, Sydney, Australia. ${ }^{3}$ Healthy Mothers, Babies and Children, South Australian Health and Medical Research Institute, North Adelaide, Australia. ${ }^{4}$ School of Nursing and Midwifery, Western Sydney University, Penrith, Australia

Contact: Caroline A Smith, National Institute of Complementary Medicine (NICM), Western Sydney University, Locked Bag 1797, Penrith, New South Wales, 2751, Australia. caroline.smith@westernsydney.edu.au.

Editorial group: Cochrane Pregnancy and Childbirth Group.

Publication status and date: New search for studies and content updated (no change to conclusions), published in Issue 3, 2018.

Citation: Smith CA, Levett KM, Collins CT, Armour M, Dahlen HG, Suganuma M. Relaxation techniques for pain management in labour. Cochrane Database of Systematic Reviews 2018, Issue 3. Art. No.: CD009514. DOI: 10.1002/14651858.CD009514.pub2.

Copyright @ 2018 The Cochrane Collaboration. Published by John Wiley \& Sons, Ltd.

\section{A B S T R A C T}

\section{Background}

Many women would like to avoid pharmacological or invasive methods of pain management in labour and this may contribute to the popularity of complementary methods of pain management. This review examined currently available evidence on the use of relaxation therapies for pain management in labour. This is an update of a review first published in 2011.

\section{Objectives}

To examine the effects of mind-body relaxation techniques for pain management in labour on maternal and neonatal well-being during and after labour.

\section{Search methods}

We searched Cochrane Pregnancy and Childbirth's Trials Register (9 May 2017), the Cochrane Central Register of Controlled Trials (CENTRAL) (The Cochrane Library, Issue 5 2017), MEDLINE (1966 to 24 May 2017), CINAHL (1980 to 24 May 2017), the Australian New Zealand Clinical Trials Registry (18 May 2017), ClinicalTrials.gov (18 May 2017), the ISRCTN Register (18 May 2017), the WHO International Clinical Trials Registry Platform (ICTRP) (18 May 2017), and reference lists of retrieved studies.

\section{Selection criteria}

Randomised controlled trials (including quasi randomised and cluster trials) comparing relaxation methods with standard care, no treatment, other non-pharmacological forms of pain management in labour or placebo.

\section{Data collection and analysis}

Two review authors independently assessed trials for inclusion and risk of bias, extracted data and checked them for accuracy. We attempted to contact study authors for additional information. We assessed evidence quality with GRADE methodology.

\section{Main results}

This review update includes 19 studies (2519 women), 15 of which (1731 women) contribute data. Interventions examined included relaxation, yoga, music and mindfulness. Approximately half of the studies had a low risk of bias for random sequence generation and attrition bias. The majority of studies had a high risk of bias for performance and detection bias, and unclear risk of bias for, allocation concealment, reporting bias and other bias. We assessed the evidence from these studies as ranging from low to very low quality, and therefore the effects below should be interpreted with caution.

\section{Relaxation}


We found that relaxation compared to usual care provided lowered the intensity of pain (measured on a scale of 0 to 10 with low scores indicating less pain) during the latent phase of labour (mean difference (MD) $-1.25,95 \%$ confidence interval ( $\mathrm{Cl}$ ) -1.97 to -0.53 , one trial, 40 women). Four trials reported pain intensity in the active phase; there was high heterogeneity between trials and very low-quality evidence suggested that there was no strong evidence that the effects were any different between groups for this outcome (MD $-1.08,95 \% \mathrm{Cl}-2.57$ to 0.41 , four trials, 271 women, random-effects analysis). Very low-quality evidence showed that women receiving relaxation reported greater satisfaction with pain relief during labour (risk ratio (RR) $8.00,95 \% \mathrm{Cl} 1.10$ to 58.19 , one trial, 40 women), and showed no clear benefit for satisfaction with childbirth experience (assessed using different scales) (standard mean difference (SMD) $-0.03,95 \% \mathrm{Cl}-0.37$ to 0.31 , three trials, 1176 women). For safety outcomes there was very low-quality evidence of no clear reduction in assisted vaginal birth (average $\mathrm{RR} 0.61,95 \% \mathrm{Cl} 0.20$ to 1.84 , four trials, 1122 women) or in caesarean section rates (average RR $0.73,95 \% \mathrm{Cl} 0.26$ to 2.01 , four trials, 1122 women). Sense of control in labour, and breastfeeding were not reported under this comparison.

\section{Yoga}

When comparing yoga to control interventions there was low-quality evidence that yoga lowered pain intensity (measured on a scale of 0 to 10 ) with low scores indicating less pain) (MD -6.12, 95\% Cl -11.77 to -0.47 , one trial, 66 women), greater satisfaction with pain relief (MD 7.88, 95\% Cl 1.51 to 14.25, one trial, 66 women) and greater satisfaction with childbirth experience (MD $6.34,95 \% \mathrm{Cl} 0.26$ to 12.42 one trial, 66 women (assessed using the Maternal Comfort Scale with higher score indicating greater comfort). Sense of control in labour, breastfeeding, assisted vaginal birth, and caesarean section were not reported under this comparison.

\section{Music}

When comparing music to control interventions there was evidence of lower pain intensity in the latent phase for women receiving music (measured on a scale of 0 to 10 with low scores indicating less pain) (MD $-0.73,95 \% \mathrm{Cl}-1.01$ to -0.45 , random-effects analysis, two trials, 192 women) and very low-quality evidence of no clear benefit in the active phase (MD $-0.51,95 \% \mathrm{Cl}-1.10$ to 0.07 , three trials, 217 women). Very low-quality evidence suggested no clear benefit in terms of reducing assisted vaginal birth (RR $0.41,95 \% \mathrm{Cl} 0.08$ to 2.05 , one trial, 156 women) or caesarean section rate (RR $0.78,95 \% \mathrm{Cl} 0.36$ to 1.70 , two trials, 216 women). Satisfaction with pain relief, sense of control in labour, satisfaction with childbirth experience, and breastfeeding were not reported under this comparison.

\section{Audio analgesia}

One trial evaluating audio analgesia versus control only reported one outcome and showed no evidence of benefit in satisfaction with pain relief.

\section{Mindfulness}

One trial evaluating mindfulness versus usual care found an increase in sense of control for the mindfulness group (using the Childbirth Self-Efficacy Inventory) (MD 31.30, 95\% Cl 1.61 to 60.99, 26 women). There is no strong evidence that the effects were any different between groups for satisfaction in childbirth, or for caesarean section rate, need for assisted vaginal delivery or need for pharmacological pain relief. No other outcomes were reported in this trial.

\section{Authors' conclusions}

Relaxation, yoga and music may have a role with reducing pain, and increasing satisfaction with pain relief, although the quality of evidence varies between very low to low. There was insufficient evidence for the role of mindfulness and audio-analgesia. The majority of trials did not report on the safety of the interventions. Further randomised controlled trials of relaxation modalities for pain management in labour are needed. Trials should be adequately powered and include clinically relevant outcomes such as those described in this review.

\section{PLAIN LANGUAGE SUMMARY}

\section{Relaxation techniques for pain management in labour}

\section{What is the issue?}

This Cochrane Review looked at whether mind-body techniques for relaxation such as breathing techniques, visualisation, yoga or music would help with reducing pain, and improve women's experiences of labour. We collected and analysed all relevant studies to answer this question (date of search: May 2017).

\section{Why is this important?}

The pain of labour can be intense, with body tension, anxiety and fear making it worse. Many women would like to go through labour without using drugs, or invasive methods such as an epidural. These women often turn to complementary therapies to help to reduce the intensity of pain in labour and improve their experiences of labour.

Many complementary therapies are used by women in labour, including acupuncture, mind-body techniques, massage, reflexology, herbal medicines or homoeopathy, hypnosis, music and aromatherapy. Mind-body techniques for relaxation can be widely accessible to 
women through the teaching of these techniques during antenatal classes. The relaxation techniques include guided imagery, progressive relaxation and breathing techniques. We also include yoga and music in this review. Other Cochrane Reviews cover hypnosis in labour, manual methods (like massage and reflexology), aromatherapy and acupuncture/acupressure. Many of these relaxation techniques are coping strategies used to reduce the experience of pain. These techniques utilise practices that aim to reduce stress and reduce the perception of pain. It is important to examine if these therapies work and are safe, to enable women to make informed decisions about their care.

\section{What evidence did we find?}

We found 15 studies involving 1731 women that contributed data to the analyses. Studies were undertaken across the world, including countries in Europe and Scandinavia, and Iran, Taiwan, Thailand, Turkey and USA.

We found that relaxation techniques, yoga and music may help women manage labour pain, although the quality of the evidence varied between low and very low, and more data are needed. Also, in these trials there were variations in how these techniques were used. There was no clear evidence that these therapies had an impact on assisted vaginal or caesarean birth. There were insufficient data to say if these techniques influenced the baby's condition at birth.

\section{What does this mean?}

The use of some relaxation therapies, yoga, or music may possibly be helpful with reducing the intensity of pain, and in helping women feel more in control and satisfied with their labours. However, the wide variations in types of techniques used in these studies make it difficult to say specifically what might help women. Therefore further research studies are needed. 


\begin{tabular}{|c|c|c|c|c|c|c|}
\hline \multicolumn{7}{|c|}{$\begin{array}{l}\text { S U M M A R Y O F F I N D I N G S } \\
\text { Summary of findings for the main comparison. Relaxation compared to usual care for pain management in labour }\end{array}$} \\
\hline \multicolumn{7}{|c|}{ Relaxation compared to usual care for pain management in labour } \\
\hline \multicolumn{7}{|c|}{$\begin{array}{l}\text { Patient or population: women in labour } \\
\text { Setting: hospital settings in Brazil, Italy, Sweden, Turkey, UK } \\
\text { Intervention: relaxation } \\
\text { Comparison: usual care }\end{array}$} \\
\hline \multirow[t]{2}{*}{ Outcomes } & \multicolumn{2}{|c|}{ Anticipated absolute effects ${ }^{*}(95 \% \mathrm{Cl})$} & \multirow{2}{*}{$\begin{array}{l}\text { Relative effect } \\
(95 \% \mathrm{CI})\end{array}$} & \multirow{2}{*}{$\begin{array}{l}\text { No of partici- } \\
\text { pants } \\
\text { (studies) }\end{array}$} & \multirow{2}{*}{$\begin{array}{l}\text { Quality of the } \\
\text { evidence } \\
\text { (GRADE) }\end{array}$} & \multirow[t]{2}{*}{ Comments } \\
\hline & Risk with usual care & Risk with relaxation & & & & \\
\hline $\begin{array}{l}\text { Pain intensity: active phase } \\
\text { (lower scores indicate less intense } \\
\text { pain) }\end{array}$ & $\begin{array}{l}\text { The mean pain intensity - } \\
\text { active phase was } 7.8\end{array}$ & $\begin{array}{l}\text { MD } 1.08 \text { lower } \\
\text { ( } 2.57 \text { lower to } 0.41 \text { high- } \\
\text { er) }\end{array}$ & - & $\begin{array}{l}271 \\
\text { (4 RCTs) }\end{array}$ & $\begin{array}{l}\oplus \ominus \odot \odot \\
\text { Very low1,2,3,4 }\end{array}$ & \\
\hline \multirow{2}{*}{$\begin{array}{l}\text { Satisfaction with pain relief } \\
\text { (higher proportion high satisfaction) }\end{array}$} & \multicolumn{2}{|l|}{ Study population } & \multirow{2}{*}{$\begin{array}{l}\text { RR } 8.00 \\
\text { (1.10 to } 58.19)\end{array}$} & \multirow{2}{*}{$\begin{array}{l}40 \\
(1 \mathrm{RCT})\end{array}$} & \multirow{2}{*}{$\begin{array}{l}\oplus \ominus \odot \ominus \\
\text { Very low } 5,6\end{array}$} & \\
\hline & 50 per 1000 & $\begin{array}{l}400 \text { per } 1000 \\
(55 \text { to } 1000)\end{array}$ & & & & \\
\hline Sense of control in labour & - & - & - & - & - & $\begin{array}{l}\text { No trial report- } \\
\text { ed this out- } \\
\text { come }\end{array}$ \\
\hline $\begin{array}{l}\text { Satisfaction with childbirth experi- } \\
\text { ence } \\
\text { (higher scores indicate more satis- } \\
\text { faction) }\end{array}$ & $\begin{array}{l}\text { The mean satisfaction } \\
\text { with childbirth experience } \\
\text { using a variety of outcome } \\
\text { measures was } 27.1\end{array}$ & $\begin{array}{l}\text { SMD } 0.03 \text { lower } \\
\text { ( } 0.37 \text { lower to } 0.31 \text { high- } \\
\text { er) }\end{array}$ & - & $\begin{array}{l}1176 \\
\text { (3 RCTs) }\end{array}$ & $\begin{array}{l}\oplus \Theta \Theta \Theta \\
\text { Very low } 2,4,7\end{array}$ & \\
\hline Breastfeeding & - & - & - & - & - & $\begin{array}{l}\text { No trial report- } \\
\text { ed this out- } \\
\text { come }\end{array}$ \\
\hline \multirow[t]{2}{*}{ Assisted vaginal birth } & \multicolumn{2}{|l|}{ Study population } & \multirow{2}{*}{$\begin{array}{l}\text { Average RR } 0.61 \\
(0.20 \text { to } 1.84)\end{array}$} & \multirow{2}{*}{$\begin{array}{l}1122 \\
\text { (4 RCTs) }\end{array}$} & \multirow{2}{*}{$\begin{array}{l}\oplus \odot \Theta \odot \\
\text { Very low2,8,9 }\end{array}$} & \\
\hline & 149 per 1000 & $\begin{array}{l}91 \text { per } 1000 \\
\text { (30 to } 275 \text { ) }\end{array}$ & & & & \\
\hline
\end{tabular}

Setting: hospital settings in Brazil, Italy, Sweden, Turkey, UK

ntervention: relaxation 


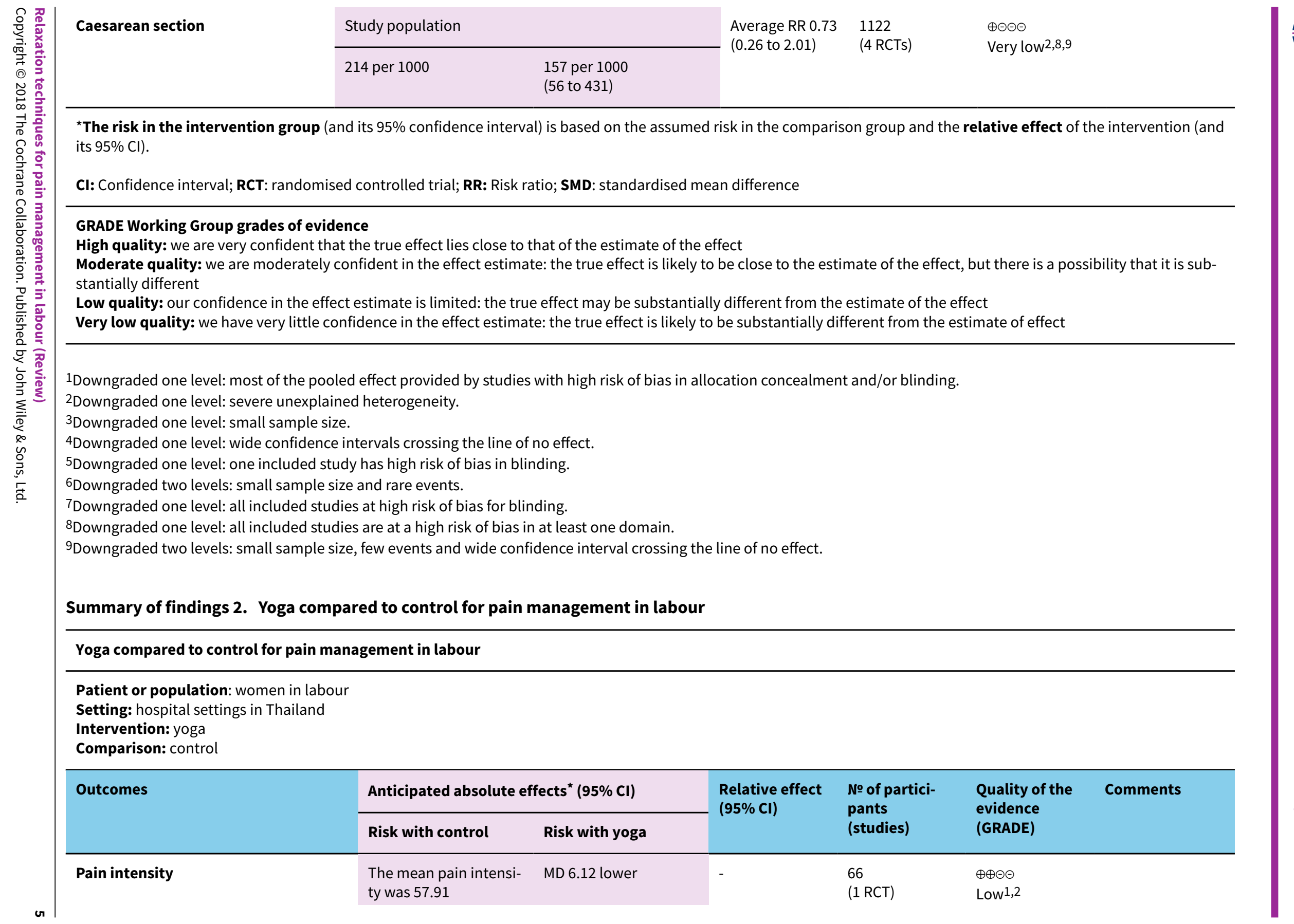




satisfaction with pain relief

\section{Satisfaction with pain relief}

Higher scores indicate greater satisfac-

The mean satisfaction

lower)

Higher scores indicate
tion with pain relief

Sense of control in labour

with pain relief was 45

MD 7.88 higher

(1.51 higher to 14.25

66

higher)

(1 RCT)

$\oplus \oplus \ominus \ominus$

\begin{tabular}{|c|c|c|c|c|c|c|}
\hline Sense of control in labour & - & - & - & - & - & $\begin{array}{l}\text { No trial reported } \\
\text { this outcome }\end{array}$ \\
\hline $\begin{array}{l}\text { Satisfaction with childbirth experi- } \\
\text { ence }\end{array}$ & $\begin{array}{l}\text { The mean satisfaction } \\
\text { with childbirth experi- } \\
\text { ence was } 150.36\end{array}$ & $\begin{array}{l}\text { MD } 6.34 \text { higher } \\
\text { (0.26 higher to } 12.42 \\
\text { higher) }\end{array}$ & - & $\begin{array}{l}66 \\
(1 \mathrm{RCT})\end{array}$ & $\begin{array}{l}\oplus \oplus \ominus \ominus \\
\text { Low }^{1,2}\end{array}$ & \\
\hline
\end{tabular}

(higher scores indicate greater satisfac-

ence was 150.36

higher)

\begin{tabular}{|c|c|c|c|c|}
\hline Breastfeeding & - & - & - & $\begin{array}{l}\text { No trial reported } \\
\text { this outcome }\end{array}$ \\
\hline Assisted vaginal birth & - & - & - & $\begin{array}{l}\text { No trial reported } \\
\text { this outcome }\end{array}$ \\
\hline Caesarean section & - & - & - & $\begin{array}{l}\text { No trial reported } \\
\text { this outcome }\end{array}$ \\
\hline
\end{tabular}

${ }^{*}$ The risk in the intervention group (and its $95 \%$ confidence interval) is based on the assumed risk in the comparison group and the relative effect of the intervention (and its $95 \% \mathrm{Cl})$.

Cl: Confidence interval; MD: mean difference; $\mathbf{R C T}$ : randomised controlled trial; RR: Risk ratio

\section{GRADE Working Group grades of evidence}

High quality: we are very confident that the true effect lies close to that of the estimate of the effect

Moderate quality: we are moderately confident in the effect estimate: the true effect is likely to be close to the estimate of the effect, but there is a possibility that it is sub-

stantially different

Low quality: our confidence in the effect estimate is limited: the true effect may be substantially different from the estimate of the effect

Very low quality: we have very little confidence in the effect estimate: the true effect is likely to be substantially different from the estimate of effect

1Downgraded one level: high risk of bias in blinding domains.

2Downgraded one level: small sample size. 


\begin{tabular}{|c|c|c|c|c|c|c|}
\hline \multicolumn{7}{|c|}{ Music compared to control for pain management in labour } \\
\hline \multicolumn{7}{|c|}{$\begin{array}{l}\text { Patient or population: women in labour } \\
\text { Setting: hospital settings in Italy, Taiwan, and Turkey } \\
\text { Intervention: music } \\
\text { Comparison: control }\end{array}$} \\
\hline \multirow[t]{2}{*}{ Outcomes } & \multicolumn{2}{|c|}{ Anticipated absolute effects ${ }^{*}(95 \% \mathrm{Cl})$} & \multirow{2}{*}{$\begin{array}{l}\text { Relative effect } \\
(95 \% \mathrm{Cl})\end{array}$} & \multirow{2}{*}{$\begin{array}{l}\text { № of partici- } \\
\text { pants } \\
\text { (studies) }\end{array}$} & \multirow{2}{*}{$\begin{array}{l}\text { Quality of the } \\
\text { evidence } \\
\text { (GRADE) }\end{array}$} & \multirow[t]{2}{*}{ Comments } \\
\hline & Risk with control & Risk with music & & & & \\
\hline $\begin{array}{l}\text { Pain intensity - active phase } \\
\text { (lower scores indicate less intense } \\
\text { pain) }\end{array}$ & $\begin{array}{l}\text { The mean pain inten- } \\
\text { sity - active phase } \\
\text { was } 8.61\end{array}$ & $\begin{array}{l}\text { MD } 0.51 \text { lower } \\
\text { (1.10 lower to } 0.07 \\
\text { higher) }\end{array}$ & - & $\begin{array}{l}217 \\
\text { (3 RCTs) }\end{array}$ & $\begin{array}{l}\oplus \odot \Theta \Theta \\
\text { Very low } 1,2,3\end{array}$ & \\
\hline Satisfaction with pain relief & - & - & - & - & - & $\begin{array}{l}\text { No trial reported this } \\
\text { outcome }\end{array}$ \\
\hline Sense of control in labour & - & - & - & - & - & $\begin{array}{l}\text { No trial reported this } \\
\text { outcome }\end{array}$ \\
\hline $\begin{array}{l}\text { Satisfaction with childbirth experi- } \\
\text { ence }\end{array}$ & - & - & - & - & - & $\begin{array}{l}\text { No trial reported this } \\
\text { outcome }\end{array}$ \\
\hline Breastfeeding & - & - & - & - & - & $\begin{array}{l}\text { No trial reported this } \\
\text { outcome }\end{array}$ \\
\hline \multirow[t]{2}{*}{ Assisted vaginal birth } & \multicolumn{2}{|l|}{ Study population } & \multirow{2}{*}{$\begin{array}{l}\text { RR } 0.41 \\
\text { (0.08 to } 2.05)\end{array}$} & \multirow{2}{*}{$\begin{array}{l}156 \\
(1 \mathrm{RCT})\end{array}$} & \multirow{2}{*}{$\begin{array}{l}\oplus \ominus \odot \odot \\
\text { Very low } 4,5\end{array}$} & \\
\hline & 63 per 1000 & $\begin{array}{l}26 \text { per } 1000 \\
(5 \text { to } 130)\end{array}$ & & & & \\
\hline \multirow[t]{2}{*}{ Caesarean section } & Study population & & \multirow{2}{*}{$\begin{array}{l}\text { RR } 0.78 \\
(0.36 \text { to } 1.70)\end{array}$} & \multirow{2}{*}{$\begin{array}{l}216 \\
(2 \mathrm{RCTs})\end{array}$} & \multirow{2}{*}{$\begin{array}{l}\oplus \odot \odot \odot \\
\text { Very low } 1,5\end{array}$} & \\
\hline & 119 per 1000 & $\begin{array}{l}93 \text { per } 1000 \\
\text { (43 to } 203)\end{array}$ & & & & \\
\hline \multicolumn{7}{|c|}{$\begin{array}{l}{ }^{\star} \text { The risk in the intervention group (and its } 95 \% \text { confidence interval) is based on the assumed risk in the comparison group and the relative effect of the intervention (and } \\
\text { its } 95 \% \mathrm{Cl} \text { ). }\end{array}$} \\
\hline \multicolumn{7}{|c|}{ Cl: Confidence interval; $\mathbf{R C T}$ : randomised controlled trial; RR: Risk ratio } \\
\hline
\end{tabular}


GRADE Working Group grades of evidence

High quality: we are very confident that the true effect lies close to that of the estimate of the effect

Moderate quality: we are moderately confident in the effect estimate: the true effect is likely to be close to the estimate of the effect, but there is a possibility that it is substantially different

Low quality: our confidence in the effect estimate is limited: the true effect may be substantially different from the estimate of the effect

Very low quality: we have very little confidence in the effect estimate: the true effect is likely to be substantially different from the estimate of effect

1Downgraded two levels: all included studies had at least two domains with high risk of bias

2Downgraded one level: small sample size.

${ }^{3}$ Downgraded one level: severe unexplained heterogeneity.

4Downgraded two levels: the included study was at a high risk of bias in four domains.

${ }^{5}$ Downgraded two levels: small sample size, few events, and wide confidence interval crossing the line of no effect. 


\section{B A C K G R O U N D}

This review is one in a series of Cochrane Reviews examining pain management in labour. An earlier version of this review contributed to an overview of systematic reviews of pain management for women in labour (Jones 2012), and share a generic protocol (Jones 2011).

\section{Description of the condition}

Labour presents a physiological and psychological challenge for women. As labour becomes more imminent this can be a time of conflicting emotions; fear and apprehension can be coupled with excitement and happiness. Pain associated with labour has been described as one of the most intense forms of pain that can be experienced (Melzack 1984), although conversely some women do not experience intense pain during labour. Labour involves three stages, relating to dilation of the cervix, birth of the baby and delivery of the placenta. The latent phase is the early part of labour where there are irregular contractions and little cervical dilation. The active phase of the first stage of labour consists of regular contractions with increasing strength and frequency accompanied by more significant cervical dilation of at least $4 \mathrm{~cm}$ to $6 \mathrm{~cm}$. Transition may be observable or not, anywhere between $7 \mathrm{~cm}$ to 8 $\mathrm{cm}$ and full dilation. The second stage of labour commences from full cervical dilation to the birth of the baby. The third stage of labour involves expulsion of the placenta.

The pain experienced by women in labour is caused by uterine contractions, the dilatation of the cervix and, in the late first stage and second stage, by stretching of the vagina, pelvic floor and perineum to accommodate the baby. There are several philosophies of pain control, which involve using strategies to break what has been described as the fear-tension-pain cycle (Dick-Read 2004; Dowswell 2009). Dick-Read 2004, an advocate of 'natural childbirth', suggested that fear and anxiety can produce muscle tension, resulting in an increased perception of pain. The neuromatrix theory of pain understands the influence of many factors including past experience and memory (Melzack 2001). In labour the theory of pain incorporates elements of the gate control theory, but also past experiences, cultural factors, emotional state, cognitive input, stress regulation and immune systems, as well as immediate sensory input (Trout 2004). However, the complete removal of pain does not necessarily mean a more satisfying birth experience for women (Morgan 1982). A follow-up study at five years after birth found that those women who had had epidurals were less positive about the birth five years later (Maimburg 2016). Effective and satisfactory pain management needs to be individualised for each woman, and may be influenced by two paradigms, working with pain, or pain relief (Leap 2010). The working-with-pain paradigm includes the belief that there are longterm benefits to promoting normal birth, and that pain plays an important role in this process. The working-with-pain approach offers support and encouragement to women, advocates the use of interventions such as immersion in water, comfortable positions and self-help techniques to enable women to better cope with normal labour pain. The pain-relief paradigm is characterised by the belief that no woman need suffer pain in labour and women are offered a variety of pharmacological pain relief.

\section{Description of the intervention}

The Complementary Medicine Field of the Cochrane Collaboration defines complementary medicine as "practices and ideas which are outside the domain of conventional medicine in several countries", which are defined by its users as "preventing or treating illness, or promoting health and wellbeing" (Manheimer 2008). This definition is deliberately broad, as therapies considered complementary practices in one country or culture may be conventional in another. Many therapies and practices are included within the scope of the Complementary Medicine Field. These include treatments people can administer themselves (e.g. botanicals, nutritional supplements, health food, meditation, magnetic therapy), treatments that providers administer (e.g. acupuncture, massage, reflexology, chiropractic and osteopathic manipulations), and treatments people can administer under the periodic supervision of a provider (e.g. yoga, biofeedback, Tai Chi, homoeopathy, Alexander technique, Ayurveda).

The use of complementary and alternative therapies (CM) has become popular with consumers worldwide. Women are the highest users of CM (Steel 2014). Many women would like to avoid pharmacological or invasive methods of pain relief in labour and this may contribute towards the popularity of complementary methods of pain management (Bennett 1999). It is possible that a large proportion of women are using these therapies during pregnancy. A review of 14 studies with large sample sizes (200 or more participants) on the use of CM in pregnancy identified a prevalence rate ranging from $1 \%$ to $87 \%$ (with nine studies falling between $20 \%$ and $60 \%$ ) (Adams 2009). The review identified use of various complementary therapies including acupuncture and acupressure, aromatherapy, massage, yoga, homeopathy, and chiropractic care. The review also showed that many pregnant women had used more than one complementary product or service (Adams 2009). A recent Australian study also showed that women and partners who were taught a variety of complementary therapy techniques in an antenatal education class, used between three and four different therapies for pain management during labour (Levett 2016a).

The most commonly cited complementary practices associated with providing pain management in labour can be categorised into mind-body interventions (e.g. yoga, hypnosis, relaxation therapies), alternative medical practice (e.g. homoeopathy, traditional Chinese medicine), manual healing methods (e.g. massage, reflexology), pharmacologic and biological treatments, bioelectromagnetic applications (e.g. magnets) and herbal medicines. Mind-body interventions are diverse, and include relaxation, meditation, visualisation and breathing, which are commonly used for labour, and can be widely accessible to women through teaching of these techniques during antenatal classes. Yoga, meditation and hypnosis may not be so accessible to women but together these techniques may have a calming effect and provide a distraction from pain and tension (Vickers 1999). These practices focus on the interactions among the brain, mind, body, and behaviour, with the intent to use the mind to affect physical functioning and promote health.

Relaxation techniques aim to produce the body's natural relaxation response, characterised by slower breathing, lower blood pressure, and a feeling of increased well-being. Relaxation techniques are generally considered safe for healthy people, although there have been a few reports of negative experiences such as 
increased anxiety. Relaxation techniques included in this review include guided imagery, progressive muscle relaxation, breathing techniques, yoga and meditation. Hypnosis is examined in a separate Cochrane Review (Madden 2016). Guided imagery is a technique that uses the mind's own capacity to affect a person's state physically, emotionally or spiritually, and imagery is using one's imagination as a therapeutic tool (McCaffery 1979). Imagery is a learned technique whereby the patient recalls an enjoyable and relaxing experience, which is used to decrease the intensity of pain or to substitute an unpleasant sensation. The main purpose of this technique is to evoke an altered state where a person can stimulate and utilise significant bodily functions and products that are not usually available to us (Schorn 2009). Guided imagery for labour and childbirth aims to affect labour by reducing stress and thereby reducing pain perception. Progressive muscle relaxation was originally designed by Jacobson 1938 to guide people through successive tensing and relaxation of the body muscle groups from toe to head to achieve overall body relaxation (Jacobson 1938). Women are encouraged to focus on sensations associated with the release of muscle tension and feelings of comfort. Imagery may involve encouraging women to scan their bodies to identify areas of pain and to imagine replacing pain with comforting sensations such as heat or cold. This process is easy to learn and teach, safe, non-threatening and non-competitive. Breathing techniques, referred to as psychoprophylaxis, emphasise relaxation as a conditioned response to labour contractions coupled with a variety of patterned breathing techniques designed to improve oxygenation and interfere with the transmission of pain signals from the uterus to the brain (Velvovsky 1960). Breathing techniques have more recently been associated with modulation of pain perception through decreased sympathetic activity and emotional regulation (Busch 2012). Afferent signalling to the brain via the vagus nerve is thought to modulate pain perception and emotional regulation through changes to neurotransmitters in the limbic region (Klarer 2014). Yoga is a mind-body practice, and various styles of yoga can be used for health purposes by combining physical postures, breathing techniques and meditation or relaxation. A commonly practised form of yoga includes Hatha yoga. This includes breath awareness and internal centring to remove external concerns, achieve focus and become sensitive towards internal feelings; as well as relaxation and meditation to further enhance ridding the body of 'toxins' and enable release from mental and emotional blockages. Accompanying this are bodily postures that address mind-body-breath co-ordination, strength, flexibility and balance (Fisher 2004).

\section{How the intervention might work}

In the context of use during labour, relaxation techniques are used as coping strategies that may reduce pain by interrupting the transmission of pain signals, limiting the capacity to pay attention to pain, stimulating the release of endorphins, or by helping to diminish pain-exacerbating thoughts (Sharp 2001; Villemure 2002). Magnetic resonance imaging (MRI) studies examining 'imagery techniques' have shown different and distinct pathways in how the brain receives pain stimuli, and how pain is perceived (Woo 2015). In yoga, it is not fully known what changes occur in the body in response to yoga. The physical postures are just one component, and are generally done with deep breathing (Field 2011). A review of yoga research (Field 2011) suggests that yoga is designed to keep the spine and joints flexible while toning and strengthening the muscles. The deep twisting and stretching and bending movements are thought to 'massage' the internal organs and glands.

\section{Why it is important to do this review}

Women are interested in using additional forms of care to assist with their pain management in labour. It is important to examine the efficacy, effectiveness and safety of under-evaluated forms of treatment to enable women, health providers and policy makers to make informed decisions about care. A number of clinical trials have been performed to study the effect of relaxation techniques for pain in labour, although it remains uncertain whether the existing evidence is rigorous enough to reach a definitive conclusion. This is an update of a review first published in 2011.

\section{O B J E C T IVES}

To examine the effects of mind-body relaxation techniques for pain management in labour on maternal and neonatal well-being during and after labour.

\section{METHODS}

\section{Criteria for considering studies for this review}

\section{Types of studies}

Randomised controlled trials (RCTs), this includes cluster- and quasi-RCTs. Cross-over trials were excluded.

\section{Types of participants}

Women in labour. (This will include women in high-risk groups, e.g. preterm labour or following induction of labour. We will use subgroup analysis to look for any possible differences in the effect of interventions in these groups.)

\section{Types of interventions}

The previous version of this review (Smith 2011) contributed to an overview of systematic reviews of interventions for pain management in labour (Jones 2012), and shared a generic protocol (Jones 2011). To avoid duplication, the different methods of pain management were listed in a specific order, from one to 15. Individual reviews focusing on particular interventions included comparisons with only the interventions above it on the list. The current list is as follows.
1. Placebo/no treatment
2. Hypnosis (Madden 2016)
3. Biofeedback (Barragán 2011)
4. Intracutaneous or subcutaneous sterile water injection (Derry 2011)
5. Immersion in water (Cluett 2009)
6. Aromatherapy (Smith 2011b)
7. Relaxation techniques (yoga, music, audio) (this review)
8. Acupuncture or acupressure (Smith 2011a)
9. Manual methods (massage, reflexology) (Smith 2011c)
10.Transcutaneous electrical nerve stimulation (TENS) (Dowswell 2009)
11.Inhaled analgesia (Klomp 2011)
12.Opioid drugs (Ullman 2010) 
13.Non-opioid drugs (Othman 2011)

14. Local anaesthetic nerve blocks (Novikova 2011)

15.Epidural (including combined spinal-epidural) (Anim-Somuah 2005; Simmons 2007)

Accordingly, this review includes the following mind-body relaxation techniques: relaxation methods, yoga, music, audio analgesia and mindfulness. Comparisons of any type of mind-body relaxation technique with any other (yoga, music, audio), as well as any type of relaxation techniques compared with: 1. placebo/ no treatment; 2 . hypnosis; 3. biofeedback; 4 . intracutaneous or subcutaneous sterile water injection; 5 . immersion in water; or 6 . aromatherapy. The intervention could comprise a single modality, or a combination of mind-body relaxation techniques that have combined to form the active intervention.

\section{Types of outcome measures}

This review is one in a series of Cochrane Reviews examining pain management in labour. The following list of primary outcomes are the ones that are common to all the reviews, as specified in the generic protocol (Jones 2011).

\section{Primary outcomes}

\section{Effects of interventions}

1. Pain intensity (as defined by trialists). We will analyse pain by the phase of labour if reported.

2. Satisfaction with pain relief (as defined by trialists)

3. Sense of control in labour (as defined by trialists)

4. Satisfaction with childbirth experience (as defined by trialists)

Safety of interventions

1. Effect (negative) on mother/baby interaction

2. Breastfeeding (at specified time points)

3. Assisted vaginal birth

4. Caesarean section

5. Side effects (for mother and baby; review specific)

6. Admission to special care nursery or neonatal intensive care (as defined by trialists)

7. Low Apgar score (less than 7 at five minutes)

8. Poor infant outcomes at long-term follow-up (as defined by trialists)

\section{Other outcomes}

1. Cost (as defined by trialists)

\section{Secondary outcomes}

\section{Maternal}

Use of pharmacological pain relief; length of labour; spontaneous vaginal birth; need for augmentation with oxytocin; perineal trauma (defined as episiotomy and incidence of second- or third-degree tear); maternal blood loss (postpartum haemorrhage defined as greater than $500 \mathrm{~mL}$ ); anxiety.

\section{Search methods for identification of studies}

The following methods section of this review is based on a standard template used by Cochrane Pregnancy and Childbirth.

\section{Electronic searches}

We searched Cochrane Pregnancy and Childbirth's Trials Register by contacting their Information Specialist (9 May 2017).

The Register is a database containing over 24,000 reports of controlled trials in the field of pregnancy and childbirth. For full search methods used to populate Pregnancy and Childbirth's Trials Register including the detailed search strategies for CENTRAL, MEDLINE, Embase and CINAHL; the list of handsearched journals and conference proceedings, and the list of journals reviewed via the current awareness service, please follow this link to the editorial information about Cochrane Pregnancy and Childbirth in the Cochrane Library and select the 'Specialized Register' section from the options on the left side of the screen.

Briefly, Cochrane Pregnancy and Childbirth's Trials Register is maintained by their Information Specialist and contains trials identified from:

1. monthly searches of the Cochrane Central Register of Controlled Trials (CENTRAL);

2. weekly searches of MEDLINE (Ovid);

3. weekly searches of Embase (Ovid);

4. monthly searches of CINAHL (EBSCO);

5. handsearches of 30 journals and the proceedings of major conferences;

6. weekly current awareness alerts for a further 44 journals plus monthly BioMed Central email alerts.

Search results are screened by two people and the full text of all relevant trial reports identified through the searching activities described above is reviewed. Based on the intervention described, each trial report is assigned a number that corresponds to a specific Pregnancy and Childbirth review topic (or topics), and is then added to the Register. The Information Specialist searches the Register for each review using this topic number rather than keywords. This results in a more specific search set that has been fully accounted for in the relevant review sections (Included studies; Excluded studies; Studies awaiting classification; Ongoing studies).

In addition, we searched the Cochrane Central Register of Controlled Trials (CENTRAL; 2017, Issue 5) in the Cochrane Library (Appendix 1), MEDLINE (1966 to 24 May 2017) (Appendix 2), and CINAHL (1980 to 24 May 2017) (Appendix 3).

We also searched the following for ongoing or unpublished trials: the Australian New Zealand Clinical Trials Registry (18 May 2017); ClinicalTrials.gov (18 May 2017); the ISRCTN Register (18 May 2017); and the WHO International Clinical Trials Registry Platform (ICTRP) (18 May 2017). See: Appendix 4 for search terms used in these sources.

\section{Searching other resources}

We searched the reference lists of retrieved studies.

We did not apply any language or date restrictions.

\section{Data collection and analysis}

For methods used in the previous version of this review, see Smith 2011. 
For this update, we used the following methods for assessing the reports that we identified as a result of the updated search.

The following methods section of this review is based on a standard template used by Cochrane Pregnancy and Childbirth.

\section{Selection of studies}

Two review authors independently assessed for inclusion all the potential studies identified as a result of the search strategy. We resolved any disagreement through discussion or, if required, we consulted the third review author.

\section{Data extraction and management}

We designed a form to extract data. For eligible studies, at least two review authors extracted the data using the agreed form. We resolved discrepancies through discussion or, if required, we consulted the third review author. We entered data into Review Manager 5 (RevMan 5) software (RevMan 2014) and checked them for accuracy.

When information regarding any of the above was unclear, we planned to contact authors of the original reports to provide further details.

\section{Assessment of risk of bias in included studies}

Two review authors independently assessed risk of bias for each study using the criteria outlined in the Cochrane Handbook for Systematic Reviews of Interventions (Higgins 2011a). We resolved any disagreement by discussion or by involving a third assessor.

\section{(1) Random sequence generation (checking for possible selection bias)}

We described the method used to generate the allocation sequence in sufficient detail to allow an assessment of whether it should produce comparable groups.

For each included study we assessed the method as being at:

- low risk of bias (any truly random process, e.g. random number table; computer random number generator);

- high risk of bias (any non-random process, e.g. odd or even date of birth; hospital or clinic record number);

- unclear risk of bias.

\section{(2) Allocation concealment (checking for possible selection bias)}

For each included study we described the method used to conceal allocation to interventions prior to assignment and assessed whether intervention allocation could have been foreseen in advance of, or during recruitment, or changed after assignment.

We assessed the methods as being at:

- low risk of bias (e.g. telephone or central randomisation; consecutively numbered, sealed, opaque envelopes);

- high risk of bias (open random allocation; unsealed or nonopaque envelopes, alternation; date of birth);

- unclear risk of bias.

\section{(3.1) Blinding of participants and personnel (checking for possible performance bias)}

For each included study we described the methods used, if any, to blind study participants and personnel from knowledge of which intervention a participant received. We considered that studies were at low risk of bias if they were blinded, or if we judged that the lack of blinding was unlikely to affect results. We assessed blinding separately for different outcomes or classes of outcomes.

We assessed the methods as being at:

- low, high or unclear risk of bias for participants;

- low, high or unclear risk of bias for personnel.

\section{(3.2) Blinding of outcome assessment (checking for possible detection bias)}

For each included study we described the methods used, if any, to blind outcome assessors from knowledge of which intervention a participant received. We assessed blinding separately for different outcomes or classes of outcomes.

We assessed methods used to blind outcome assessment as being at:

- low, high or unclear risk of bias.

\section{(4) Incomplete outcome data (checking for possible attrition bias due to the amount, nature and handling of incomplete outcome data)}

For each included study, and for each outcome or class of outcomes, we described the completeness of data including attrition and exclusions from the analysis. We stated whether attrition and exclusions were reported and the numbers included in the analysis at each stage (compared with the total randomised participants), reasons for attrition or exclusion where reported, and whether missing data were balanced across groups or were related to outcomes. Where sufficient information was reported, or could be supplied by the trial authors, we planned to re-include missing data in the analyses that we undertook.

We assessed methods as being at:

- low risk of bias (e.g. no missing outcome data; missing outcome data balanced across groups);

- high risk of bias (e.g. numbers or reasons for missing data imbalanced across groups; 'as treated' analysis done with substantial departure of intervention received from that assigned at randomisation);

- unclear risk of bias.

\section{(5) Selective reporting (checking for reporting bias)}

For each included study we described how we investigated the possibility of selective outcome reporting bias and what we found.

We assessed the methods as being at:

- low risk of bias (where it was clear that all of the study's prespecified outcomes and all expected outcomes of interest to the review were reported);

- high risk of bias (where not all the study's prespecified outcomes were reported; one or more reported primary outcomes 
were not prespecified; outcomes of interest were reported incompletely and so could not be used; study failed to include results of a key outcome that we expected that they would have reported);

- unclear risk of bias.

(6) Other bias (checking for bias due to problems not covered by (1) to (5) above)

For each included study we described any important concerns we had about other possible sources of bias.

\section{(7) Overall risk of bias}

We made explicit judgements about whether studies were at high risk of bias, according to the criteria given in the Cochrane Handbook for Systematic Reviews of Interventions (Higgins 2011a). With reference to (1) to (6) above, we planned to assess the likely magnitude and direction of the bias and whether we considered it was likely to have an impact on the findings. In future updates, we will explore the impact of the level of bias through undertaking sensitivity analyses (Sensitivity analysis).

\section{Assessment of the quality of the evidence using the GRADE approach}

For this update we assessed the quality of the evidence using the GRADE approach as outlined in the GRADE handbook in order to assess the quality of the body of evidence for the following outcomes.

\section{Effects of interventions}

1. Pain intensity (as defined by trialists)

2. Satisfaction with pain relief (as defined by trialists)

3. Sense of control in labour (as defined by trialists)

4. Satisfaction with childbirth experience (as defined by trialists)

\section{Safety of interventions}

1. Breastfeeding (at specified time points)

2. Assisted vaginal birth

3. Caesarean section

We have graded evidence for our three main comparisons (relaxation, yoga and music).

We used the GRADEpro Guideline Development Tool to import data from RevMan 5 (RevMan 2014) in order to create 'Summary of findings' tables. We produced a summary of the intervention effect and a measure of quality for each of the above outcomes using the GRADE approach. The GRADE approach uses five considerations (study limitations, consistency of effect, imprecision, indirectness and publication bias) to assess the quality of the body of evidence for each outcome. The evidence can be downgraded from 'high quality' by one level for serious (or by two levels for very serious) limitations, depending on assessments for risk of bias, indirectness of evidence, serious inconsistency, imprecision of effect estimates or potential publication bias.

\section{Measures of treatment effect}

\section{Dichotomous data}

For dichotomous data, we presented results as summary risk ratio (RR) with 95\% confidence intervals (Cls).

\section{Continuous dato}

We used the mean difference (MD) if outcomes were measured in the same way between trials. We used the standardised mean difference (SMD) to combine trials that measured the same outcome, but used different methods.

\section{Unit of analysis issues}

We included trials with multiple arms and described them in the Characteristics of included studies. One trial had three groups (Kimber 2008), one had four groups (Gatelli 2000), and one trial had five groups (Phumdoung 2007). For all of these trials, we selected one pair of interventions and excluded the others that were not relevant to this review, as per the methods described in the in the Cochrane Handbook for Systematic Reviews of Interventions (Higgins 2011b). In Kimber 2008 there was one intervention group (massage and relaxation), one placebo group (music and relaxation) and a control group (usual care). For Kimber 2008 we disregarded the intervention group (massage and relaxation) and only included the placebo and control group data. In Gatelli 2000 the four groups were: psychoprophylaxis and relaxation; psychoprophylaxis and counselling; psychoprophylaxis only; and antenatal checks and birthing only. Again we disregarded two groups and only included two groups (psychoprophylaxis and relaxation versus psychoprophylaxis only). For Phumdoung 2007 the five groups were: yoga cat position with high head and music; yoga cat position with high head; yoga cat position supine; high head position; and supine position group. For Phumdoung 2007 we disregarded three groups and only included two groups: yoga cat position with high head and music versus the supine position group.

\section{Cluster-randomised trials}

If we had identified cluster-randomised trials we planned to include them in the analyses along with individually randomised trials. If such trials are identified in future updates of the review we will adjust their sample sizes using the methods described in the Cochrane Handbook for Systematic Reviews of Interventions (Higgins 2011b) using an estimate of the intracluster correlation co-efficient (ICC) derived from the trial (if possible), from a similar trial or from a study of a similar population. If we use ICCs from other sources, we will report this and conduct sensitivity analyses to investigate the effect of variation in the ICC. If we identify both cluster-randomised trials and individually-randomised trials, we plan to synthesise the relevant information. We will consider it reasonable to combine the results from both if there is little heterogeneity between the study designs and the interaction between the effect of intervention and the choice of randomisation unit is considered to be unlikely.

We will also acknowledge heterogeneity in the randomisation unit and perform a sensitivity analysis to investigate the effects of the randomisation unit.

\section{Cross-over trials}

Cross-over trials are not a suitable design for trials looking at interventions in labour and have been excluded.

\section{Dealing with missing data}

For included studies, we noted levels of attrition. In future updates, if more eligible studies are included, we will explore the impact 
of including studies with high levels of missing data in the overall assessment of treatment effect by using sensitivity analysis.

For all outcomes, we carried out analyses, as far as possible, on an intention-to-treat basis, that is, we attempted to include all participants randomised to each group in the analyses. The denominator for each outcome in each trial was the number randomised minus any participants whose outcomes were known to be missing.

\section{Assessment of heterogeneity}

We assessed statistical heterogeneity in each meta-analysis using the $\mathrm{Tau}^{2}, \mathrm{I}^{2}$ (Higgins 2003) and $\mathrm{Chi}^{2}$ statistics (Deeks 2011). We regarded heterogeneity as substantial if $\mathrm{I}^{2}$ was greater than $30 \%$ and either $\mathrm{Tau}^{2}$ was greater than zero, or there was a low $\mathrm{P}$ value (less than 0.10 ) in the $\mathrm{Chi}^{2}$ test for heterogeneity. If we identified substantial heterogeneity (above $30 \%$ ), provided sufficient data were available, we planned to explore it by pre-specified subgroup analysis.

\section{Assessment of reporting biases}

In future updates, if there are 10 or more studies in the metaanalysis we will investigate reporting biases (such as publication bias) using funnel plots. We will assess funnel plot asymmetry visually. If asymmetry is suggested by a visual assessment, we will perform exploratory analyses to investigate it (Sterne 2011).

\section{Data synthesis}

We carried out statistical analysis using the RevMan 5 software (RevMan 2014). We used fixed-effect meta-analysis for combining data where it was reasonable to assume that studies were estimating the same underlying treatment effect: that is, where trials were examining the same intervention, and the trials' populations and methods were judged sufficiently similar.

If there was clinical heterogeneity sufficient to expect that the underlying treatment effects differed between trials, or if substantial statistical heterogeneity was detected, we used random-effects meta-analysis to produce an overall summary if an average treatment effect across trials was considered clinically meaningful. The random-effects summary was treated as the average range of possible treatment effects and we discuss the clinical implications of treatment effects differing between trials. If the average treatment effect was not clinically meaningful, we did not combine trials. If we used random-effects analyses, we presented the results as the average treatment effect with $95 \% \mathrm{Cls}$, and the estimates of $\mathrm{Tau}^{2}$ and $\mathrm{I}^{2}$.

\section{Subgroup analysis and investigation of heterogeneity}

Where studies presented data on the length of labour or pain during the three different phases of labour we grouped data for these outcomes according to the phase of labour (latent; active; transition).

In future updates if more data are available we plan to investigate substantial heterogeneity using subgroup analyses and to consider whether an overall summary is meaningful, and if it is, use a random-effects analysis.

We will carry out the following subgroup analyses for primary outcomes.

1. Spontaneous labour versus induced labour

2. Primiparous versus multiparous

3. Term versus preterm birth

4. Continuous support in labour versus no continuous support

We will assess subgroup differences by interaction tests available within RevMan 5 (RevMan 2014). We will report the results of subgroup analyses quoting the $\mathrm{Chi}^{2}$ statistic and $\mathrm{P}$ value, and the interaction test $\mathrm{I}^{2}$ value (Deeks 2011).

\section{Sensitivity analysis}

We planned to conduct sensitivity analyses to explore the effect of risk of bias for each comparison by restricting analysis to those trials rated as 'low risk of bias' for random sequence generation and allocation concealment. In this version of the review there were too few trials in any one comparison (with design limitations) contributing data and so we did not carry out this additional analysis. In future updates if sufficient data become available to carry out sensitivity analysis we will limit analyses to the primary outcomes.

\section{RE S U L T S}

\section{Description of studies}

\section{Results of the search}

See: Figure 1 


\section{Figure 1. Study flow diagram}

11 studies included in the previous version of the review (Smith 2011)

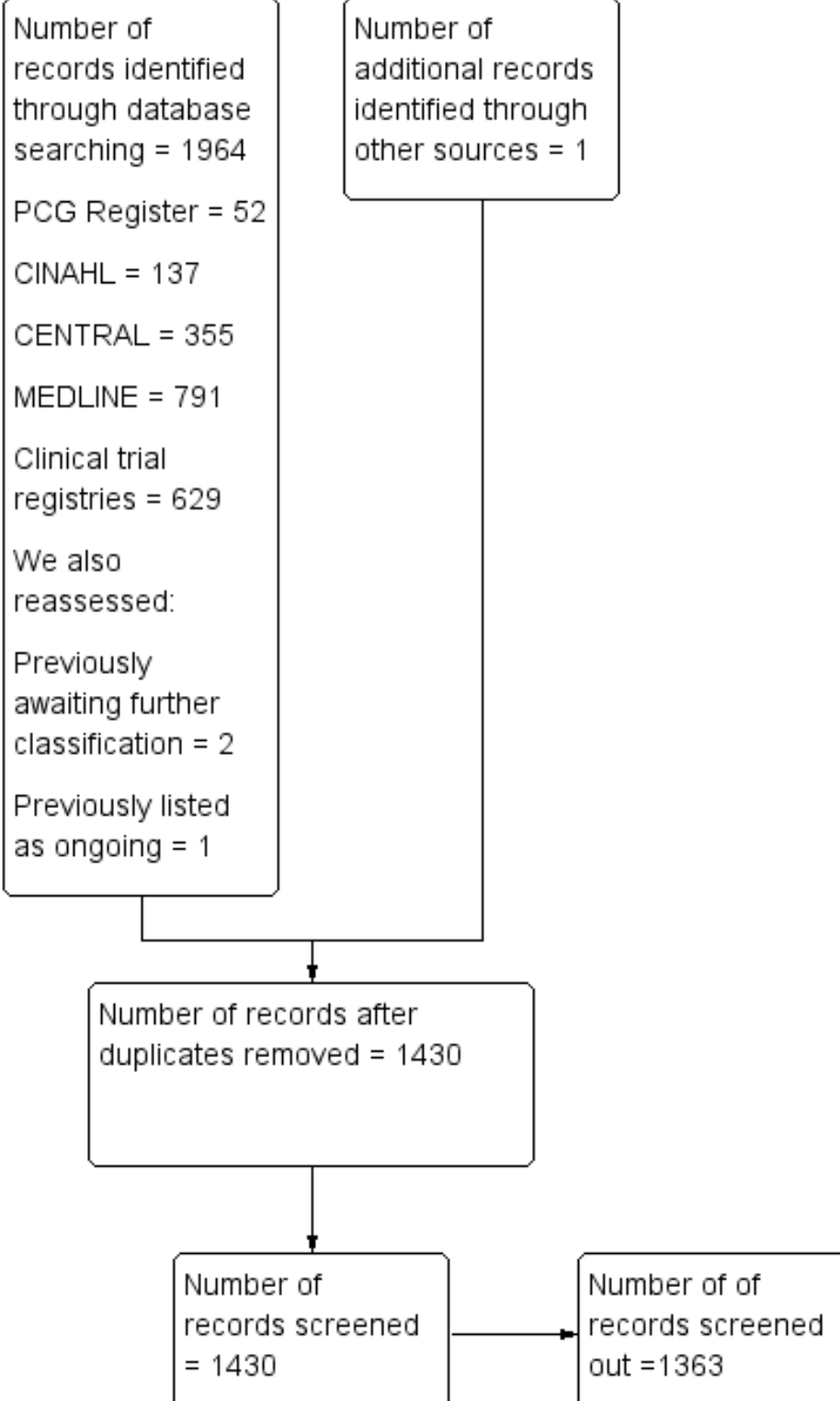

Number of identified through other sources $=1$ out $=1363$

Number of studies excluded, with reasons $=34(45$ reports)

(see:

Characteristics of excluded studies)

Number of studies awaiting further classification $=4$ 
Figure 1. (Continued)

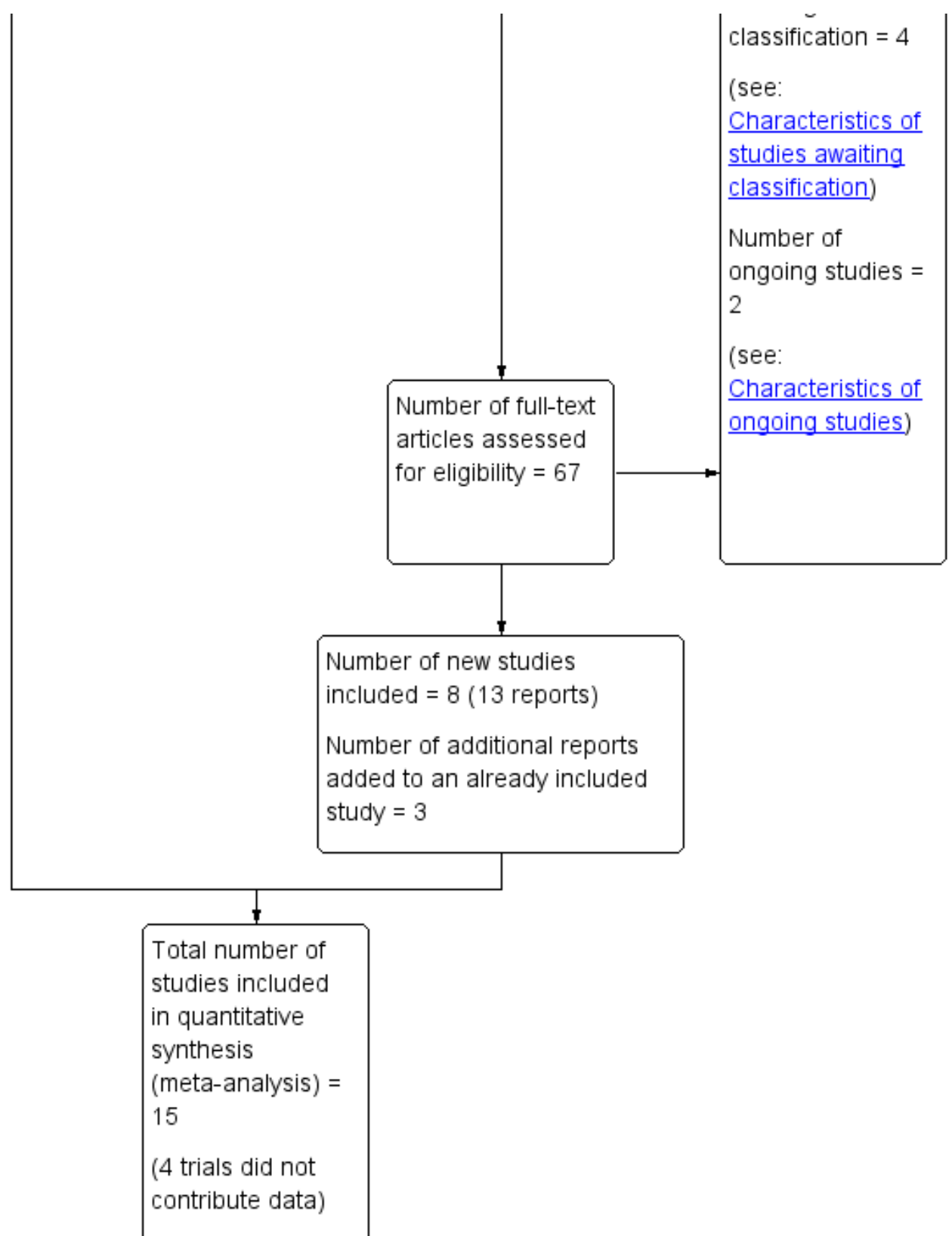

We assessed 67 trial reports for this update including the two studies awaiting classification in the previous version of the review (Escott 2005; Salem 2004), and the one previously listed as ongoing (NCT00917332).

The original review included a range of complementary therapies (Smith 2006). The 2011 review update (Smith 2011) included trials of therapies involving relaxation techniques.

In the previous version (Smith 2011) there were 11 included studies; in this update we have included eight new studies (Bahadoran 2010; Boaviagem 2017; Dizavandi 2012; Duncan 2017; Gedde-Dahl 2012; Hosseini 2013; Kimber 2008; Simavli 2014).

Altogether we have included 19 studies involving 2519 women, and excluded 45 studies. Four included studies involving 227 women

(Bagharpoosh 2006; Dizavandi 2012; Durham 1986; Hosseini 2013) did not contribute any data to this update. In total, 15 studies involving 1731 women contributed to the meta-analysis.

\section{Included studies}

\section{Study design}

Nineteen trials were parallel design, one trial used a factorial design (Phumdoung 2007). Sixteen studies had two groups, one trial had three groups (Kimber 2008), one had four groups (Gatelli 2000), and one trial had five groups (Phumdoung 2007).

\section{Sample size}

Sample size ranged from 25 (Moore 1965) to 1087 (Bergstrom 2009). 


\section{Study location, dates, and source of women}

Four studies were undertaken in Iran (Bagharpoosh 2006; Bahadoran 2010; Dizavandi 2012; Hosseini 2013). Two studies were undertaken each in Brazil (Almeida 2005; Boaviagem 2017), Italy (Dolcetta 1979; Gatelli 2000), Thailand (Chuntharapat 2008; Phumdoung 2007), Turkey (Simavli 2014; Yildirim 2004), the UK (Kimber 2008; Moore 1965), and USA (Duncan 2017; Durham 1986), and one study each from Norway (Gedde-Dahl 2012), Sweden (Bergstrom 2009), and Taiwan (Liu 2010). Only eight studies reported their study dates: Almeida 2005 between 2000 and 2001, Bagharpoosh 2006 in 2002, Bahadoran 2010 in 2010, Bergstrom 2009 in 2006-2007, Chuntharapat 2008 from 2005 to 2006, Kimber 2008 from 2004 to 2006, Simavli 2014 from 2011 to 2012, and Yildirim 2004 in 2000.

Eleven studies recruited women during their antenatal care (Almeida 2005; Bahadoran 2010; Bergstrom 2009; Chuntharapat 2008; Dolcetta 1979; Duncan 2017; Durham 1986, Gatelli 2000; Gedde-Dahl 2012; Kimber 2008; Simavli 2014), and seven trials recruited women in the labour ward (Bagharpoosh 2006; Boaviagem 2017; Hosseini 2013; Liu 2010; Moore 1965; Phumdoung 2007; Yildirim 2004), and one trial did not report on recruitment location (Dizavandi 2012).

\section{Participants}

Twelve studies included primiparous women only, one included primiparous and multiparous women (Bahadoran 2010), and the remaining seven studies (Dizavandi 2012; Dolcetta 1979; Durham 1986; Gedde-Dahl 2012; Kimber 2008; Moore 1965) did not specify parity.

\section{Types of interventions}

We grouped the interventions into relaxation, yoga, music, audio-analgesia and mindfulness. Ten trials used relaxation. This consisted of relaxation of bodily muscles and use of the breath in one trial (Almeida 2005), deep breathing and relaxation in one study (Boaviagem 2017), relaxation, music and guided imagery in one trial (Gedde-Dahl 2012), relaxation and music in one trial (Kimber 2008), stretching, relaxation, massage and breathing in one trial (Bahadoran 2010). Two trials used progressive muscle relaxation (Bagharpoosh 2006; Yildirim 2004). Three trials used psychoprophylaxis (Bergstrom 2009; Dolcetta 1979; Gatelli 2000). Two trials used yoga. The yoga trial undertaken by Chuntharapat 2008 comprised postures, breathing, chanting and education, and Phumdoung 2007 comprised using yoga postures. One trial used audio-analgesia (Moore 1965) and six trials used music (Dizavandi 2012; Durham 1986, Gedde-Dahl 2012; Hosseini 2013; Liu 2010; Simavli 2014), and one trial used massage and relaxation or music and relaxation (Kimber 2008), and one trial used mindfulness (Duncan 2017). The interventions are described in greater detail in the Characteristics of included studies.

Control groups varied, 13 trials used usual care, three trials used psychoprophylaxis (Dolcetta 1979; Durham 1986; Gatelli 2000), one trial used education (Duncan 2017), one trial used a different dose of audio-analgesia (Moore 1965), and one trial used different forms of postural management (Phumdoung 2007). Details of the comparator group using usual care were frequently underreported.

\section{Outcome measures}

Twelve trials reported data on pain (Almeida 2005; Bagharpoosh 2006; Bergstrom 2009; Boaviagem 2017; Chuntharapat 2008; Dolcetta 1979; Gedde-Dahl 2012; Kimber 2008; Liu 2010; Phumdoung 2007; Simavli 2014; Yildirim 2004). Three trials reported on use of pharmacological analgesia (Bergstrom 2009; Durham 1986; Kimber 2008). Maternal outcomes (sense of control, satisfaction) were reported in eight trials (Bergstrom 2009; Boaviagem 2017; Chuntharapat 2008; Duncan 2017; Gatelli 2000; Kimber 2008; Moore 1965; Yildirim 2004). No clinical outcomes were reported in two trials (Bagharpoosh 2006; Dolcetta 1979). See details of all outcomes reported within the Characteristics of included studies.

\section{Funding and conflicts of interest}

Bergstrom 2009 was funded by the Swedish Research Council and Karolinska Institute. All study authors state their independence. Boaviagem 2017 was funded by a scholarship from Foundation for Science and Technology of the State of Pernambuco (FACEPE), Chuntharapat 2008 by the Faculty of Graduate Studies, Prince of Songkla University, Thailand, Duncan 2017 was funded by a grant from the Mount Zion Health Fund, administered by the University of California, and two authors were supported by the US National Institutes of Health/National Center for Complementary and Integrative Health through career development awards. Financial support in Gedde-Dahl 2012 was provided by the investigators' employing institutions (university hospitals in Norway). Kimber 2008 through a complementary medicine grant from Oxfordshire Health Services Research Committee (OHSRC), Liu 2010 by the National Science Council, Taipei, Taiwan, and Phumdoung 2007 through a Prince of Songkla University Grant. No other study reported funding sources.

Bagharpoosh 2006, Bahadoran 2010, Bergstrom 2009, Gedde-Dahl 2012, Hosseini 2013, and Liu 2010 all reported to have no conflicts of interest. The remaining studies did not mention conflicts of interest.

\section{Excluded studies}

We excluded a total of 45 studies; see Characteristics of excluded studies.

Nine studies did not meet the eligibility criteria for the study population (Bastani 2006; Buxton 1973; Geden 1989; Huang 2015; Korol 1992; Miquelutti 2015; Sammons 1984; Schorn 2009; ZilchaMano 2016).

The intervention was not eligible in 22 studies (Ahmadian 2009; Barbieri 2013; Delgado-Garcia 2012; Drzymalski 2017; Escott 2005; Gau 2011; Hao 1997; Jain 2015; Janke 1999; Levett 2016b; Mathew 2012; Mirzakhani 2015; Musa 2011; NCT01389128; NCT01601860; NCT02190591; Phumdoung 2010; Ran 2005; Roth 2016; Taavoni 2016; Tragea 2014; Tussey 2015).

The comparator was not eligible in four studies (Ahmadi 2017; Field 1999; Kamalifard 2012; Taghinejad 2010).

The study design was not eligible in 10 studies (Browning 2000; Chuang 2012; Dehcheshmeh 2015, Firouzbakht 2014; Narendran 2005; Phumdoung 2003; Podder 2007; Shim 2012; Sun 2010; Taghavi 2009), 


\section{Risk of bias in included studies}

See Figure 2 and Figure 3 for a graphical summary of the risk of bias assessment made by the review authors. No study was at low risk of bias on all domains.

Figure 2. Risk of bias graph: review authors' judgements about each risk of bias item presented as percentages across all included studies

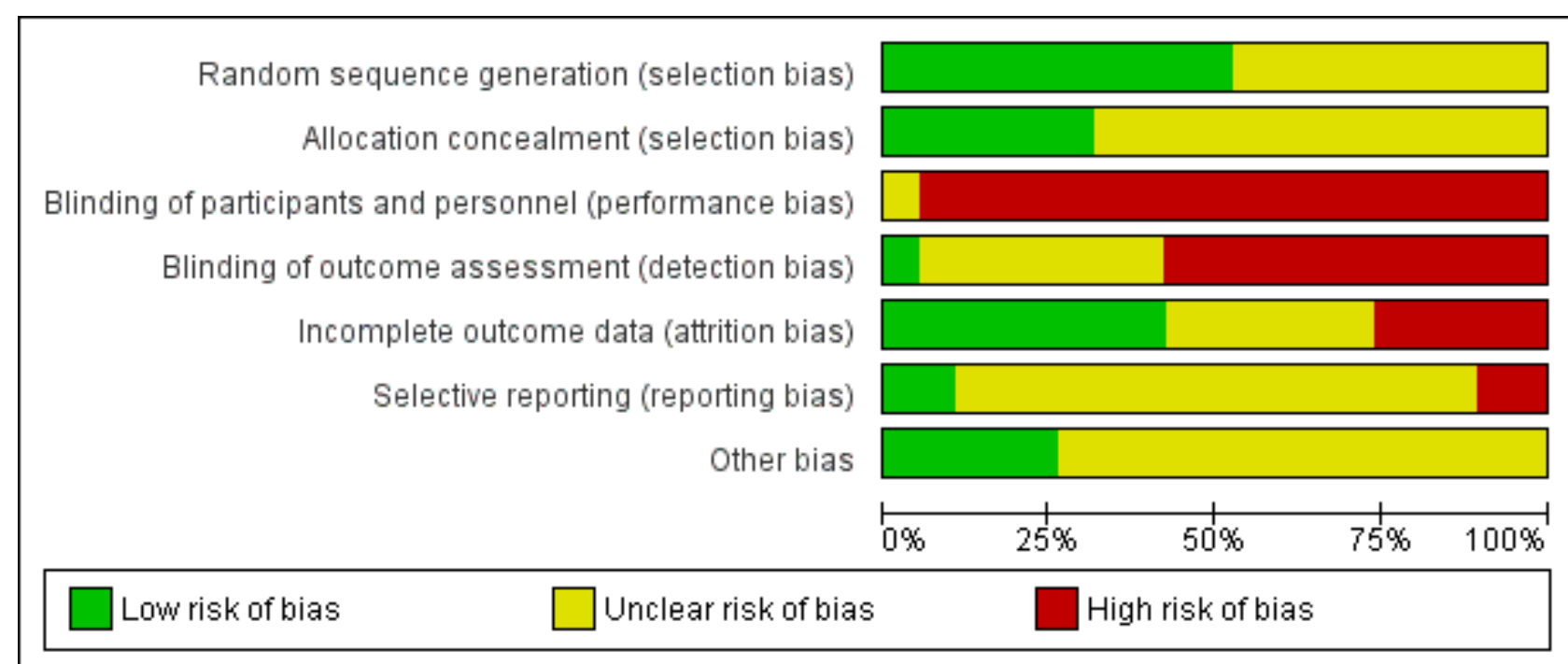


Figure 3. Risk of bias summary: review authors' judgements about each risk of bias item for each included study

\begin{tabular}{|c|c|c|c|c|c|c|c|}
\hline & 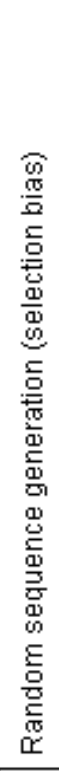 & 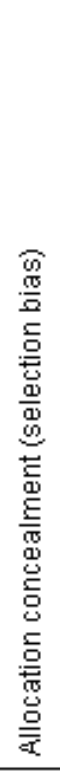 & 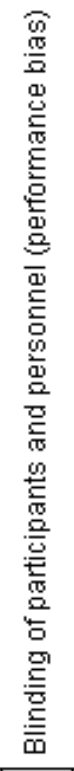 & 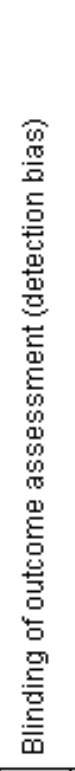 & 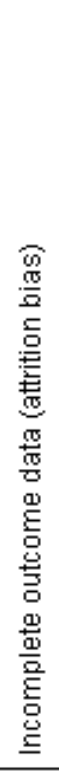 & 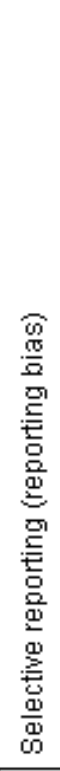 & 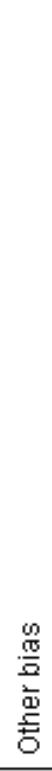 \\
\hline Almeida 2005 & + & $\oplus$ & $\odot$ & $\odot$ & $\odot$ & $?$ & $?$ \\
\hline Bagharpoosh 2006 & $?$ & $?$ & - & $\odot$ & $?$ & $?$ & $?$ \\
\hline Bahadoran 2010 & $?$ & $?$ & - & $O$ & $?$ & $?$ & $?$ \\
\hline Bergstrom 2009 & + & + & 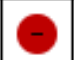 & 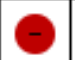 & + & + & + \\
\hline Boaviagem 2017 & $\odot$ & $\odot$ & $\rightarrow$ & - & 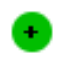 & $?$ & $?$ \\
\hline Chuntharapat 2008 & + & $?$ & $\theta$ & $\odot$ & $?$ & $?$ & $\odot$ \\
\hline Dizavandi 2012 & $?$ & $?$ & 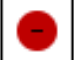 & $\odot$ & $?$ & $?$ & $?$ \\
\hline Dolcetta 1979 & $?$ & $?$ & 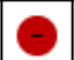 & $?$ & $?$ & $?$ & + \\
\hline Duncan 2017 & + & 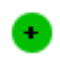 & 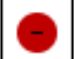 & + & + & $?$ & $?$ \\
\hline Durham 1986 & + & $?$ & $\rightarrow$ & $?$ & $?$ & $?$ & $?$ \\
\hline Gatelli 2000 & $?$ & $?$ & $\theta$ & $?$ & $\odot$ & $?$ & $?$ \\
\hline Gedde-Dahl 2012 & $?$ & 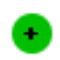 & 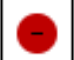 & $?$ & $\odot$ & - & $?$ \\
\hline Hosseini 2013 & $?$ & $?$ & $\Rightarrow$ & $?$ & $\odot$ & $?$ & $?$ \\
\hline Kimber 2008 & + & $?$ & 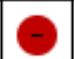 & O & + & + & $?$ \\
\hline Liu 2010 & + & + & 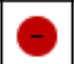 & $\theta$ & - & $?$ & $?$ \\
\hline Moore 1965 & $?$ & $?$ & $?$ & $?$ & + & $?$ & $?$ \\
\hline Phumdoung 2007 & + & $?$ & 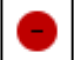 & $?$ & + & $?$ & + \\
\hline Simavli 2014 & + & $?$ & $\Rightarrow$ & $\theta$ & $\odot$ & $\theta$ & $?$ \\
\hline Yildirim 2004 & $?$ & $?$ & $\odot$ & $\theta$ & + & $?$ & + \\
\hline
\end{tabular}




\section{Allocation}

The method of sequence generation was at low risk of bias in 10 trials. Randomisation was by coin toss in the Almeida 2005 trial, and one trial used lot drawing (Liu 2010). Computer generation was used in seven trials (Bergstrom 2009; Boaviagem 2017; Chuntharapat 2008; Duncan 2017; Kimber 2008; Phumdoung 2007; Simavli 2014). A random number table was used by Durham 1986 The risk of bias was unclear due to insufficient reporting in the remaining nine trials.

Allocation concealment was at a low risk of bias in six trials (Almeida 2005; Bergstrom 2009; Boaviagem 2017; Duncan 2017; Gedde-Dahl 2012; Liu 2010). Three trials used sealed envelopes (Boaviagem 2017; Duncan 2017; Gedde-Dahl 2012, Bergstrom 2009 used central allocation by computer, and Almeida 2005 and Liu 2010 used coded balls and coin toss to conceal allocation. The risk of bias was unclear due to insufficient reporting in the remaining 13 trials.

\section{Blinding}

The interventions could not be administered blind. No trial was at a low risk of bias, and 18 trials were at a high risk of bias (Ahmadi 2017; Bagharpoosh 2006; Bahadoran 2010; Bergstrom 2009; Boaviagem 2017; Chuntharapat 2008; Dizavandi 2012; Dolcetta 1979; Duncan 2017; Durham 1986; Gatelli 2000; Gedde-Dahl 2012; Hosseini 2013; Kimber 2008; Liu 2010; Phumdoung 2007; Simavli 2014; Yildirim 2004). We assessed Moore 1965 as unclear because they used two forms of white noise, with one assumed to be physiologically inactive, although they gave no evidence to support this statement.

Detection bias was low risk in one trial (Duncan 2017) where blinding of the analyst was reported. We assessed seven trials as unclear risk due to a lack of reporting (Dolcetta 1979; Durham 1986; Gatelli 2000; Gedde-Dahl 2012; Hosseini 2013; Moore 1965; Phumdoung 2007). We assessed 11 trials at high risk due to no blinding (Almeida 2005; Bagharpoosh 2006; Bahadoran 2010; Bergstrom 2009; Boaviagem 2017; Chuntharapat 2008; Dizavandi 2012; Kimber 2008; Liu 2010; Simavli 2014; Yildirim 2004).

\section{Incomplete outcome data}

We assessed outcome reporting at low risk of bias in eight trials (Bergstrom 2009; Boaviagem 2017; Duncan 2017; Hosseini 2013; Kimber 2008; Moore 1965; Phumdoung 2007; Yildirim 2004) and at high risk in five trials due to a high number of postrandomisation exclusions (Almeida 2005, Simavli 2014), and large numbers of dropouts (Gatelli 2000; Gedde-Dahl 2012; Liu 2010).

\section{Selective reporting}

The risk of bias was low in two trials (Bergstrom 2009; Kimber 2008). In these papers a protocol was available, or several manuscripts were published with a comprehensive range of relevant outcomes to this review. We assessed two trials at high risk of bias (GeddeDahl 2012; Simavli 2014) due to not all outcome being reported, or there were discrepancies in data reported between papers. We assessed trials as unclear if there was insufficient reporting, or the protocol was not available.

\section{Other potential sources of bias}

Five trials were at a low risk of bias (Bergstrom 2009; Chuntharapat 2008; Dolcetta 1979; Phumdoung 2007; Yildirim 2004), with no obvious sources of bias. In the remaining trials it was unclear.

\section{Effects of interventions}

See: Summary of findings for the main comparison Relaxation compared to usual care for pain management in labour; Summary of findings 2 Yoga compared to control for pain management in labour; Summary of findings 3 Music compared to control for pain management in labour

\section{1) Relaxation}

We included 10 trials compared with usual care. Data from three trials could not be entered into the meta-analysis (Almeida 2005; Bagharpoosh 2006; Dizavandi 2012) and so we included 1382 women in the meta-analysis.

\section{Primary outcomes}

There were no data available on the outcomes; sense of control in labour, effect on mother/baby interaction, breastfeeding, and other poor outcomes for infants.

\section{1) Pain intensity}

\subsubsection{Latent phase}

Yildirim 2004 found a reduction in pain intensity (using a 10-point visual analogue scale (VAS)) for women receiving instruction on relaxation during the latent phase (mean difference (MD) -1.25, 95\% confidence interval ( $\mathrm{Cl})-1.97$ to $-0.53,40$ women (Analysis 1.1).

\subsubsection{Active phase}

The effect of relaxation on pain intensity during the active phase of labour (using a 10-point VAS) was not clear; due to high heterogeneity between trials we used a random-effects model (MD $-1.08,95 \% \mathrm{Cl}-2.57$ to 0.41 , four trials, 271 women, $\mathrm{I}^{2}=90 \%$, $\mathrm{Tau}^{2}$ $=1.99$, very low-quality evidence) (Analysis 1.1). The heterogeneity was explained primarily by Yildirim 2004, and potentially by the bias introduced from unclear randomisation and high risk of bias in relation to blinding.

Data from Almeida 2005 (36 women) were excluded from the analysis due to the large number of postrandomisation exclusions.

Data from Bagharpoosh 2006 were not reported in full and could not be entered into the meta-analysis. This trial reported lower pain intensity for the group receiving relaxation instruction compared with usual care during the latent phase ( 4.6 versus $6.3, P=001$ ), the active phase $(7.03$ versus 9.12. $P=0.0001)$ and during the second stage of labour (6.96 versus $9.64, \mathrm{P}=0.001$ ).

We did not include data from Dizavandi 2012 in the review as we could not extract any useful data from the outcomes reported.

\section{2) Pain intensity (at follow-up)}

This assessment of pain intensity was assessed at follow-up. There was no clear evidence of a difference between groups in maternal perception of pain (assessed along a Likert scale, where 0 indicated 'no pain at all' and 7 was 'worst imaginable pain'). (MD -0.00, 95\% $\mathrm{Cl}-0.23$ to 0.23 , one trial, 977 women) (Analysis 1.2). 


\section{3) Satisfaction with pain relief in labour}

There was increased satisfaction with pain relief for women receiving relaxation compared with the control (risk ratio (RR) $8.00,95 \% \mathrm{Cl} 1.10$ to 58.19 , one trial, 40 women, very low-quality evidence) (Analysis 1.3).

\section{4) Satisfaction with childbirth experience}

There was no clear evidence that the effects were any different between groups (MD $-0.03,95 \% \mathrm{Cl}-0.37$ to 0.31 , random-effects, three trials, 1176 women, substantial heterogeneity $\mathrm{I}^{2}=73 \%$, Tau ${ }^{2}$ $=0.06$, very low-quality evidence) (Analysis 1.4). The heterogeneity maybe explained by the use of different scales, lower scores used in the scales by Bergstrom 2009 and Kimber 2008 indicated greater satisfaction. Heterogeneity may also be explained by clinical heterogeneity of the intervention with Bergstrom 2009 a complex pre-birth intervention, and Kimber 2008 a short pre-birth intervention, whilst Boaviagem 2017 used a shorter intervention with no prior practise of the intervention by women.

\section{5) Assisted vaginal birth}

We combined data from four trials and there was no clear evidence that the effects were any different between groups (average RR $0.61,95 \% \mathrm{Cl} 0.20$ to 1.84 , four trials, 1122 women, substantial heterogeneity $\mathrm{I}^{2}=68 \%, \mathrm{Tau}^{2}=0.70$, very low-quality evidence) (Analysis 1.5). The heterogeneity was explained by the Gatelli 2000 trial and may have been influenced by the poor reporting and unclear and high risk of bias.

\section{6) Caesarean section}

We combined data from four trials and found no clear evidence of a difference between groups (average RR $0.73,95 \% \mathrm{Cl} 0.26$ to 2.01, random-effects model, four trials, 1122 women, substantial heterogeneity $\mathrm{I}^{2}=63 \%$, Tau ${ }^{2}=0.62$, very low-quality evidence) (Analysis 1.6). Heterogenity was not explained by any single trial, and may have been influenced by the risk of bias as well heterogeneity in the interventions administered.

\section{7) Admission to special care nursery}

There was no strong evidence that the effects were any different between groups (RR 1.03, 95\% Cl 0.07 to 15.77 , one trial, 59 women) (Analysis 1.7).

\section{8) Low Apgar score less than 7 at five minutes}

There was no clear evidence of a difference between groups (RR $0.47,95 \% \mathrm{Cl} 0.02$ to 10.69 , one trial, 34 women) (Analysis 1.8).

\section{Secondary outcomes}

There were no data available on the outcomes spontaneous vaginal birth, perineal trauma (defined as episiotomy and incidence of second- or third-degree tear), or maternal blood loss (postpartum haemorrhage defined as greater than $500 \mathrm{~mL}$ ).

\section{9) Use of pharmacological of pain relief}

\subsubsection{Epidural}

There was no clear evidence of a difference between groups with the use of epidural (RR 1.00, $95 \% \mathrm{Cl} 0.88$ to 1.13, one trial, 977 women) (Analysis 1.9).

\subsubsection{Any additional pharmacological intervention}

There was no clear evidence of a difference between groups with the use of any additional pharmacological intervention (RR 0.89, $95 \% \mathrm{Cl} 0.61$ to $1.28,59$ women, one trial).

\subsection{0) Length of labour}

There was no strong evidence that the effects were any different between groups in the duration of the length of labour (assessed in minutes) (MD 39.30, 95\% Cl -41.34 to 119.93 ; random-effects, three trials, 224 women, substantial heterogeneity $\mathrm{I}^{2}=56 \%$, Tau ${ }^{2}$ $=2878.06$ ) (Analysis 1.10).The heterogeneity was explained by the Boaviagem 2017 trial, and may have arisen from the clinical heterogeneity with this trial using a short intervention with no prior practise.

Dolcetta 1979 reported on the time (minutes) of active phase of labour and found no difference between groups (251.5 (102.1) versus $318.3(145.6)$ ).

\subsection{1) Need for augmentation with oxytocin}

There was no strong evidence that the effects were any different between groups (RR $1.14,95 \% \mathrm{Cl} 0.82$ to 1.59 , one trial, 34 women) (Analysis 1.11).

\subsection{2) Anxiety}

There was no clear evidence of a difference in anxiety assessed using the State-Trait Anxiety Inventory (STAI) scale between groups in anxiety in labour (MD $0.30,95 \% \mathrm{Cl}-4.15$ to 4.75 , one trial, 140 women) (Analysis 1.12).

\subsection{3) Non-prespecified: vitality}

There was a higher level of vitality (unspecified scale) reported in the relaxation group post partum (MD 13.10, $95 \% \mathrm{Cl} 10.58$ to 15.62 , one trial, 117 women) (Analysis 1.13).

\subsection{4) Non-prespecified: fatigue in labour}

There was no clear evidence of difference in fatigue between groups (MD $0.50,95 \% \mathrm{Cl}-1.44$ to 2.44 , one trial, 140 women) (Analysis 1.14).

\section{2) Yoga}

We included two trials and 149 women in the meta-analysis. One trial compared yoga with usual care, and one trial compared yoga with supine positioning.

\section{Primary outcomes}

There were no data available on sense of control in labour, effect on mother/baby interaction, breastfeeding, assisted vaginal birth, caesarean section, admission to special care nursery and other poor infant outcomes.

\section{1) Pain intensity}

There was lower pain intensity reported by women (VAS 0 to 100) in the latent phase for women receiving yoga compared with the control group (MD $-6.12,95 \% \mathrm{Cl}-11.77$ to -0.47 , one trial, 66 women, low-quality evidence) (Analysis 2.1).

\section{2) Satisfaction with pain relief}

There was greater satisfaction (assessed with a visual analogue sensation of pain scale ) with pain relief for women receiving yoga 
compared with the control (MD 7.88,95\% Cl 1.51 to 14.25 , one trial, 66 women, low-quality evidence) (Analysis 2.2).

\section{3) Satisfaction with childbirth experience}

There was greater satisfaction with childbirth experienced (measured using the maternal comfort questionnaire for women receiving yoga compared with the control (MD 6.34, 95\% $\mathrm{Cl} 0.26$ to 12.42, one trial, 66 women, low-quality evidence) (Analysis 2.3).

\section{4) Low Apgar score less than 7 at five minutes}

No babies in yoga or the control group had an Apgar score less than 7 at five minutes (Analysis 2.4).

\section{Secondary outcomes}

There were no data available on the outcomes spontaneous vaginal birth, perineal trauma (defined as episiotomy and incidence of second- or third-degree tear), maternal blood loss (postpartum haemorrhage defined as greater than $500 \mathrm{~mL}$ ), or anxiety.

\section{5) Use of pharmacological pain relief}

A comparison between yoga and usual care found no strong evidence that the effects were identical between groups (RR 0.82 , $95 \% \mathrm{Cl} 0.49$ to 1.38 , one trial, 66 women).

A comparison between yoga and supine position found reduced use of pharmacological methods for women receiving yoga (RR 0.05 , $95 \% \mathrm{Cl} 0.01$ to 0.35 , one trial, 83 women) (Analysis 2.5).

\section{6) Length of labour}

The length of labour in minutes was reduced for women receiving yoga compared with usual care (MD $-139.91,95 \% \mathrm{Cl}-252.50$ to -27.32, one trial, 66 women), and when compared to supine position (MD $-191.34,95 \% \mathrm{Cl}-243.72$ to -138.96 , one trial, 83 women) (Analysis 2.6).

\section{6) Need for augmentation in labour}

There was no strong evidence that the effects were any different between groups (RR $0.76,95 \% \mathrm{Cl} 0.45$ to 1.31 , one trial, 66 women) (Analysis 2.7).

\section{3) Music}

We included five trials for this intervention (Dizavandi 2012; Durham 1986; Gedde-Dahl 2012; Liu 2010; Simavli 2014). Four trials compared music with usual care (Dizavandi 2012; Gedde-Dahl 2012; Liu 2010; Simavli 2014) and one trial compared music and breathing techniques to breathing techniques alone (Durham 1986). We were only able to include data from three trials of music versus usual care including 217 women in the meta-analysis. Data from the Durham 1986 trial were not in a form that could be used in the meta-analysis. We were unable to obtain data on the Dizavandi 2012 trial.

\section{Primary outcomes}

There were no data available on satisfaction with maternal perception of pain, satisfaction with childbirth, sense of control in labour, Apgar score less than 7 at five minutes, effect on mother/ baby interaction, breastfeeding, and other poor outcomes for infants.

\section{1) Pain intensity}

\subsubsection{Latent phase}

There was evidence of lower pain scores (VAS 0 to 10) in the music group in the latent phase (MD $-0.73,95 \% \mathrm{Cl}-1.01$ to -0.45 , randomeffects, two trials, 192 women) (Analysis 3.1).

\subsubsection{Active phase}

There was no strong evidence that pain scores differed between groups (VAS 0 to 10) in the music group in the active phase (MD $-0.51,95 \% \mathrm{Cl}-1.10$ to 0.07 , random-effects, 217 women, three studies, substantial heterogeneity $\mathrm{I}^{2}=67 \%$, Tau ${ }^{2}=0.15$, very lowquality evidence) (Analysis 3.1). The heterogeneity was explained by Simavli 2014 and the influence of high risk of bias on several domains. There was high attrition for the Gedde-Dahl 2012 trial.

\subsubsection{Transition phase}

During transition there were lower pain scores (0 to $10 \mathrm{VAS}$ ) in the relaxation group (MD $-0.70,95 \% \mathrm{Cl}-0.86$ to -0.54 , one trial, 132 women) (Analysis 3.1).

\section{Secondary outcomes}

There were no data available on the outcomes: spontaneous vaginal birth; need for augmentation with oxytocin; perineal trauma (defined as episiotomy and incidence of second- or third-degree tear); maternal blood loss (postpartum haemorrhage defined as greater than $500 \mathrm{~mL}$ ).

\section{2) Assisted vaginal birth}

There was no strong evidence that the effects were any different between groups (RR $0.41,95 \% \mathrm{Cl} 0.08$ to 2.05 , one trial, 156 women, very low-quality evidence) (Analysis 3.2).

\section{3) Caesarean birth}

There was no strong evidence that the effects were any different between groups (RR $0.78,95 \% \mathrm{Cl} 0.36$ to 1.70 , two trials, 216 women, very low-quality evidence) (Analysis 3.3).

\section{4) Admission to special care nursery}

There were fewer admissions to special care in the music group (RR $0.23,95 \% \mathrm{Cl} 0.05$ to 1.01 , one trial, 155 women) (Analysis 3.4).

\section{5) Use of pharmacological pain relief}

There was no strong evidence that the effects were any different between groups (RR $0.83,95 \% \mathrm{Cl} 0.53$ to 1.32 , one trial, 60 women) (Analysis 3.5). Durham 1986 reported on this outcome and found no difference between groups $\left(\mathrm{Chi}^{2} 6.17, \mathrm{P}>0.05\right)$.

\section{6) Length of labour}

There was no clear evidence of a difference in length of second stage between groups in minutes (MD $-2.60,95 \% \mathrm{Cl}-11.58$ to 6.38 , one trial, 60 women) (Analysis 3.6).

\section{7) Anxiety}

There was no clear evidence of a reduction in anxiety (VAS 0 to 10 ) in the music group during the latent phase of labour (MD 0.08 , $95 \% \mathrm{Cl}-1.86$ to 2.02, random-effects, 192 women, two studies, $\mathrm{I}^{2}=$ $88 \%, \mathrm{Tau}^{2}=1.74$ ) or in the active phase of labour (MD $-0.30,95 \%$ $\mathrm{Cl}-1.74$ to 1.13 , random-effects, 192 women, two studies, $\mathrm{I}^{2}=85 \%$, $\left.\mathrm{Tau}^{2}=0.93\right)$. However in the two trials including 192 women, there 
was considerable heterogeneity $\left(I^{2}\right.$ more than $\left.80 \%\right)$ and we used random-effects analyses for these outcomes. The heterogeneity was explained by Simavli 2014 and the influence of high risk of bias on several domains. There was a reduction in anxiety during transition phase in the music group (MD $-0.66,95 \% \mathrm{Cl}-0.82$ to -0.50 , one trial, 132 women) (Analysis 3.7).

\section{4) Audio-analgesia}

One trial of 24 women was included in the meta-analysis in a comparison with white noise.

\section{Primary outcome}

Only one outcome on maternal satisfaction was reported for this trial.

\section{1) Satisfaction with pain relief}

There was no clear evidence of a difference between groups (RR $2.00,95 \% \mathrm{Cl} 0.82$ to 4.89 , one trial, 24 women) (Analysis 4.1).

\section{Secondary outcomes}

There were no data available on the outcomes use of pharmacological pain relief, length of labour, spontaneous vaginal birth, need for augmentation with oxytocin, perineal trauma (defined as episiotomy and incidence of second- or third-degree tear), maternal blood loss (postpartum haemorrhage defined as greater than $500 \mathrm{~mL}$ ), anxiety.

\section{5) Mindfulness}

One trial of 29 women was included in the analysis of mindfulness compared with education.

\section{Primary outcome}

\section{1) Sense of control in labour}

There was an increase in sense of control for the mindfulness group using the Childbirth Self-Efficacy Inventory although the $95 \% \mathrm{Cl}$ was wide for this outcome (MD 31.30, 95\% Cl 1.61 to 60.99, 26 women) (Analysis 5.1).

\section{2) Satisfaction with childbirth}

There was no clear evidence of a difference found between groups using the Wijma Delivery Expectancy/Experience Questionnaire (MD -4.50, 95\% -17.61 to 8.61, 26 women, one trial) (Duncan 2017) (Analysis 5.2)

\section{Secondary outcomes}

\section{3) Assisted vaginal birth}

There was no strong evidence that the effects were different between groups ( $R R=.31,95 \% \mathrm{Cl} 0.01$ to $7.09,29$ women, one trial) (Analysis 5.3).

\section{4) Caesarean section}

There was no strong evidence that the effects were different between groups (RR $0.93,95 \% \mathrm{Cl} 0.15$ to 5.76 ) (Analysis 5.4).

\section{5) Need for pharmacological relief}

There was no strong evidence that the effects were different between groups (RR $0.50,95 \% \mathrm{Cl} 0.20$ to $1.26,26$ women) (Analysis 5.5).

\section{Sensitivity analysis}

There were too few trials in any one comparison to conduct any meaningful sensitivity analyses.

\section{Subgroup analysis}

There were too few trials in any one comparison to conduct any meaningful subgroup analyses.

\section{DISCUSSION}

\section{Summary of main results}

Nineteen studies involving 2519 women included in the review suggest current limited evidence of benefit from relaxation techniques in relation to the primary outcomes of reduced pain intensity and increased satisfaction. Relaxation was associated with lower pain intensity during the latent phase, while evidence of lower pain scores in the active phase of labour was not clear (very low-quality evidence). Instruction on relaxation demonstrated increased satisfaction with pain relief (very low-quality evidence). Effects of relaxation on mode of birth was not clear (very lowquality evidence). Yoga was associated with lower pain scores, increased satisfaction with pain relief, and satisfaction with the childbirth experience. Trials evaluating music found lower pain scores during the latent phase but no strong evidence that the effects were any different between groups for the active phase (very low-quality evidence) and no clear evidence of an effect on anxiety in the latent and active phases but reduced anxiety in the transition phase (very low-quality evidence). Trials of audio analgesia found no strong evidence that the effects were any different between groups in the primary outcomes of pain intensity, satisfaction with pain relief, and caesarean birth. For the single mindfulness trial there was an increase in the sense of control. Currently there are a small number of trials included within each comparison, and this limits the power of the review to detect meaningful differences between groups and analyses, suggesting that these limited benefits should be interpreted with caution.

\section{Overall completeness and applicability of evidence}

There are only a few trials, mainly with small samples, of relaxation, yoga, music, mindfulness and audio-analgesia interventions that assess the role of these therapies for pain management in labour. The completeness and applicability of the evidence is limited from these trials, and there are no well-designed trials at a low risk of bias. The inclusion of relevant outcomes was limited in the majority of trials with a lack of outcomes relating to both safety and effectiveness.

Trials recruited nulliparous and multiparous women, from both the second and third trimester of pregnancy, with the interventions administered in the antenatal and labour ward environment. Some trials recruited women during labour and taught women relaxation techniques during this time. This may not result in the most efficacious practise of relaxation techniques, which may require significant time to practise and master. Studies were conducted in different countries, and this may reflect the use of particular modalities or techniques as part of their culture. This systematic review illustrates variation in how these modalities were practised, although it is unclear how the treatment protocols used in the research are generalisable to clinical practice or practice within the community. 


\section{Quality of the evidence}

The 'Risk of bias' figures, Figure 2 and Figure 3, demonstrate that relaxation techniques have not been subject to consistent rigorous evaluation. The quality of reporting was poor in most trials, consequently it is difficult to assess the overall risk of bias across studies and domains. For many studies, blinding of women and the practitioner was not possible, and reporting indicated that some outcomes may have been influenced by a lack of blinding, and consequently were rated at a high risk of bias. The small number of studies within comparisons and lack of high-quality trials indicates that there is currently insufficient evidence of a consistent treatment effect from the relaxation modalities included in the review. We contacted the chief investigators of some studies for additional methodological and statistical information, however, only a few responses were obtained (Liu 2010; Phumdoung 2007).

Many of the comparisons also had substantial statistical heterogeneity $\left(I^{2}\right.$ greater than $\left.50 \%\right)$. While some of the heterogeneity can be explained due to the heterogeneity in the interventions themselves as well as the controls used, this was often significant enough to result in a downgrade in the level of evidence. We also downgraded the evidence due to high risk of bias and small sample sizes. We were unable to examine the effect of study quality using a sensitivity analysis due to too few studies at a low risk of bias. The quality of reporting remains poor in many trials.

The quality of evidence using GRADE for relaxation compared with usual care was very low for pain intensity, satisfaction with pain relief and childbirth experience, assisted vaginal birth and caesarean section. Sense of control in labour and breastfeeding were not reported. We downgraded evidence for study design limitations such as high risk of bias in one or more domain, unexplained heterogeneity, and imprecision in effect estimates (Summary of findings for the main comparison). For yoga compared with control, we graded evidence for pain intensity, satisfaction with pain relief and childbirth experience as low-quality due to high risk of bias in blinding domains and small sample sizes. Sense of control, breastfeeding, assisted vaginal birth, and caesarean section were not reported (Summary of findings 2). For music compared with control for pain intensity, assisted vaginal birth, and caesarean section, we graded evidence as very low quality, downgrading for study design limitations, unexplained heterogeneity, and imprecision of effect estimates. Satisfaction with pain relief and childbirth experience, sense of control in labour, and breastfeeding were not reported (Summary of findings 3).

\section{Potential biases in the review process}

We attempted to minimise bias during the review process. Two review authors assessed the eligibility of studies, carried out data extraction and assessed the risk of bias. We are aware that some literature on relaxation therapies may not be published in mainstream journals and therefore maybe excluded from the main databases. Our search was comprehensive and we included studies identified in languages other than English, however we did not systematically search the other language databases, for example, Chinese language-only databases. We cannot rule out the possibility that some studies may have been missed.

\section{Agreements and disagreements with other studies or reviews}

Due to the lack of research examining the effect of relaxation modalities on pain management in labour we are limited to making comparisons with other trials and reviews. Two other recent Cochrane Reviews have covered the effectiveness of nonpharmaceutical modalities on labour pain and childbirth-related outcomes. A 2016 Cochrane Review on hypnosis, Madden 2016, with data from nine studies and 2954 women, found that there was no clear difference between hypnosis and control groups with respect to epidural use but women having hypnosis did use less pain medication during labour (low-quality evidence). There was no difference in terms of the number of caesarean sections between groups. A 2017 Cochrane Review on massage, reflexology and other manual methods, Smith 2011c, with data from 10 trials and 1055 women, found that both massage (low-quality evidence) and warm packs (very-low quality evidence), reduced the amount of pain in the first stage of labour, during cervical dilation. There was some evidence from two small trials of increased sense of satisfaction in childbirth (low-quality evidence) with massage. This review found, similar to massage and warm packs, relaxation (very low-quality evidence), yoga (low-quality evidence) and music (very low-quality evidence) reduced pain scores in the active phase of labour. Similar to hypnosis there was no clear evidence of a difference between any intervention and the control group for caesarean section rate or epidural usage. This review did not look at analgesic usage as a primary outcome so this cannot be compared between reviews.

\section{AUTHORS' CONCLUSIONS}

\section{Implications for practice}

The limited data available suggested that relaxation modalities may be a helpful modality for pain management in labour and there is no evidence of harm; however, there is insufficient evidence to inform clinical practice. Overall there are insufficient data to demonstrate whether relaxation modalities prove an additive benefit when used in combination with usual care, or whether they are more effective than usual care. Due to the unknown risk of bias of in the majority of trials and limited number of trials, further highquality research is needed.

\section{Implications for research}

Further randomised controlled trials of relaxation modalities for pain management in labour are needed. Trials should be adequately powered and include clinically relevant outcomes such as those described in this review. A methodological issue for trials of relaxation is the choice of an appropriate control group. Trials of relaxation modalities may be difficult to blind in relation to women and midwives, and pragmatic designs should be considered, enabling meaningful comparisons to be made. There is a need for improving the quality and reporting of future trials. In particular, consideration should be given in the analysis and reporting on the person providing the intervention: for example, their training, length of experience and relationship to the woman. In addition, further research is required, which includes data measuring neonatal outcomes and other maternal and clinical outcomes. 


\section{ACK N OWLEDGEMENTS}

We are grateful for the assistance of the staff in the editorial office for their help with preparing this review, in particular Therese Dowswell, Anna Cuthbert and Lynn Hampson, and the helpful comments from the consumer and statistical referees, and the Cochrane Pregnancy and Childbirth Editor.

We thank Caroline Crowther for her contribution to the protocol and previous versions of the review.
As part of the pre-publication editorial process, this review has been commented on by two peers (an editor and referee who is external to the editorial team), a member of Pregnancy and Childbirth's international panel of consumers and the Group's Statistical Adviser.

This project was supported by the National Institute for Health Research, via Cochrane Infrastructure funding to Cochrane Pregnancy and Childbirth. The views and opinions expressed therein are those of the review authors and do not necessarily reflect those of the Systematic Reviews Programme, NIHR, NHS or the Department of Health. 


\section{R E F E R E N C E S}

\section{References to studies included in this review}

Almeida 2005 \{published data only\}

Almeida NA, De Sousa JT, Bachion MM, Silveira NA. The use of respiration and relaxation techniques for pain and anxiety relief in the parturition process [Utilizacao de tecnicas de respiracao e relaxamento para alivio de dor e ansiedade no processo de parturicao]. Revista Latino-Americana de Enfermagem 2005;13(1):52-8.

\section{Bagharpoosh 2006 \{published data only\}}

Bagharpoosh M, Sangestani G, Goodarzi M. Effect of progressive muscle relaxation technique on pain relief during labor. Acta Medica Iranica 2006;44(3):187-90.

\section{Bahadoran 2010 \{published data only\}}

Bahadoran P, Asefi F, Oreyzi H, Valiani M. The effect of participating in the labor preparation classes on maternal vitality and positive affect during the pregnancy and after the labor. Iranian Journal of Nursing and Midwifery Research 2010;15(Suppl 1):331-6.

\section{Bergstrom 2009 \{published data only\}}

Bergstrom M, Kieler $\mathrm{H}$, Waldenstrom U. A randomised controlled multicentre trial of women's and men's satisfaction with two models of antenatal education. Midwifery 2011;27(6):e195-200.

* Bergstrom M, Kieler H, Waldenstrom U. Effects of natural childbirth preparation versus standard antenatal education on epidural rates, experience of childbirth and parental stress in mothers and fathers: a randomised controlled multicentre trial. BJOG 2009;116(9):1167-76.

Bergstrom M, Kieler H, Waldenstrom U. Effects of natural childbirth preparation versus standard antenatal education on epidural rates, experience of childbirth and parental stress in mothers and fathers: a randomised controlled multicentre trial. International Journal of Gynaecology \& Obstetrics 2009;107(Suppl 2):S546.

Bergstrom M, Kieler H, Waldenstrom U. Psychoprophylaxis during labor: associations with labor-related outcomes and experience of childbirth. Acta Obstetricia et Gynecologica Scandinavica 2010;89(6):794-800.

Bergstrom M, Rudman A, Waldenstrom U, Kieler H. Fear of childbirth in expectant fathers, subsequent childbirth experience and impact of antenatal education: subanalysis of results from a randomized controlled trial. Acta Obstetricia et Gynecologica Scandinavica 2013;92(8):967-73.

\section{Boaviagem 2017 \{published data only\}}

Boaviagem A, Belo MCF, Lemos A, de Melo Jr EF, Souza P, Lubambo L. Efficacy of breathing patterns in the first stage of labor for maternal pain, anxiety, and satisfaction. Obstetrics \& Gynecology 2015;125(5 Suppl):94S.

* Boaviagem A, Melo Junior E, Lubambo L, Sousa P, Aragao C, Albuquerque $S$, et al. The effectiveness of breathing patterns to control maternal anxiety during the first period of labor: a randomized controlled clinical trial. Complementary Therapies in Clinical Practice 2017;26:30-5.

\section{Chuntharapat 2008 \{published data only\}}

Chuntharapat S, Petpichetchian W, Hatthakit U. Yoga during pregnancy: effects on maternal comfort, labor pain and birth outcomes. Complementary Therapies in Clinical Practice 2008;14(2):105-15.

\section{Dizavandi 2012 \{published data only\}}

Dizavandi EB, Movaghati MA, Rezaean SM. The effect of music therapy on labour pain in nulliparous women in Mashad, Iran in 2010. Pain Practice 2012;12:81.

\section{Dolcetta 1979 \{published data only\}}

Dolcetta G, Azzini V, Zacche G, Tansella CZ, Bertagni P, Siani $\mathrm{R}$, et al. Traditional and respiratory autogenic training in psychoprophylaxis for childbirth. A controlled study on psychological and clinical effects in primiparous. 5th International Congress on Psychosomatic Medicine in Obstetrics and Gynaecology, "Emotion and Reproduction"; 1977 November 13-19; Rome, Italy. London: Academic Press, 1979:929-36.

\section{Duncan 2017 \{published data only\}}

Duncan L, Cohn M, Chao M, Cook J, Riccobono J, Bardacke N. Mind in labor: effects of mind/body training on childbirth appraisals and pain medication use during labor. Journal of Alternative \& Complementary Medicine 2014;20(5):A17.

* Duncan LG, Cohn MA, Chao MT, Cook JG, Riccobono J, Bardacke N. Benefits of preparing for childbirth with mindfulness training: a randomized controlled trial with active comparison. BMC Pregnancy and Childbirth 2017; Vol. 17, issue 1:140. [1471-2393: (Electronic)]

Weng H, Duncan L, Cohn M, Cook J, Hecht F, Bardacke N, et al. Mindfulness to alleviate fear and pain in childbirth increases body awareness and decreases pain catastrophizing. Journal of Alternative and Complementary Medicine 2016;22(6):A90.

Durham 1986 \{published data only\}

Durham L, Collins M. The effect of music as a conditioning aid in prepared childbirth education. Journal of Obstetric, Gynecologic and Neonatal Nursing 1986;15:268-70.

Gatelli 2000 \{published data only\}

Gatelli L, Panzeri M, Casadei D, Pagan F. Obstetric psychophysiology and quality of the experience of labour/ delivery: application within hospitals. Medicina Psicosomatica 2000;45:89-100.

Gedde-Dahl 2012 \{published data only\}

Gedde-Dahl M, Fors EA. Impact of self-administered relaxation and guided imagery techniques during final trimester and birth. Complementary Therapies in Clinical Practice 2012;18(1):60-5. 
Hosseini 2013 \{published data only\}

Hosseini SE, Bagheri M, Honarparvaran N. Investigating the effect of music on labor pain and progress in the active stage of first labor. European Review for Medical and Pharmacological Sciences. 2013/07/31 2013; Vol. 17, issue 11:1479-87. [1128-3602: (Print)]

\section{Kimber 2008 \{published data only\}}

ISRCTN43151584. Alternative labour pain strategies study. www.isrctn.com/ISRCTN43151584 (first received: 21 September 2005).

* Kimber L, McNabb M, Mc Court C, Haines A, Brocklehurst P. Massage or music for pain relief in labour: a pilot randomised placebo controlled trial. European Journal of Pain 2008;12(8):961-9. [1090-3801]

Liu 2010 \{published data only\}

Liu YH, Chang MY, Chen CH. Effects of music therapy on labour pain and anxiety in Taiwanese first time mothers. Journal of Clinical Nursing 2010;19(7-8):1065-72. [PUBMED: 20492051]

\section{Moore 1965 \{published data only\}}

Moore WMO, Browne JCM. Clinical trial of audio analgesia in childbirth. Journal of Obstetrics and Gynaecology of the British Commonwealth 1965;72:626-9.

\section{Phumdoung 2007 \{published data only\}}

Phumdoung S, Youngvanichsate S, Jongpaiboonpatana W, Leetanaporn R. The effects of the PSU Cat position and music on length of time in the active phase of labor and labor pain. Thai Journal of Nursing Research 2007;11(2):96-105.

\section{Simavli 2014 \{published data only\}}

* Simavli S, Gumus I, Kaygusuz I, Yildirim M, Usluogullari B, Kafali $\mathrm{H}$. Effect of music on labor pain relief, anxiety level and postpartum analgesic requirement: a randomized controlled clinical trial. Gynecologic and Obstetric Investigation 2014;78:244-50.

Simavli S, Kaygusuz I, Gumus I, Usluogullari B, Yildirim M, Kafali $\mathrm{H}$. Effect of music therapy during vaginal delivery on postpartum pain relief and mental health. Journal of Affective Disorders 2014;156:194-9.

\section{Yildirim 2004 \{published data only\}}

* Yildirim G, Sahin NH. The effect of breathing and skin stimulation on labour pain perception of Turkish women. Pain Research \& Management 2004;9(4):183-7.

Yildirim G, Sahin NH. The effects of breathing and tactile stimulation techniques on the pain perception of pregnants during labour. Jinekoloji Ve Dergisi 2004;18(2):115-21.

\section{References to studies excluded from this review}

\section{Ahmadi 2017 \{published data only\}}

Ahmadi Z, Torkzahrani S, Roosta F, Shakeri N, Mhmoodi Z. Effect of breathing technique of blowing on the extent of damage to the perineum at the moment of delivery: a randomized clinical trial. Iranian Journal of Nursing and Midwifery Research. 2017/04/07 2017; Vol. 22, issue 1:62-6. [1735-9066: (Print)]

Ahmadian 2009 \{published data only\}

Ahmadian Heris S, Taghavi S, Hoseininasab D. The effect of antenatal education interventions on state-trait anxiety in the parturition process. International Journal of Gynecology \& Obstetrics 2009;107(Suppl 2):S548.

Barbieri 2013 \{published data only\}

Barbieri M, Henrique AJ, Chors FM, Maia NL, Gabrielloni MC. Warm shower aspersion, perineal exercises with Swiss ball and pain in labor [Banho quente de aspersão, exercícios perineais com bola suíça e dor no trabalho de parto]. Acta Paulista de Enfermagem 2013;26(5):478-84.

Bastani 2006 \{published data only\}

Bastani F, Hidarnia A, Montgomery KS, Aguilar-Vafaei ME, Kazemnejad A. Does relaxation education in anxious Iranian women influence adverse pregnancy outcomes?. Journal of Perinatal and Neonatal Nursing 2006;20(2):138-46.

Browning 2000 \{published data only\} Browning CA. Using music during childbirth. Birth 2000;27(4):272-6.

\section{Buxton 1973 \{published data only\}}

Buxton R St J. Maternal respiration in labour. Nursing Mirror 1973;137:22-5.

Chuang 2012 \{published data only\}

Chuang LL, Lin LC, Cheng PJ, Chen CH, Wu SC, Chang CL. The effectiveness of a relaxation training program for women with preterm labour on pregnancy outcomes: a controlled clinical trial. International Journal of Nursing Studies 2012;49(3):257-64. [0020-7489]

Dehcheshmeh 2015 \{published data only\}

Dehcheshmeh FS, Rafiei H. Complementary and alternative therapies to relieve labor pain: a comparative study between music therapy and Hoku point ice massage. Complementary Therapies in Clinical Practice 2015;21(4):229-32. [1744-3881]

Delgado-Garcia 2012 \{published data only\}

Delgado-Garcia BE, Orts-Cortes MI, Poveda-Bernabeu A, Caballero-Perez P. Randomised controlled clinical trial to determine the effects of the use of birth balls during labour [Ensayo clínico controlado y aleatorizado para determinar los efectos del uso de pelotas de parto durante el trabajo de parto]. Enfermeria Clinica 2012;22(1):35-40.

\section{Drzymalski 2017 \{published data only\}}

Drzymalski D, Tsen L, Palanisamy A, Zhou J, Kodali B. Is music beneficial during labor epidural technique placement? Unexpected findings from a randomized controlled trial. In: Society for Obstetric Anesthesia and Perinatology (SOAP) 48th Annual Meeting;2016 May 18-22; Boston USA. 2016:01-06.

* Drzymalski DM, Tsen LC, Palanisamy A, Zhou J, Huang CC, Kodali BS. A randomized controlled trial of music use during epidural catheter placement on laboring parturient 
anxiety, pain, and satisfaction. Anesthesia and Analgesia 2017;124(2):542-7.

\section{Escott 2005 \{published data only\}}

Escott D, Slade P, Spiby H, Fraser RB. Preliminary evaluation of a coping strategy enhancement method of preparation for labour. Midwifery 2005;21(3):278-91.

Field 1999 \{published data only\}

Field T, Hernandez-Reif M, Hart S, Theakston H, Schanberg S, Kuhn C. Pregnant women benefit from massage therapy. Journal of Psychosomatic Obstetrics and Gynaecology 1999;20(1):31-8. [0167-482X: (Print)]

Firouzbakht 2014 \{published data only\}

Firouzbakht M, Nikpour M, Salmalian H, Ledari FM, Khafri S. The effect of perinatal education on Iranian mothers' stress and labor pain. Global Journal of Health Science 2014;6(1):61-8.

\section{Gau 2011 \{published data only\}}

Gau ML, Chang CY, Tian SH, Lin KC. Effects of birth ball exercise on pain and self-efficacy during childbirth: a randomised controlled trial in Taiwan. Midwifery 2011;27(6):e293-300.

\section{Geden 1989 \{published data only\}}

Geden E, Lower M, Beattie S, Beck N. Effects of music and imagery on physiologic and self report of analogues labour pain. Nursing Research 1989;38(1):37-41.

Hao 1997 \{published data only\}

Hao TY, Li YH, Yao SF. Clinical study on shortening birth process by psychological suggestion therapy. Chinese Journal of Nursing 1997;32(10):568-670.

\section{Huang 2015 \{published data only\}}

Huang J, Li HJ, Wang J, Mao HJ, Jiang WY, Zhou H, et al. Prenatal emotion management improves obstetric outcomes: a randomized control study. International Journal of Clinical and Experimental Medicine 2015;8(6):9667-75.

\section{Jain 2015 \{published data only\}}

Jain P, Srivastava H, Goel N, Khaliq F, Dewan P, Sharma R, et al. Effect of antenatal exercises on pulmonary functions and labour outcome in uncomplicated primigravida women: a randomized controlled study. International Journal of Reproduction, Contraception, Obstetrics and Gynecology 2015;4(5):1478-84.

\section{Janke 1999 \{published data only\}}

Janke J. The effect of relaxation therapy on preterm labor outcomes. Journal of Obstetric, Gynecologic, and Neonatal Nursing 1999;28(3):255-63. [0884-2175: (Print)]

\section{Kamalifard 2012 \{published data only\}}

Kamalifard M, Shahnazi M, Sayyah Melli M, Allahverdizadeh S, Toraby S, Ghahvechi A. The efficacy of massage therapy and breathing techniques on pain intensity and physiological responses to labor pain. Jounal of Caring Sciences 2012;1(2):73-8. [2251-9920]

\section{Korol 1992 \{published data only\}}

Korol C, Von Baeyer C. Effects of brief instruction in imagery and birth visualization in prenatal education. Journal of Mental Imagery 1992;16(3-4):167-72.

Levett 2016b \{published data only\}

Levett KM, Smith CA, Dahlen HG, Bensoussan A. Complementary therapies for labour and birth: results from a mixed methods study. Journal Paediatrics and Child Health 2014;50(Suppl 1):19.

\section{Mathew 2012 \{published data only\}}

Mathew A, Nayak S, Vandana K. A comparative study on effect of ambulation and birthing ball on maternal and newborn outcome among primigravida mothers in selected hospitals in Mangalore. Nitte University Journal of Health Science 2012;2(2):2-5.

\section{Miquelutti 2015 \{published data only\}}

* Miquelutti MA, Cecatti JG, Makuch MY. Developing strategies to be added to the protocol for antenatal care: an exercise and birth preparation program. Clinics (Sao Paulo, Brazil) 2015;70(4):231-6.

Miquelutti MA, Cecatti JG, Makuch MY. Evaluation of a birth preparation program on lumbopelvic pain, urinary incontinence, anxiety and exercise: a randomized controlled trial. BMC Pregnancy and Childbirth 2013;13:154.

Miquelutti MA, Cecatti JG, Makuch MY. Evaluation of the efficacy of an antenatal birth preparation program. International Journal of Gynecology and Obstetrics 2012;119(Suppl 3):S414.

Mirzakhani 2015 \{published data only\}

Mirzakhani C, Hejazinia Z, Golmakani N, Mirteimouri M, Sardar MA, Shakeri MT. The effect of exercise with special ball during pregnancy on duration of active phase of first stage of birth in nulliparous women. Iranian Journal of Obstetrics, Gynecology and Infertility 2015;18(174):12-21.

\section{Musa 2011 \{published data only\}}

Musa DI, Daniel J. Effect of exercise on labour duration and pain in pregnant women at Aminu Kano teaching hospital Kano Nigeria. 16th International WCPT Congress; 2011 June 20-23; Amsterdam, Holland. 2011.

\section{Narendran 2005 \{published data only\}}

Narendran S, Nagarathna R, Narendran V, Gunasheela S, Nagendra HR. Efficacy of yoga on pregnancy outcome. Journal of Alternative and Complementary Medicine 2005;11(2):237-44. [1075-5535: (Print)]

\section{NCT01389128 \{published data only\}}

NCT01389128. Non-pharmacological resources in assisting labor. clinicaltrials.gov/ct2/show/NCT01389128 (first received: 30 June 2011).

\section{NCT01601860 \{published data only\}}

NCT01601860. Evaluation of maternal and perinatal outcomes associated with the use of non-pharmacological in 
parturients in active phase of labor. clinicaltrials.gov/ct2/show/ NCT01601860 Date first received: 19 September 2011.

\section{NCT02190591 \{published data only\}}

NCT02190591. Use of peanut labor ball for pelvic positioning for nulliparous patients following epidural. clinicaltrials.gov/ct2/ show/NCT02190591 (first received: 16 May 2014).

\section{Phumdoung 2003 \{published data only\}}

Phumdoung S, Good M. Music reduces sensation and distress of labor pain. Pain Management Nursing 2003;4(2):54-61.

\section{Phumdoung 2010 \{published data only\}}

Phumdoung S, Morkruengsai S, Tachapattarakul S, Lawantrakul J, Junsuwan P. Effect of the Prince of Songkla University locked-upright position on the duration, pain and comfort of second-stage labor in primiparous women. Pacific Rim International Journal of Nursing Research 2010;14(2):112-21.

\section{Podder 2007 \{published data only\}}

Podder L. Effects of music therapy on anxiety levels and pain perception. Nursing Journal of India 2007;98(7):161.

\section{Ran 2005 \{published data only\}}

Ran KQ, He AM, Han QR, Tang ZL, Lei FH. Comfortable nursing and the mental state in parturient women. Chinese Journal of Clinical Rehabilitation 2005;9(32):62-3.

\section{Roth 2016 \{published data only\}}

Roth C, Dent SA, Parfitt SE, Hering SL, Curtis Bay R. Use of the peanut ball during labor. MCN. The American Journal of Maternal Child Nursing 2016;41:140-6.

\section{Sammons 1984 \{published data only\}}

Sammons LN. The use of music by women during childbirth. Journal of Nurse Midwifery 1984;29:266-70.

\section{Schorn 2009 \{published data only\}}

Schorn MN. The effect of guided imagery on the third stage of labor: a pilot study. Journal of Alternative and Complementary Medicine 2009;15(8):863-70.

\section{Shim 2012 \{published data only\}}

Shim CS, Lee YS. Effects of a yoga-focused prenatal program on stress, anxiety, self confidence and labor pain in pregnant women with in vitro fertilization treatment. Journal of Korean Academy of Nursing. 2012/08/03 2012; Vol. 42, issue 3:369-76. [2005-3673]

\section{Sun 2010 \{published data only\}}

Sun YC, Hung YC, Chang Y, Kuo SC. Effects of a prenatal yoga programme on the discomforts of pregnancy and maternal childbirth self-efficacy in Taiwan. Midwifery. 2009/02/28 2010; Vol. 26, issue 6:e31-6. [0266-6138]

\section{Taavoni 2016 \{published data only\}}

Taavoni S, Abdolahian S, Haghani H. Effect of birth ball on active phase of physiologic labor: randomized control trial study. International Journal of Medicine 2010;40(Suppl 1):171.
Taavoni S, Abdolahian S, Haghani H. Effect of pelvic tilt by birth ball usage on active phase labor pain during physiologic labor: a randomized control trial. Regional Anesthesia and Pain Medicine 2013;38(5 Suppl 1):E163.

Taavoni S, Abdolahian S, Haghani H. Effect of pelvic tilt by birth ball usage, sacrum-perinea heat therapy and combination of them on active phase of physiologic labor. International Confederation of Midwives 30th Triennial Congress. Midwives: Improving Women's Health; 2014 June 1-4; Prague, Czech Republic. 2014:C169.

Taavoni S, Abdolahian S, Haghani H, Neisani L. Effect of pelvic tilt by using birth ball on active phase of physiologic labor: a randomized control trial study. International Journal of Gynecology and Obstetrics 2012;119(Suppl 3):S496.

Taavoni S, Abdolahian S, Haghani H, Neysani L. Effect of birth ball usage on pain in the active phase of labor: a randomized controlled trial. Journal of Midwifery \& Women's Health 2011;56(2):137-40.

Taavoni S, Abdolahian S, Neisani L, Haghani H. Three noninvasive interventions for physiologic labour pain management: use of birth ball, sacrum-perinea heat therapy, and combined use of them during active phase. International Journal of Gynecology and Obstetrics 2015;131(Suppl 5):E217.

Taavoni S, Abdolahian S, Neisani L, Hamid H. Labor pain management: effect of pelvic tilt by birth ball, sacrumperinea heat therapy, and combined use of them, a randomized controlled trial. European Psychiatry 2016;33S:S503.

* Taavoni S, Sheikhan F, Abdolahian S, Ghavi F. Birth ball or heat therapy? A randomized controlled trial to compare the effectiveness of birth ball usage with sacrum-perineal heat therapy in labor pain management. Complementary Therapies in Clinical Practice 2016;24:99-102.

\section{Taghavi 2009 \{published data only\}}

Taghavi S, Hoseininasab D, Ahmadian heris S. The effect of antenatal education on pain intensity and labor. International Journal of Gynecology \& Obstetrics 2009;107(Suppl 2):S493.

Taghinejad 2010 \{published data only\}

Taghinejad H, Delpisheh A, Suhrabi Z. Comparison between massage and music therapies to relieve the severity of labor pain. Women's Health (London, England) 2010;6(3):377-81. [1745-5057]

\section{Tragea 2014 \{published data only\}}

Tragea C, Chrousos GP, Alexopoulos EC, Darviri C. A randomized controlled trial of the effects of a stress management programme during pregnancy. Complementary Therapies in Medicine 2014;22(2):203-11.

Tussey 2015 \{published data only\}

Tussey C, Botsios E. Use of a labor ball to decrease the length of labor in patients who receive an epidural. JOGN Nursing; Journal of Obstetric, Gynecologic, and Neonatal Nursing 2011;40:S105-6. 
* Tussey CM, Botsios E, Gerkin RD, Kelly LA, Gamez J, Mensik J. Reducing length of labor and cesarean surgery rate using a peanut ball for women laboring with an epidural. Journal of Perinatal Education 2015;24(1):16-25.

Zilcha-Mano 2016 \{published data only\}

Zilcha-Mano S, Langer E. Mindful attention to variability intervention and successful pregnancy outcomes. Journal of Clinical Psychology 2016;72(9):897-907. [0021-9762]

\section{References to studies awaiting assessment}

Jahdi 2017 \{published data only\}

Jahdi F, Sheikhan F, Haghani H, Sharifi B, Ghaseminejad A, Khodarahmian $M$, et al. Yoga during pregnancy: the effects on labor pain and delivery outcomes (a randomized controlled trial). Complementary Therapies in Clinical Practice 2017;27:1-4.

\section{Salem 2004 \{published data only\}}

Salem SG. The Effect of Music on Pain During the First Stage of Labor in Egypt [thesis]. Cleveland, OH: Case Western Reserve University, 2004.

\section{Shafai 2013 \{published data only\}}

Shafai FS, Kazemi S, Ghojazadeh M. Comparing maternal outcomes in nulliparous women in labor in physiological and conventional labor: a randomized clinical trial. Journal of Mazandaran University of Medical Sciences 2013;23(97):122-31.

\section{Tehrani 2006 \{published data only\}}

Tehrani GS. The effect of meditation and relaxation techniques on pain during the active phase of labor in nulliparous women. HAYAT 2006;12(3):51-61.

\section{References to ongoing studies}

NCT00917332 \{published data only\}

NCT00917332. Effects of relaxation and guided imagery training on pain at childbirth. clinicaltrials.gov/show/NCT00917332 (first received: 8 June 2009).

\section{NCT03066973 \{published data only\}}

NCT03066973. The effectiveness of breathing exercises to labor pain and duration: a randomized controlled trial. clinicaltrials.gov/ct2/show/NCT03066973 (first received: 21 February 2017).

\section{Additional references}

\section{Adams 2009}

Adams J, Lui C-W, Sibbritt D, Broom A, Wardle J, Homer C, et al. Women's use of complementary and alternative medicine during pregnancy: a critical review of the literature. Birth 2009;36(3):237-45

\section{Anim-Somuah 2005}

Anim-Somuah M, Smyth R, Howell CJ. Epidural versus non-epidural or no analgesia in labour. Cochrane
Database of Systematic Reviews 2005, Issue 4. [DOI: 10.1002/14651858.CD000331.pub2]

\section{Barragán 2011}

Barragán LIM, Solà I, Juandó PC. Biofeedback for pain management during labour. Cochrane Database of Systematic Reviews 2011, Issue 6. [DOI: 10.1002/14651858.CD006168.pub2]

\section{Bennett 1999}

Bennett VR, Brown LK. Myles Textbook for Midwives. 13th Edition. London: Churchill Livingstone, 1999.

\section{Busch 2012}

Busch V, Magerl W, Kern U, Haas J, Hajak G, Eichhammer P. The effect of deep and slow breathing on pain perception, autonomic activity, and mood processing-an experimental study. Pain Medicine 2012;13(2):215-28.

\section{Cluett 2009}

Cluett ER, Burns E. Immersion in water in labour and birth. Cochrane Database of Systematic Reviews 2009, Issue 2. [DOI: 10.1002/14651858.CD000111.pub3]

\section{Deeks 2011}

Deeks JJ, Higgins JPT, Altman DG (editors). Chapter 9: Analysing data and undertaking meta-analyses. In: Higgins JPT, Green $S$ (editors). Cochrane Handbook for Systematic Reviews of Interventions Version 5.1.0 (updated March 2011). The Cochrane Collaboration, 2011. Available from handbook.cochrane.org.

\section{Derry 2011}

Derry S, Straube S, Moore RA, Hancock H, Collins SL. Intracutaneous or subcutaneous sterile water injection for relieving pain in labour. Cochrane Database of Systematic Reviews 2011, Issue 5. [DOI: 10.1002/14651858.CD009107]

\section{Dick-Read 2004}

Dick-Read G. Childbirth Without Fear: the Principles and Practice of Natural Childbirth. London: Pinter \& Martin, 2004.

\section{Dowswell 2009}

Dowswell T, Bedwell C, Lavender T, Neilson JP. Transcutaneous electrical nerve stimulation (TENS) for pain relief in labour. Cochrane Database of Systematic Reviews 2009, Issue 2. [DOI: 10.1002/14651858.CD007214.pub2]

\section{Field 2011}

Field T. Yoga clinical research review. Complementary Therapies in Clinical Practice 2011;17(1):1-8.

\section{Fisher 2004}

Fisher L. Introduction to yoga. Australian Yoga Life 2004;10:6-7.

\section{Higgins 2003}

Higgins JPT, Thompson SG, Deeks JJ, Altman DG. Measuring inconsistency in meta-analyses. BMJ 2003;327:557-60.

\section{Higgins 2011a}

Higgins JPT, Altman DG, Sterne JAC (editors). Chapter 8: Assessing risk of bias in included studies. In: Higgins JPT, Green $\mathrm{S}$ (editors). Cochrane Handbook for Systematic Reviews of 
Interventions Version 5.1.0 (updated March 2011). The Cochrane Collaboration, 2011. Available from handbook.cochrane.org.

\section{Higgins 2011b}

Higgins JPT, Deeks JJ, Altman DG (editors). Chapter 16: Special topics in statistics. In: Higgins JPT, Green S (editors), Cochrane Handbook for Systematic Reviews of Interventions Version 5.1.0 (updated March 2011). The Cochrane Collaboration, 2011. Available from handbook.cochrane.org.

\section{Jacobson 1938}

Jacobson E. Progressive Relaxation. 2nd Edition. Chicago: University of Chicago, 1938.

\section{Jones 2011}

Jones L, Dou L, Dowswell T, Alfirevic Z, Neilson James P. Pain management for women in labour: generic protocol. Cochrane Database of Systematic Reviews 2011, Issue 6. [DOI: 10.1002/14651858.CD009167]

\section{Jones 2012}

Jones L, Othman M, Dowswell T, Alfirevic Z, Gates S, Newburn M, et al. Pain management for women in labour: an overview of systematic reviews. Cochrane Database of Systematic Reviews 2012, Issue 3. [DOI: 10.1002/14651858.CD009234.pub2]

\section{Klarer 2014}

Klarer M, Arnold M, Günther L, Winter C, Langhans W, Meyer U. Gut vagal afferents differentially modulate innate anxiety and learned fear. Journal of Neuroscience 2014;34(21):7067-76.

\section{Klomp 2011}

Klomp T, Van Poppel M, Lazet J, Di Nisio M. Inhaled analgesia for pain management in labour. Cochrane Database of Systematic Reviews 2011, Issue 10. [DOI: 10.1002/14651858.CD009351]

\section{Leap 2010}

Leap N, Dodwell M, Newburn M. Working with pain in labour: an overview of evidence. New Digest 2010;49:22-6.

\section{Levett 2016a}

Levett KM, Dahlen HG, Bensoussan A, Smith CA. Complementary therapies for labour and birth study: a randomised controlled trial of antenatal integrative medicine for pain management in labour. BMJ Open 2016;6(7):e010691. [DOI: 10.1136/bmjopen-2015-010691]

\section{Madden 2016}

Madden K, Middleton P, Cyna AM, Matthewson M, Jones L. Hypnosis for pain management during labour and childbirth. Cochrane Database of Systematic Reviews 2016, Issue 5. [DOI: 10.1002/14651858.CD009356.pub3]

\section{Maimburg 2016}

Maimburg, RD, Vaeth M, Dahlen H. Women's experience of childbirth-a five year follow up of the randomised controlled trial "Ready for Child Trial". Women and Birth 2016;5:450-4.

\section{Manheimer 2008}

Manheimer E, Berman B. Cochrane Complementary Medicine. About The Cochrane Collaboration (Fields) 2008, Issue 2. Art. No.: CE000052. [DOI: CE000052]

\section{McCaffery 1979}

McCaffery M. Nursing Management of the Patient with Pain. 2nd Edition. Philadelphia: Lippincott, 1970.

\section{Melzack 1984}

Melzack R. The myth of painless childbirth. Pain 1984;19:331-7.

\section{Melzack 2001}

Melzack R. Pain and neuromatrix in the brain. Journal of Dental Education 2001;65:1378-82.

\section{Morgan 1982}

Morgan BM, Bulpitt CJ, Clifton P, Lewis PJ. Analgesia and satisfaction in childbirth (the Queen Charlotte's 1000 mother survey). Lancet 1982;2(8302):808-10.

\section{Novikova 2011}

Novikova N, Cluver C. Local anaesthetic nerve block for pain management in labour. Cochrane Database of Systematic Reviews 2011, Issue 7. [DOI: 10.1002/14651858.CD009200]

\section{Othman 2011}

Othman M, Jones L, Neilson James P. Non-opioid drugs for pain management in labour. Cochrane Database of Systematic Reviews 2011, Issue 7. [DOI: 10.1002/14651858.CD009223]

\section{RevMan 2014 [Computer program]}

Nordic Cochrane Centre, The Cochrane Collaboration. Review Manager 5 (RevMan 5). Version 5.3. Copenhagen: Nordic Cochrane Centre, The Cochrane Collaboration, 2014.

\section{Sharp 2001}

Sharp TJ. Chronic pain: a reformulation of the cognitivebehavioural model. Behaviour Research and Therapy 2001;39:787-800.

\section{Simmons 2007}

Simmons S, Cyna AM, Dennis AT, Hughes D. Combined spinal-epidural versus epidural analgesia in labour. Cochrane Database of Systematic Reviews 2007, Issue 3. [DOI: 10.1002/14651858.CD003401.pub2]

\section{Smith 2011a}

Smith CA, Collins CT, Crowther CA, Levett KM. Acupuncture or acupressure for pain management in labour. Cochrane Database of Systematic Reviews 2011, Issue 7. [DOI: 10.1002/14651858.CD009232]

\section{Smith 2011b}

Smith CA, Collins CT, Crowther CA. Aromatherapy for pain management in labour. Cochrane Database of Systematic Reviews 2011, Issue 7. [DOI: 10.1002/14651858.CD009215]

\section{Smith 2011c}

Smith CA, Levett KM, Collins CT, Jones L. Manual healing methods including massage and reflexology for pain 
management in labour. Cochrane Database of Systematic Reviews 2011, Issue 9. [DOI: 10.1002/14651858.CD009290]

\section{Steel 2014}

Steel A, Adams J, Sibbritt D, Broom A, Frawley J, Gallois C. The influence of complementary and alternative medicine use in pregnancy on labor pain management choices: results from a nationally representative sample of 1,835 women. Journal of Alternative and Complementary Medicine (New York, N.Y.) 2014;20(2):87-97.

\section{Sterne 2011}

Sterne JAC, Egger M, Moher D (editors). Chapter 10: Addressing reporting biases. In: Higgins JPT, Green S (editors). Cochrane Handbook for Systematic Reviews of Intervention. Version 5.1.0 (updated March 2011). The Cochrane Collaboration, 2011. Available from handbook.cochrane.org.

\section{Trout 2004}

Trout KK. The neuromatrix theory of pain: implications for selected non-pharmacological methods of pain relief for labor. Journal of Midwifery \& Women's Health 2004;49(6):482-8.

\section{Ullman 2010}

Ullman R, Smith LA, Burns E, Mori R, Dowswell T. Parenteral opioids for maternal pain relief in labour. Cochrane Database of Systematic Reviews 2010, Issue 9. [DOI: 10.1002/14651858.CD007396.pub2]

\section{Velvovsky 1960}

Velvovsky IPK, Ploticher V, Shugom E. Painless Childbirth Through Psychoprophylaxis. Moscow: Foreign Languages Publishing House, 1960.

\section{CHARACTERISTICS OF STUDIES}

Characteristics of included studies [ordered by study ID]

\section{Vickers 1999}

Vickers A, Zolloman C. ABC of complementary medicine: hypnosis and relaxation therapies. BMJ 1999;319:1346-9.

\section{Villemure 2002}

Villemure CM, Bushnell MC. Cognitive modulation of pain: how do attention and emotion influence pain processing?. Pain 2002;95:195-99.

\section{Woo 2015}

Woo CW, Roy M, Buhle JT, Wager TD. Distinct brain systems mediate the effects of nociceptive input and self-regulation on pain. PLoS Biology 2015;13(1):e1002036.

\section{References to other published versions of this review Smith 2006}

Smith CA, Collins CT, Cyna AM, Crowther CA. Complementary and alternative therapies for pain management in labour. Cochrane Database of Systematic Reviews 2006, Issue 4. [DOI: 10.1002/14651858.CD003521.pub2]

\section{Smith 2011}

Smith CA, Levett KM, Collins CT, Crowther CA. Relaxation techniques for pain management in labour. Cochrane Database of Systematic Reviews 2011, Issue 12. [DOI: 10.1002/14651858.CD009514]

* Indicates the major publication for the study

Almeida 2005

Methods Parallel RCT of breathing techniques and relaxation compared with usual care (nursing)

Participants

65 women were recruited from the antenatal ward, obstetric ward and postnatal ward of a public hospital, located in Goias, Brazil.

Inclusion criteria: primiparas with normal labour and at low risk, in latent phase ( $\leqq 4 \mathrm{~cm}$ dilation) of labour on admission, no obstetric disease or complications, not having previously participated in psychoprophylactic preparation courses for childbirth

Exclusion criteria: dystocia, fetal distress, obstetrical disease or indication for caesarean, requirement for forceps delivery or use of analgesia

Interventions

Intervention: Individualised nursing care with advice and encouraging the use of breathing techniques and relaxation. Adopted from Grantly Dick Read and Fernand Lamaze from admission of mother until delivery. Breathing techniques used during contractions at different stages of labour and during delivery.

Latent phase total respiration (thoracic abdominal breathing slowly, with deep inspiration and expiration, in a natural rhythm.

Active phase: thoracic breathing slowly (slow breathing with deep inspiration and expiration, a natural rhythm, directing the breath to the chest. 
Transition phase: pressure breathing without performing abdominal pressure force (breath slow, deep breathing with sustained for periods during contractile pull in order to maintain the diaphragm force acting on the uterus, followed by long expiration.

Explusion period; pressure breathing with the exertion of the abdominal force (contraction of skeletal muscle) at the time of the tugs.

Relaxation techniques: release all body muscles associated with the total respiration, in intervals of uterine contractions

Control: routine nursing care

\begin{tabular}{ll}
\hline Outcomes & Self-assessment scales: STAI and VAS to evaluate the intensity of pain \\
& VAS evaluated in early stages of latent, active and transition, at the time of contraction \\
& STAl administered in latent phase of labour and state of anxiety and active phases of transition and in \\
the immediate postpartum period & \\
Length of labour \\
\hline Study duration May 2000-March 2001 \\
Funding: not reported \\
Conflicts of interest: not reported
\end{tabular}

\section{Risk of bias}

\begin{tabular}{|c|c|c|}
\hline Bias & Authors' judgement & Support for judgement \\
\hline $\begin{array}{l}\text { Random sequence genera- } \\
\text { tion (selection bias) }\end{array}$ & Low risk & $\begin{array}{l}\text { Coin toss with randomisation in a 1:1 ratio (17 control group, } 19 \text { experimental } \\
\text { group) }\end{array}$ \\
\hline $\begin{array}{l}\text { Allocation concealment } \\
\text { (selection bias) }\end{array}$ & Low risk & Allocation unknown until the moment of coin toss \\
\hline $\begin{array}{l}\text { Blinding of participants } \\
\text { and personnel (perfor- } \\
\text { mance bias) } \\
\text { All outcomes }\end{array}$ & High risk & $\begin{array}{l}\text { Interventions were substantially different and obvious to an observer. Alloca- } \\
\text { tion was known to participants and clinicians }\end{array}$ \\
\hline $\begin{array}{l}\text { Blinding of outcome as- } \\
\text { sessment (detection bias) } \\
\text { All outcomes }\end{array}$ & High risk & $\begin{array}{l}\text { Outcomes would be recorded by staff providing care, who would be aware of } \\
\text { the intervention }\end{array}$ \\
\hline $\begin{array}{l}\text { Incomplete outcome data } \\
\text { (attrition bias) } \\
\text { All outcomes }\end{array}$ & High risk & $\begin{array}{l}\text { Postrandomisation exclusions: } 29 \text { ( } 44.62 \%) \text { were excluded, } 12 \text { for use of exoge- } \\
\text { nous oxytocin, } 2 \text { for forceps delivery and } 15 \text { caesarean delivery. Data not pre- } \\
\text { sented by group }\end{array}$ \\
\hline $\begin{array}{l}\text { Selective reporting (re- } \\
\text { porting bias) }\end{array}$ & Unclear risk & The study protocol is not available but the study excluded clinical outcomes \\
\hline Other bias & Unclear risk & $\begin{array}{l}\text { Data were not presented on the baselines characteristics of those excluded af- } \\
\text { ter randomisation }\end{array}$ \\
\hline
\end{tabular}


Bagharpoosh 2006

\begin{tabular}{ll}
\hline Methods & Parallel RCT of relaxation compared with usual care \\
\hline Participants & 62 women aged 20-30 years recruited from the Fatemieh Hospital, Hamadan, Iran \\
& Inclusion criteria: primiparous with no obstetric complications \\
& Exclusion criteria: no exclusion criteria were specified \\
\hline Interventions & No women in either group received analgesics before or during labour. \\
& $\begin{array}{l}\text { Intervention: followed instructions under the supervision of } 1 \text { of the researchers. The relaxation inter- } \\
\text { vention followed a standard method involving the participants to be positioned in a comfortable state, }\end{array}$ \\
in a quiet environment and tensing and relaxing muscles in the toes, feet, ankles, calves, knees, thighs, \\
lower abdomen, upper abdomen, shoulders, arms, hands, fingers, neck, face and heads. \\
Control: standard care \\
$\begin{array}{l}\text { Pain was assessed along a NRS. Pain intensity was measured during the first phase of labour, active } \\
\text { phase (dilatation < } 7 \mathrm{~cm}), \text { second phase of labour (dilatation } 10 \mathrm{~cm}), \text { and pain intensity was expressed } \\
\text { as low (1-4), mild (5-6), severe (7-8), very severe (9-10). Behavioural indicators of pain were also record- } \\
\text { ed }\end{array}$ \\
$\begin{array}{l}\text { Dates of study: } 2002 \\
\text { Funding: not reported } \\
\text { Conflicts of interest: none }\end{array}$ \\
\hline Notes
\end{tabular}

\section{Risk of bias}

\begin{tabular}{lll}
\hline Bias & Authors' judgement & Support for judgement \\
\hline $\begin{array}{l}\text { Random sequence genera- } \\
\text { tion (selection bias) }\end{array}$ & Unclear risk & No details could be obtained from the study author \\
\hline $\begin{array}{l}\text { Allocation concealment } \\
\text { (selection bias) }\end{array}$ & Unclear risk & No details could be obtained from the study author \\
\hline $\begin{array}{l}\text { Blinding of participants } \\
\text { and personnel (perfor- } \\
\text { mance bias) }\end{array}$ & High risk & Women and clinicians were not blind to group allocation \\
All outcomes & \\
\hline $\begin{array}{l}\text { Blinding of outcome as- } \\
\text { sessment (detection bias) }\end{array}$ & High risk & $\begin{array}{l}\text { Outcomes would be recorded by staff providing care, who would be aware of } \\
\text { the intervention }\end{array}$ \\
\hline $\begin{array}{l}\text { Incomplete outcome data } \\
\text { (attrition bias) }\end{array}$ & Unclear risk & Not reported \\
$\begin{array}{l}\text { All outcomes } \\
\text { Selective reporting (re- } \\
\text { porting bias) }\end{array}$ & Unclear risk & Protocol not reported \\
\hline \begin{tabular}{l} 
Other bias \\
\hline
\end{tabular} & Unclear risk & Insufficient reporting \\
\hline
\end{tabular}


Bahadoran 2010

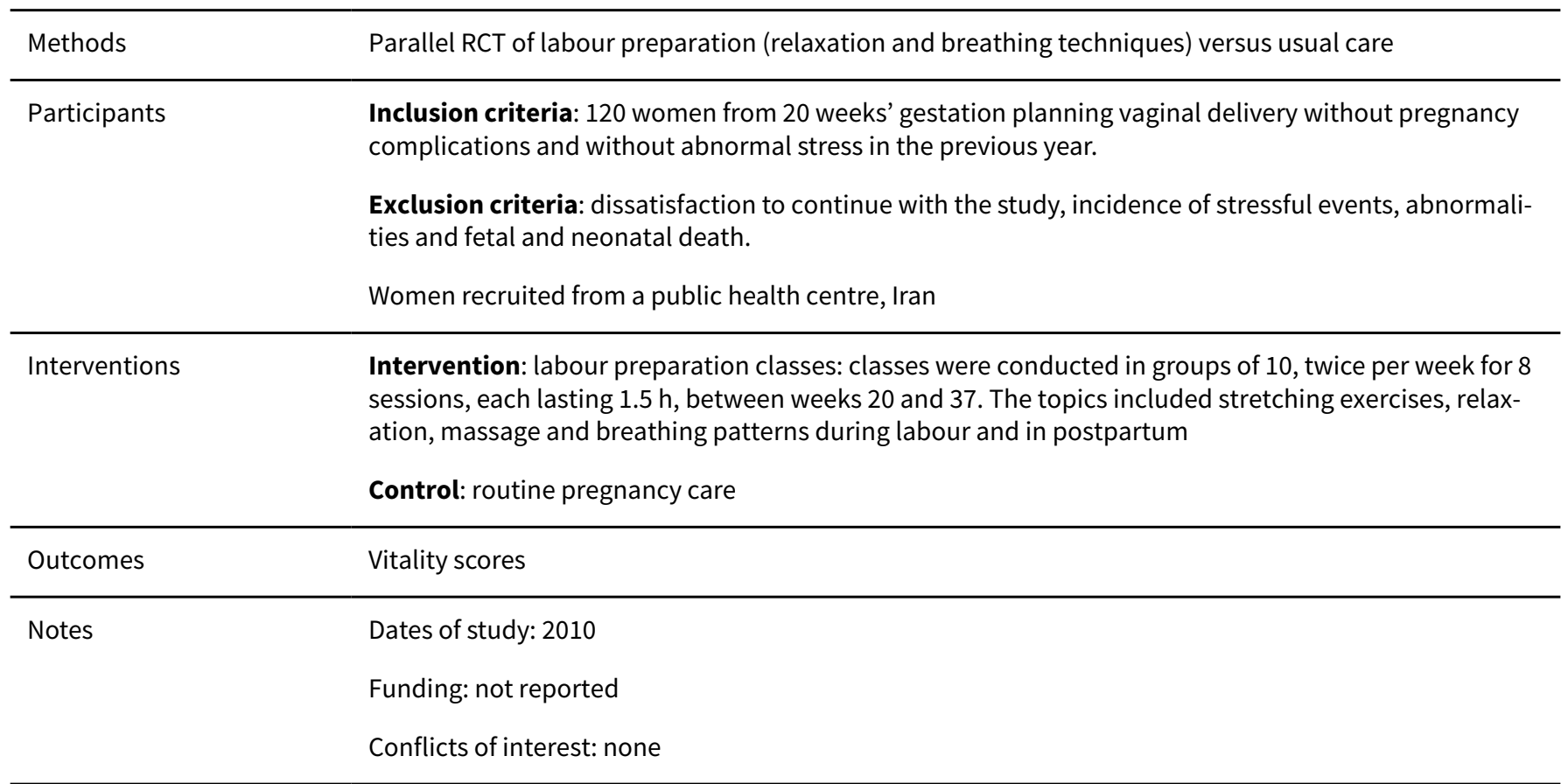

\section{Risk of bias}

\begin{tabular}{lll}
\hline Bias & Authors' judgement & Support for judgement \\
\hline $\begin{array}{l}\text { Random sequence genera- } \\
\text { tion (selection bias) }\end{array}$ & Unclear risk & Not reported \\
\hline $\begin{array}{l}\text { Allocation concealment } \\
\text { (selection bias) }\end{array}$ & Unclear risk & Not reported \\
\hline $\begin{array}{l}\text { Blinding of participants } \\
\text { and personnel (perfor- } \\
\text { mance bias) }\end{array}$ & High risk & Not described but staff and participants likely to be aware of this intervention \\
All outcomes & \\
\hline $\begin{array}{l}\text { Blinding of outcome as- } \\
\text { sessment (detection bias) }\end{array}$ & High risk & \\
All outcomes & & Not reported but likely to be high as outcomes were assessed in labour and \\
\hline $\begin{array}{l}\text { Incomplete outcome data } \\
\text { (attrition bias) } \\
\text { All outcomes }\end{array}$ & Unclear risk & Insufficient reporting \\
\hline $\begin{array}{l}\text { Selective reporting (re- } \\
\text { porting bias) }\end{array}$ & Unclear risk & Insufficient reporting \\
\hline \begin{tabular}{l} 
Other bias \\
\hline
\end{tabular} & Unclear risk & Insufficient reporting \\
\hline
\end{tabular}

\section{Bergstrom 2009}

$\begin{array}{ll}\text { Methods } & \text { Multicentre RCT of natural childbirth preparation with psychoprophylactic training versus usual ante- } \\ \text { natal care. }\end{array}$


Bergstrom 2009 (Continued)

Pregnant women and their partners were randomised into groups of approximately 12 people (median 6 couples). 106 natural groups: 101 standard care groups. Educators were randomised individually to lead groups according to either model during the entire study period

Participants

1087 nulliparous women and 1064 partners. Recruitment was from 15 antenatal clinics in Sweden

Inclusion criteria: nulliparous, Swedish-speaking and attending any of the participating clinics

Exclusion criteria: multiparous, non Swedish-speaking, attendance at other clinic

Interventions

Intervention: natural model for antenatal education focusing on preparation for childbirth only, including training in psychoprophylaxis. Information was given about nonpharmacological methods for pain relief and the partner's role as a coach during labour. In each session, 30 min were spent on practical training in breathing, relaxation and massage techniques. Psychoprophylactic training between sessions was encouraged and a booklet to facilitate homework was distributed. The attitude of the educator was encouraged to be in favour of natural birth. No parenthood preparation was included.

Control: the standard care model, equal time was allocated to information and discussion about childbirth and parenthood issues to reflect the content of antenatal education as provided by antenatal clinics in Sweden. Within these limits the teaching methods of the standard care groups could vary. The educators in this model were free to present films, arrange visits to the delivery ward. No information about breathing, relaxation or other specific techniques for coping with labour pain was included.

\section{Outcomes}

Epidural analgesia during labour, labour pain, mode of delivery, experience of childbirth as measured by Wijma Delivery Experience Questionnairere at baseline and 3 months postnatal, parental stress measured by the Swedish Parenthood Stress Questionnaire at baseline and 3 months postnatal

\begin{tabular}{ll}
\hline Notes & Duration of study: January 2006-May 2007 \\
& Funding: this work was funded by the Swedish Research Council and Karolinska Institute. All study au- \\
thors state their independence \\
Conflicts of interest: none
\end{tabular}

\section{Risk of bias}

\section{Bias \\ Authors' judgement Support for judgement}

\begin{tabular}{lll}
\hline $\begin{array}{l}\text { Random sequence genera- } \\
\text { tion (selection bias) }\end{array}$ & Low risk & $\begin{array}{l}\text { Stratified computer-generated group randomisation Randomisation stratified } \\
\text { per clinic and within clinic }\end{array}$ \\
\hline $\begin{array}{l}\text { Allocation concealment } \\
\text { (selection bias) }\end{array}$ & Low risk & Central randomisation \\
\hline $\begin{array}{l}\text { Blinding of participants } \\
\begin{array}{l}\text { and personnel (perfor- } \\
\text { mance bias) } \\
\text { All outcomes }\end{array}\end{array}$ & High risk & There was no blinding \\
\hline
\end{tabular}

\begin{tabular}{lll}
\hline $\begin{array}{l}\text { Blinding of outcome as- } \\
\text { sessment (detection bias) } \\
\text { All outcomes }\end{array}$ & High risk & $\begin{array}{l}\text { Data entry was blind to group allocation but analysis was not undertaken } \\
\text { blinded }\end{array}$ \\
\hline $\begin{array}{l}\text { Incomplete outcome data } \\
\text { (attrition bias) }\end{array}$ & Low risk & $\begin{array}{l}11 \% \text { of women, and } 19 \% \text { men did not receive the active intervention, } 10 \% \\
\text { women, and } 17 \% \text { men did not receive standard care. The reasons were the } \\
\text { same: inconvenient timing of classes, preterm labour, medical complications. } \\
\text { Loss at 3-month follow-up was similar between groups }\end{array}$ \\
\hline
\end{tabular}

Selective reporting (re- Low risk Study protocol not available but manuscript includes all expected outcomes.
porting bias)
porting bias) 
Bergstrom 2009 (Continued)

Other bias Low risk
The trialists noted that while individual women were randomised to intervention and control groups, the intervention was delivered at the level of groups and there may have been a group effect. They report that there was minimal differences between groups and there was no adjustment needed for possible group effects.

Boaviagem 2017

\begin{tabular}{ll}
\hline Methods & Parallel RCT of a deep breathing relaxation techniques compared with usual care \\
\hline Participants & Recruitment from Professor Bandeira Filho Maternity Hospital, in Recife, Brazil \\
& $\begin{array}{l}\text { Inclusion criteria: low-risk primigravid women, } 16-35 \text { years old, 37-41 weeks of gestation in active } \\
\text { labour }\end{array}$
\end{tabular}

Exclusion criteria: women with multiple pregnancies, pregnancy with a dead fetus, analgesic use, clinical instability and psychiatric disorders

Interventions

Intervention: breathing patterns during contraction - deep inspiration and prolonged or fractional exhalation. Respiratory patterns, used in accordance with dilation period, were interrupted at signs of breathing discomfort or when respiratory rate increased $>20$ breaths $/ \mathrm{min}$

Women were instructed to inhale slowly, count from 1-5 and breathe out gradually, counting from 5-1. The inspiratory phase was not stimulated to full lung capacity; thus, there was an inspiratory reserve volume. For the breathing pattern with postexhalation pause, they were instructed to take a deep breath and increase the postexhalation pause (1e2 s). With respect to expiratory deceleration, the participant was instructed to take an extended exhalation, propelling the lips forward (pursed lip breathing). This pattern was used mainly when contractions were strong

The physiotherapist demonstrated these patterns so the women would be able to execute them properly.

Total number randomised: $\mathrm{n}=67$

Control: usual care 73 women randomised; "treated in-line with standard procedures" - usual care not described

Outcomes Primary outcome: maternal anxiety - STAI

Secondary outcome: pain (VAS), satisfaction, fatigue, mode of delivery and duration of labour

Neonatal: the 5-minute Apgar score

Dates of study: not reported
Funding: scholarship from Foundation for Science and Technology of the State of Pernambuco
(FACEPE)
Conflicts of interest: not reported

\section{Risk of bias}

\begin{tabular}{lll}
\hline Bias & Authors' judgement & Support for judgement \\
\hline $\begin{array}{l}\text { Random sequence genera- } \\
\text { tion (selection bias) }\end{array}$ & Low risk & Random Allocation Software 1.0 \\
\hline $\begin{array}{l}\text { Allocation concealment } \\
\text { (selection bias) }\end{array}$ & Low risk & $\begin{array}{l}\text { Opaque envelopes sequentially numbered from 1-140 were prepared. Each } \\
\text { number indicated the participant's group, according to a randomisation chart. }\end{array}$ \\
\hline
\end{tabular}




\begin{tabular}{|c|c|c|}
\hline $\begin{array}{l}\text { Blinding of participants } \\
\text { and personnel (perfor- } \\
\text { mance bias) } \\
\text { All outcomes }\end{array}$ & High risk & Not feasible and no separate delivery suites \\
\hline $\begin{array}{l}\text { Blinding of outcome as- } \\
\text { sessment (detection bias) } \\
\text { All outcomes }\end{array}$ & High risk & $\begin{array}{l}\text { Not reported although staff recording outcomes in labour were likely to be } \\
\text { aware of treatment group }\end{array}$ \\
\hline $\begin{array}{l}\text { Incomplete outcome data } \\
\text { (attrition bias) } \\
\text { All outcomes }\end{array}$ & Low risk & $\begin{array}{l}\text { Total missing data } n=19 \text { ( } n=7 \text { intervention and } n=12 \text { control). Multiple impu- } \\
\text { tation methods were used to address missing values which could be included } \\
\text { in the analysis }\end{array}$ \\
\hline $\begin{array}{l}\text { Selective reporting (re- } \\
\text { porting bias) }\end{array}$ & Unclear risk & $\begin{array}{l}\text { ClinicalTrials.gov Identifier: NCT02164227 - only primary outcome listed on } \\
\text { register - protocol not available }\end{array}$ \\
\hline Other bias & Unclear risk & Insufficient reporting \\
\hline
\end{tabular}

\section{Chuntharapat 2008}

\begin{tabular}{ll}
\hline Methods & Parallel RCT of yoga compared with usual care \\
\hline Participants & 74 women were recruited from 2 public hospitals in Southern Thailand. \\
& $\begin{array}{l}\text { Inclusion criteria: primiparous women without serious illness or high-risk complications during preg- } \\
\text { nancy; receiving antenatal care from the start, or at least 2nd trimester of pregnancy; and, without prior } \\
\text { experience of practising yoga; }>18 \text { years old; able to communicate and write in Thai }\end{array}$
\end{tabular}

Exclusion criteria: not specified

Interventions

Intervention: participants in the experimental group received a series of six 60-min yoga practice sessions at the 26th, 28th, 30th, 32nd, 34th, 36th, and 37th week of gestation. The yoga programme was a combination of: (a) educational activities, giving a brief description of basic anatomical structures related to pregnancy and birth and (b) yoga, explaining the concepts related to each session. Yoga asanas, chanting om, breathing awareness, yoga nidra, and dhyana were practiced harmoniously and in an orderly manner. The women were provided a booklet and tape cassette, for self-study, that explained the principles and benefits of each yoga practice. All were asked to practise at home at least 3 times a week, starting after the first yoga practice session and continuing for a period of 10-12 weeks. The number of weeks of practice $(10,11$ or 12$)$ depended upon whether the women started their first yoga practice session at the 26th, 27 th or $28^{\text {th }}$ week of gestation. Participants were informed they could practice, at home, $>3$ times a week. So investigators could monitor participants' involvement in each yoga session they performed at home, they were asked to maintain a record, in diary format. In addition, to ensure compliance with the research protocol, weekly telephone calls were made by investigators to each participant.

Control: usual care. Control group participants were seen by researchers at each of their hospital visits. They engaged in casual conversation for 20-30 min. To ensure compliance with research protocol, weekly phone calls were made by investigators to each participant.

$\begin{array}{ll}\text { Outcomes } & \text { VAS Total Comfort } \\ & \text { Maternal comfort questionnaire (MCQ) } \\ & \text { Labour pain using visual analogue sensation of pain scale (VASPS) to assess labour pain }\end{array}$


Chuntharapat 2008 (Continued)

Pain behavioural observation scale (PBOS) to assess investigator-observed labour pain

Birth outcomes by Apgar scores

Length of labour

Augmentation

Pethidine usage for pain relief

$\begin{array}{ll}\text { Notes } & \text { Study duration: January 2005-February } 2006 \\ & \text { Funding: partially funded by the Faculty of Graduate Studies, Prince of Songkla University, Hat Yai, } \\ & \text { Songkhla, Thailand } \\ \text { Conflicts of interest: not reported }\end{array}$

\section{Risk of bias}

\begin{tabular}{|c|c|c|}
\hline Bias & Authors' judgement & Support for judgement \\
\hline $\begin{array}{l}\text { Random sequence genera- } \\
\text { tion (selection bias) }\end{array}$ & Low risk & $\begin{array}{l}\text { Computer-generated sequence. Stratified randomisation according to mater- } \\
\text { nal age, marital status, education, income and trait-anxiety. Randomisation in } \\
\text { ratio of } 1: 1\end{array}$ \\
\hline $\begin{array}{l}\text { Allocation concealment } \\
\text { (selection bias) }\end{array}$ & Unclear risk & Not reported \\
\hline $\begin{array}{l}\text { Blinding of participants } \\
\text { and personnel (perfor- } \\
\text { mance bias) } \\
\text { All outcomes }\end{array}$ & High risk & $\begin{array}{l}\text { Participants and the clinician were not blind and it is possible the outcome } \\
\text { measurement may have been influenced by a lack of blinding }\end{array}$ \\
\hline $\begin{array}{l}\text { Blinding of outcome as- } \\
\text { sessment (detection bias) } \\
\text { All outcomes }\end{array}$ & High risk & $\begin{array}{l}\text { Not reported but outcome measurement may have been influenced by lack of } \\
\text { blinding }\end{array}$ \\
\hline $\begin{array}{l}\text { Incomplete outcome data } \\
\text { (attrition bias) } \\
\text { All outcomes }\end{array}$ & Unclear risk & Insufficient reporting \\
\hline $\begin{array}{l}\text { Selective reporting (re- } \\
\text { porting bias) }\end{array}$ & Unclear risk & Study protocol unavailable \\
\hline Other bias & Low risk & No imbalance in baseline characteristics or differential diagnosis \\
\hline
\end{tabular}

Dizavandi 2012

\begin{tabular}{ll}
\hline Methods & Reported to be RCT but no information on methods in the brief abstract \\
\hline Participants & 95 women expecting a normal spontaneous birth. Iran \\
\hline
\end{tabular}

Interventions

Intervention: routine care and music therapy for $45 \mathrm{~min}$

Total number randomised: $\mathrm{n}=45$

Control: routine care only 
Dizavandi 2012 (Continued)

Total number randomised: $\mathrm{n}=50$

Outcomes Labour pain reported on a VAS

Notes

Although this study is eligible for inclusion in the review no usable outcome data were reported and so no data from this study are included in our analyses. We have attempted to find contact information for the study author, but have been unsuccessful.

Dates of study: not reported

Funding: not reported

Conflicts of interest: not reported

\section{Risk of bias}

\begin{tabular}{|c|c|c|}
\hline Bias & Authors' judgement & Support for judgement \\
\hline $\begin{array}{l}\text { Random sequence genera- } \\
\text { tion (selection bias) }\end{array}$ & Unclear risk & Not described in brief abstract \\
\hline $\begin{array}{l}\text { Allocation concealment } \\
\text { (selection bias) }\end{array}$ & Unclear risk & Not described in brief abstract \\
\hline $\begin{array}{l}\text { Blinding of participants } \\
\text { and personnel (perfor- } \\
\text { mance bias) } \\
\text { All outcomes }\end{array}$ & High risk & $\begin{array}{l}\text { Not described but likely to be high as it is difficult to blind this type of interven- } \\
\text { tion }\end{array}$ \\
\hline $\begin{array}{l}\text { Blinding of outcome as- } \\
\text { sessment (detection bias) } \\
\text { All outcomes }\end{array}$ & High risk & $\begin{array}{l}\text { Not described but likely to be high as it is difficult to blind this type of interven- } \\
\text { tion }\end{array}$ \\
\hline $\begin{array}{l}\text { Incomplete outcome data } \\
\text { (attrition bias) } \\
\text { All outcomes }\end{array}$ & Unclear risk & Not described \\
\hline $\begin{array}{l}\text { Selective reporting (re- } \\
\text { porting bias) }\end{array}$ & Unclear risk & Very little information \\
\hline Other bias & Unclear risk & Too little information to assess \\
\hline
\end{tabular}

\section{Dolcetta 1979}

\begin{tabular}{ll}
\hline Methods & Parallel controlled partial double-blind trial of RAT versus traditional psychoprophylaxis method \\
\hline Participants & $\begin{array}{l}53 \text { women were randomly assigned to their study group. Women were aged 20-35 years, participated in } \\
\text { no fewer than } 5 \text { sessions }\end{array}$ \\
Inclusion criteria: no physical abnormalities, obstetric score $<30$ \\
The study was undertaken at a University Clinic in Verona, Italy
\end{tabular}

Interventions

Intervention: RAT consists of the woman learning to auto-induce an autogenous state and to reduce her muscle tone by deep relaxation.

Control: no details provided 
Dolcetta 1979 (Continued)

Outcomes Emotional state during labour and after childbirth, pain, pain experience, Apgar score, length of labour

\begin{tabular}{ll}
\hline Notes & There was no power analysis \\
Dates of study: not reported \\
Funding: not reported \\
Conflicts of interest: not reported
\end{tabular}

\section{Risk of bias}

\begin{tabular}{|c|c|c|}
\hline Bias & Authors' judgement & Support for judgement \\
\hline $\begin{array}{l}\text { Random sequence genera- } \\
\text { tion (selection bias) }\end{array}$ & Unclear risk & Randomisation was used but no details provided \\
\hline $\begin{array}{l}\text { Allocation concealment } \\
\text { (selection bias) }\end{array}$ & Unclear risk & Unclear \\
\hline $\begin{array}{l}\text { Blinding of participants } \\
\text { and personnel (perfor- } \\
\text { mance bias) } \\
\text { All outcomes }\end{array}$ & High risk & Partcipants were not blind to their group allocation \\
\hline $\begin{array}{l}\text { Blinding of outcome as- } \\
\text { sessment (detection bias) } \\
\text { All outcomes }\end{array}$ & Unclear risk & The outcome analyst was reported to be blind to group allocation \\
\hline $\begin{array}{l}\text { Incomplete outcome data } \\
\text { (attrition bias) } \\
\text { All outcomes }\end{array}$ & Unclear risk & Data available on 34 women \\
\hline $\begin{array}{l}\text { Selective reporting (re- } \\
\text { porting bias) }\end{array}$ & Unclear risk & Study protocol unavailable \\
\hline Other bias & Low risk & No imbalance at baseline. No other biases apparent \\
\hline
\end{tabular}

Duncan 2017

\begin{tabular}{ll}
\hline Methods & Parallel RCT comparing mindfulness in labour versus education alone \\
\hline Participants & $\begin{array}{l}\text { go first time mothers in their third trimester of pregnancy were randomly assigned to } 1 \text { of } 2 \text { study } \\
\text { groups. } \\
\text { Inclusion criteria: English-speaking nulliparous women with low-risk, healthy, singleton pregnancies } \\
\text { in their third trimester who were planning a hospital birth and willing to be randomised. } \\
\text { Exclusion criteria: high-risk pregnancy, extensive prior experience with meditation or yoga practice } \\
\text { (brief prenatal yoga did not lead to exclusion), participation in other mind/body childbirth preparation } \\
\text { courses (e.g. Hypnobirthing, Bradley Method), or planned caesarean birth. } \\
\text { Classes were delivered in a community setting in the USA } \\
\text { Intervention: Mindfullness in Labor (MIL) is a brief intervention for pregnant women and their partners } \\
\text { specifically designed to target labour-related fear and pain by teaching tailored mindfulness-based } \\
\text { coping strategies. It is a childbirth-specific, short form of the 9-week Mindfulness-Based Childbirth and }\end{array}$ \\
\hline Interventions
\end{tabular}


Duncan 2017 (Continued)

Parenting program (MBCP). The MIL course is delivered by professionally certified MBCP instructors and it is held over 1 weekend (Friday evening and all day Saturday and Sunday) for a total of $18 \mathrm{~h}$ of mindfulness training. Mindfulness strategies for coping with labour-related pain and fear are taught through interactive, experiential activities, with periods of didactic instruction. To meet these objectives, instruction in formal mindfulness meditation are given during the workshop, including body scan, mindful movement/yoga, sitting and walking meditation, and mindful eating, as well as activities of daily living and pain coping strategies, such as mindfulness of breath, partner touch, body movement, and "sounding" (using low and/or loud vocal tones during periods of intense physical sensation).

Control: participants assigned to the TAU control condition were provided with a list of study-approved childbirth courses of comparable length and quality to the MIL intervention, but without any mindfulness meditation, mindful movement/yoga, or other core mind/body component (e.g. hypnosis)

\begin{tabular}{|c|c|}
\hline \multirow[t]{5}{*}{ Outcomes } & Childbirth Self-Efficacy Inventory \\
\hline & Pain Catastrophizing Scale \\
\hline & Perceived labour pain (VAS) \\
\hline & Use of pain medication in labour was ascertained from medical record review \\
\hline & Birth satisfaction (Wijma Delivery Expectancy/Experience Questionnaire) \\
\hline \multirow[t]{2}{*}{ Notes } & Dates of study: not reported. \\
\hline & $\begin{array}{l}\text { Funding: funding for this study was provided by a grant from the Mount Zion Health Fund, San Francis- } \\
\text { co, CA, administered by the University of California, San Francisco (UCSF) School of Medicine. } 2 \text { study } \\
\text { authors were supported by the US National Institutes of Health/National Center for Complementary } \\
\text { and Integrative Health (NIH/NCCIH) through career development awards (LGD: K01 AT005270; MTC: K01 } \\
\text { AT006545) } \\
\text { Conflicts of interest: Nancy Bardacke receives royalties from the sale of her book on the topic of the in- } \\
\text { tervention tested here, related CD/mp3 audio materials, and an app. Through the not-for-profit Mind- } \\
\text { ful Birthing and Parenting Foundation, she also receives payments for professional training and mind- } \\
\text { fulness workshops for pregnant women and their partners. Larissa Duncan holds an unpaid position as } \\
\text { board member of the Mindful Birthing and Parenting Foundation. The other study authors declare that } \\
\text { they have no competing interests. }\end{array}$ \\
\hline
\end{tabular}

\section{Risk of bias}

Bias Authors' judgement Support for judgement

Random sequence genera- Low risk tion (selection bias)
Allocation concealment Low risk (selection bias)
Randomisation was stratified by pre-course intention to use epidural anaesthesia and was performed with randomly varying blocks of 2 and 5 using a preprogrammed computer database. A UCSF senior biostatistician not affiliated with the study generated the randomisation scheme.

The study project manager (JGC) enrolled and consented study participants; group assignment and subsequent debriefing regarding intervention attendance was conducted by opening a sealed envelope provided by the biostatistician.

\begin{tabular}{lll}
\hline $\begin{array}{l}\text { Blinding of participants } \\
\text { and personnel (perfor- } \\
\text { mance bias) }\end{array}$ & High risk & No blinding attempted \\
All outcomes & \\
\hline $\begin{array}{l}\text { Blinding of outcome as- } \\
\text { sessment (detection bias) } \\
\text { All outcomes }\end{array}$ & Low risk & $\begin{array}{l}\text { Data collection was completed online and through medical record review. The } \\
\text { remaining study authors (including data analysts) were blinded to participant } \\
\text { study condition }\end{array}$ \\
\hline
\end{tabular}


Duncan 2017 (Continued)

$\begin{array}{ll}\begin{array}{l}\text { Incomplete outcome data } \\ \text { (attrition bias) }\end{array} & \text { Low risk } \\ \text { L } & \text { Loss to follow-up low }\end{array}$

All outcomes

Loss to follow-up low

\begin{tabular}{lll}
\hline $\begin{array}{l}\text { Selective reporting (re- } \\
\text { porting bias) }\end{array}$ & Unclear risk & No trial protocol available \\
\hline Other bias & Unclear risk & Insufficient information to assess \\
\hline
\end{tabular}

Durham 1986

\begin{tabular}{|c|c|}
\hline Methods & RCT of music plus Lamaze breathing techniques versus Lamaze breathing techniques alone \\
\hline \multirow[t]{3}{*}{ Participants } & 30 primiparous couples recruited from the Kansas medical centre, USA. \\
\hline & Inclusion criteria: not specified \\
\hline & Exclusion criteria: not specified \\
\hline \multirow[t]{2}{*}{ Interventions } & $\begin{array}{l}\text { All groups received instruction on Lamaze breathing techniques. During stage I, phase I (latent) labour, } \\
\text { slow chest breathing was used. With phase } 2 \text { labour, shallow chest breathing was used to assist the } \\
\text { woman cope with the increasing strength of the contractions }\end{array}$ \\
\hline & $\begin{array}{l}\text { Intervention: during phase } 1 \text { music was slow } 4 / 4 \text { tempo with a distinct drum beat. During phase } 2 \text {, the } \\
\text { tempo of the music increased as well as the volume of music. During transition the volume was regulat- } \\
\text { ed to meet the individuals' needs, a moderate-fast tempo was used. During stage II expulsion, a driving } \\
\text { melody was used with strong percussions, strong rhythm and increased volume to encourage pushing. } \\
\text { The music was tape recorded and couples had the option of using headphones. }\end{array}$ \\
\hline
\end{tabular}

Control: as above, no intervention

\begin{tabular}{ll}
\hline Outcomes & Use of pain relief \\
\hline Notes & Dates of study: not reported \\
& Funding: not reported \\
& Conflicts of interest: not reported \\
\hline
\end{tabular}

\section{Risk of bias}

\begin{tabular}{lll}
\hline Bias & Authors' judgement & Support for judgement \\
\hline $\begin{array}{l}\text { Random sequence genera- } \\
\text { tion (selection bias) }\end{array}$ & Low risk & Random number tables \\
\hline $\begin{array}{l}\text { Allocation concealment } \\
\text { (selection bias) }\end{array}$ & Unclear risk & Not reported \\
\hline $\begin{array}{l}\text { Blinding of participants } \\
\text { and personnel (perfor- } \\
\text { mance bias) } \\
\begin{array}{l}\text { All outcomes } \\
\text { Blinding of outcome as- }\end{array}\end{array}$ & High risk & Participants and therapist were not blind to group allocation \\
\hline $\begin{array}{l}\text { sessment (detection bias) } \\
\text { All outcomes }\end{array}$ & \\
\hline \hline
\end{tabular}


Durham 1986 (Continued)
Incomplete outcome data
Unclear risk
Unclear on whether data collection was complete
(attrition bias)

All outcomes

\begin{tabular}{lll}
\hline $\begin{array}{l}\text { Selective reporting (re- } \\
\text { porting bias) }\end{array}$ & Unclear risk & Insufficient reporting \\
\hline Other bias & Unclear risk & Insufficient reporting \\
\hline
\end{tabular}

Gatelli 2000

\begin{tabular}{ll}
\hline Methods & RCT initially with 3 arms with a 4th added later \\
\hline Participants & 78 primipara women were recruited from the obstetrics department at the Mirano Hospital, Italy \\
& Inclusion criteria: no obstetric complication, anxiety score of $\geq 7$ at 26 weeks of pregnancy. \\
& Exclusion criteria: not stated
\end{tabular}

Interventions Intervention commenced at 32 weeks

Intervention group 1: 26 women allocated to the intervention group, they received obstetric psychoprophylaxis and 4-weekly guided relaxation sessions on an individual level guided by 2 teachers with biofeedback.

Interventon group 2: a second intervention group of 26 women received the psychoprophylaxis, and counselling.

Control 1: 26 women received obstetric psychoprophylaxis only, and saw the psychologist for analysis of test results only.

Control 2: a second comparison group was added of 12 women who came to the hospital for antenatal checks and birthing only.

\begin{tabular}{ll}
\hline Outcomes & Duration of labour, mode of birth, anxiety scores \\
\hline Notes & Dates of study: not reported \\
& Funding: not reported \\
& Conflicts of interest: not reported \\
\hline
\end{tabular}

\section{Risk of bias}

\begin{tabular}{lll}
\hline Bias & Authors' judgement & Support for judgement \\
\hline $\begin{array}{l}\text { Random sequence genera- } \\
\text { tion (selection bias) }\end{array}$ & Unclear risk & Not described \\
\hline $\begin{array}{l}\text { Allocation concealment } \\
\text { (selection bias) }\end{array}$ & Unclear risk & Not described \\
\hline $\begin{array}{l}\text { Blinding of participants } \\
\text { and personnel (perfor- } \\
\text { mance bias) }\end{array}$ & High risk & $\begin{array}{l}\text { Not described and does not appear as if there was any attempt to introduce } \\
\text { All outcomes }\end{array}$ \\
\hline
\end{tabular}


Gatelli 2000 (Continued)
Blinding of outcome as-
Unclear risk
Not reported sessment (detection bias)

All outcomes

\begin{tabular}{|c|c|c|}
\hline $\begin{array}{l}\text { Incomplete outcome data } \\
\text { (attrition bias) } \\
\text { All outcomes }\end{array}$ & High risk & $\begin{array}{l}\text { Large number of dropouts from initial randomisation: } 26: 26: 26: 12 \text { to 6:7:23:12. } \\
\text { Reason for losses not reported }\end{array}$ \\
\hline $\begin{array}{l}\text { Selective reporting (re- } \\
\text { porting bias) }\end{array}$ & Unclear risk & Insufficient reporting \\
\hline Other bias & Unclear risk & Insufficient reporting \\
\hline
\end{tabular}

Gedde-Dahl 2012

\begin{tabular}{|c|c|}
\hline Methods & RCT with individual randomisation \\
\hline Participants & $\begin{array}{l}\text { Stavanger University Hospital, Norway. Dates of recruitment not stated. } 58 \text { women randomised } \\
\text { Inclusion criteria: healthy pregnant women at the beginning of the } 3 \text { rd trimester expected to have a } \\
\text { vaginal birth attending for regular pregnancy healthcare at the study hospital } \\
\text { Exclusion criteria: not described }\end{array}$ \\
\hline Interventions & $\begin{array}{l}\text { Intervention: usual care plus a CD and booklet. The CD included instructions and } 3 \text { relaxation tracks, } 1 \\
\text { with relaxing music and guided imagery of the birth process, } 1 \text { with music and positive affirmation, and } \\
1 \text { with music only. Women were advised to practise } 15 \text { min with the CD daily and to record when they } \\
\text { did it. They were not told to use the CDs during the birth but could if they wanted to. } \\
\text { Total number randomised: } n=29 \text { women } \\
\text { Control: usual care with no CD } \\
\text { Total number randomised: } n=29\end{array}$ \\
\hline Outcomes & $\begin{array}{l}\text { Primary outcome was well-being (measured on the Edmonton scale or ESAS) } 1 \text { day after delivery; } \\
\text { pain (NRS } 0-10,10 \text { worst) during labour and delivery ( } 3 \text { times) and } 1 \text { day after delivery, anxiety (VAS } \\
0-100,100 \text { worst) during delivery (not clear) and } 1 \text { day after delivery. Apgar score (reported as mean at } 1 \\
\text { minute) }\end{array}$ \\
\hline Notes & $\begin{array}{l}\text { Dates of study: not reported } \\
\text { Funding: funding reported to be provided by the investigators' employing institutions (university hos- } \\
\text { pitals in Norway) } \\
\text { Conflicts of interest: reported that the authors had no conflicts of interest }\end{array}$ \\
\hline
\end{tabular}

\section{Risk of bias}

\begin{tabular}{lll}
\hline Bias & Authors' judgement & Support for judgement \\
\hline $\begin{array}{l}\text { Random sequence genera- } \\
\text { tion (selection bias) }\end{array}$ & Unclear risk & Reported as “randomised ahead by pulling numbers" \\
\hline $\begin{array}{l}\text { Allocation concealment } \\
\text { (selection bias) }\end{array}$ & Low risk & Probably low risk. "participants were given a sealed unmarked envelope." \\
\hline
\end{tabular}


Gedde-Dahl 2012 (Continued)

\begin{tabular}{|c|c|c|}
\hline $\begin{array}{l}\text { Blinding of participants } \\
\text { and personnel (perfor- } \\
\text { mance bias) }\end{array}$ & High risk & $\begin{array}{l}\text { Probably high risk. It was stated that investigators were blind, but it was not } \\
\text { clear whether the CDs were distributed by staff providing care and women } \\
\text { would be aware of the intervention }\end{array}$ \\
\hline
\end{tabular}

All outcomes would be aware of the intervention

\begin{tabular}{lll}
\hline $\begin{array}{l}\text { Blinding of outcome as- } \\
\text { sessment (detection bias) }\end{array}$ & Unclear risk & $\begin{array}{l}\text { Staff providing care may have been aware of the intervention and they would } \\
\text { be recording outcomes during delivery. It is not clear whether staff or re- } \\
\text { sll outcomes }\end{array}$ \\
$\begin{array}{l}\text { searchers collected pre- and postintervention scores (e.g. for day after delivery } \\
\text { measures) }\end{array}$
\end{tabular}

\begin{tabular}{ll}
\hline $\begin{array}{l}\text { Incomplete outcome data } \\
\text { (attrition bias) }\end{array}$ & It wash risk not clear when outcome data were collected. There was reference to \\
All outcomes & "early and late responders"; some women did not complete post-test ques- \\
& tionnaires until more than a week after the birth (15/27 respondents for con- \\
& trol group and $18 / 27$ in the intervention group). While data on well-being were \\
collected $50 / 58$ of those randomised this applied to only $25 / 58$ for pain scores \\
in labour and $29 / 58$ for anxiety
\end{tabular}

Selective reporting (re- High risk Much data were not collected at the appropriate time. Further results were not porting bias) fully reported. It was suggested that pain and anxiety were measured several times during labour but there was a single pain and anxiety score reported (it was not clear whether this represented some sort of average of all time points or if not, at what point during labour outcomes were reported)

Other bias Unclear risk There was some baseline imbalance between groups for anxiety

\section{Hosseini 2013}

\begin{tabular}{ll}
\hline Methods & A clinical trial comparing music to no music on labour pain and labour progress \\
\hline Participants & $\begin{array}{l}\text { 30 primiparous women from Bentolhoda hospital of Bushehr city of Iran in the active stage of labour. } \\
\text { Inclusion criteria: primipara, aged 20-30, lived in urban dwellings, been in a complete physical and } \\
\text { mental health status }\end{array}$
\end{tabular}

Interventions

Intervention: directed imagination with music was taught to the experimental group (when there was no uterine contraction) and then the light music of "Barane Eshgh" (Love Rain) composed by Manouchehr Cheshmazar was played by headphone for $30 \mathrm{~min}$ for women of the experimental group, and after removing the headphones and in case there was no uterine contraction, the parturients were asked to explain the severity of their pain based on the 3 numerical, visual and verbal scales while listening to the music and their statements were recorded. Then, the music was played again to the parturient after half an hour and it was continued for $2 \mathrm{~h}$ after hospitalisation. At the end of the second $\mathrm{h}$, labour progress and severity of pain were again measured and recorded.

Control: no music

$\begin{array}{ll}\text { Outcomes } & \begin{array}{l}\text { Pain level (visual pain level, verbal pain level and numeric pain level) and delivery progress (uterine } \\ \text { contractions and dilation) }\end{array}\end{array}$

Notes Unclear if randomised or quasi-randomised - study authors contacted to confirm Attempted to contact study authors on the 19 June 2017

Dates of study: not reported

Funding: not reported

Conflicts of interest: none 
Hosseini 2013 (Continued)

Risk of bias

\begin{tabular}{lll}
\hline Bias & Authors' judgement & Support for judgement \\
\hline $\begin{array}{l}\text { Random sequence genera- } \\
\text { tion (selection bias) }\end{array}$ & Unclear risk & No details were reported \\
\hline $\begin{array}{l}\text { Allocation concealment } \\
\text { (selection bias) }\end{array}$ & Unclear risk & No details were reported \\
\hline $\begin{array}{l}\text { Blinding of participants } \\
\text { and personnel (perfor- } \\
\text { mance bias) }\end{array}$ & High risk & Probably high risk, women and clinicians were not blind to group allocation \\
All outcomes & \\
\hline $\begin{array}{l}\text { Blinding of outcome as- } \\
\text { sessment (detection bias) }\end{array}$ & Unclear risk & $\begin{array}{l}\text { Staff providing care may have been aware of the intervention and they would } \\
\text { All outcomes }\end{array}$ \\
\hline $\begin{array}{l}\text { Incomplete outcome data } \\
\text { (attrition bias) }\end{array}$ & Low risk & No attrition reported \\
\hline $\begin{array}{l}\text { All outcomes } \\
\text { Selective reporting (re- } \\
\text { porting bias) }\end{array}$ & Unclear risk & No protocol was available \\
\hline \begin{tabular}{l} 
Other bias \\
\hline
\end{tabular} & Unclear risk & Unclear due to insufficient reporting \\
\hline
\end{tabular}

\section{Kimber 2008}

Methods

3-armed, parallel RCT comparing massage + relaxation, music therapy + relaxation versus treatment as usual
90 pregnant women took classes at 35-37 weeks' gestation.

Inclusion criteria: from 20 weeks' gestation

Exclusion criteria: planned elective caesarean section, multiple pregnancy, existing medical problems that precluded the use of massage, previous use of the massage programme or a strong preference for a particular form of pain relief; not fluent English speaker; not intending to have a birth companion

Recruitment was undertaken through Horton Maternity Unit, Banbury, United Kingdom (2004-2006)
Intervention: women attended a $2.5 \mathrm{~h}$ class between 35-37 weeks' gestation with their chosen birth companion. Participants were asked to practise the programme at least 3 evenings a week, for about 30-45 min, until 39 weeks and then a combination of techniques every evening, until hospital admission for labour/induction. The class taught breathing and visualisation techniques, and music. The woman and her birth partner were encouraged to practise a slow breathing rhythm and visualisation techniques were taken from readings in a well known book (Broncher 1992). The woman and her birth partner chose their favourite music. Women were also able to attend usual antenatal classes.

Control group 1: usual care. Women allocated to the control group were given the option and encouraged to attend the usual antenatal preparation classes currently available at the trial site. For the duration of the trial there were three, 2.5 hour classes, which included an antenatal and labour session incorporating information about labour, methods of pain relief and types of delivery.

Control group 2: massage + relaxation 
Kimber 2008 (Continued)

Women attended a $2.5 \mathrm{~h}$ class between 35-37 weeks' gestation with their chosen birth companion. Massage techniques were taught by the midwife/therapist. The birth partner learnt to perform slow rhythmic long stroke massage movements using the flats of the hands. These strokes were combined with slow rhythmic breathing and performed primarily on the lower back and also the upper and lower limbs. The massaging hands move upwards during inspiration and downwards during expiration. The woman and her birth partner were taught to synchronise massage strokes with controlled breathing. The visualisation/mind mapping component was taught, by asking the woman to visualise/focus on the massaging hands. Participants were asked to practise the programme at least 3 evenings a week, for about 30-45 min, until 39 weeks and then a combination of techniques every evening, until hospital admission for labour/induction

The primary outcome measure was self-reported labour pain, using the VAS.
The secondary outcomes were the use of pharmacological analgesia, obstetric interventions, birth
comes and women's birth-related worries based on the Cambridge Birth Worry Scale, maternal satis
faction and sense of control (Labour Agentry Scale) $\quad \begin{aligned} & \text { Dates of study: 2004-2006 } \\ & \text { Funding: complementary medicine grant from Oxfordshire Health Services Research Committee } \\ & \text { (OHSRC) } \\ & \text { Conflicts of interest: not reported }\end{aligned}$

\section{Risk of bias}

\begin{tabular}{|c|c|c|}
\hline Bias & Authors' judgement & Support for judgement \\
\hline $\begin{array}{l}\text { Random sequence genera- } \\
\text { tion (selection bias) }\end{array}$ & Low risk & $\begin{array}{l}\text { Women were randomised to study groups by a computer-based randomisa- } \\
\text { tion program supplied by the National Perinatal Epidemiology Unit (NPEU), } \\
\text { University of Oxford }\end{array}$ \\
\hline $\begin{array}{l}\text { Allocation concealment } \\
\text { (selection bias) }\end{array}$ & Unclear risk & Not described \\
\hline $\begin{array}{l}\text { Blinding of participants } \\
\text { and personnel (perfor- } \\
\text { mance bias) } \\
\text { All outcomes }\end{array}$ & High risk & No blinding possible due to nature of intervention groups \\
\hline $\begin{array}{l}\text { Blinding of outcome as- } \\
\text { sessment (detection bias) } \\
\text { All outcomes }\end{array}$ & High risk & $\begin{array}{l}\text { Pain self-reported outcomes, may be affected by lack of blinding. No blinding } \\
\text { of research midwife collecting other outcome data }\end{array}$ \\
\hline $\begin{array}{l}\text { Incomplete outcome data } \\
\text { (attrition bias) } \\
\text { All outcomes }\end{array}$ & Low risk & $\begin{array}{l}\text { Dropouts not significantly different between groups and unlikely to be due to } \\
\text { intervention. Dropout rate } 10 \% \text { or less across all groups }\end{array}$ \\
\hline $\begin{array}{l}\text { Selective reporting (re- } \\
\text { porting bias) }\end{array}$ & Low risk & All outcomes reported from protocol \\
\hline Other bias & Unclear risk & No baseline imbalances \\
\hline
\end{tabular}

Liu 2010

\begin{tabular}{ll}
\hline Methods & Parallel RCT of music plus standard care compared with usual care \\
\hline Participants & 103 participants were recruited from 2 hospitals in southern Taiwan \\
\hline
\end{tabular}


Liu 2010 (Continued)

Inclusion criteria: normal pregnancy; primiparous, at term; planned vaginal delivery; singleton; no intention to use pharmacological analgesic during labour

Exclusion criteria: not stated

Interventions

Intervention: participants could choose 1 of the following types of relaxing, anxiety reducing music: classical (e.g. Beethoven: For Elise, Debussy: Preludes I Livre VIII, La fille aux cheveux de lin and Kreisler: Liebesfreud), light (e.g. Liszt: Liebestraum, Rachmaninoff: Piano Concerto No. 2 in C Minor and Williams: Dream of Olwen), popular (e.g. The sound of silence, Somewhere in time and The way we are), crystal children's (e.g. Doll country, Little honey-bee, Jasmine) or Chinese religious music (Buddhist music, Sutra). In addition to receiving standard nursing care, the experimental participants listened to 1 of these for at least 30 min during the latent phase $(2-4 \mathrm{~cm}$ cervical dilation) and active phase (5-7 cm cervical dilation) of labour. To account for the wide variety of music-listening habits, participants were allowed to choose whether or not to use headphones.

Control: participants in the control group were not aware that they had not had the opportunity to listen to music, but they received routine care after admission

VAS for pain and present behavioural intensity (PBI), 2 anxiety measures: VAS for anxiety (VASA) and FT
and 1 open-ended questionnaire

$24 \mathrm{~h}$ after childbirth, women in the experimental group were asked to complete an open-ended ques-
tionnaire to indicate their perceptions of the effectiveness of music therapy on pain and anxiety and a
5-point scale to evaluate the helpfulness of music

Dates of study: not reported
Funding: this study was funded by the National Science Council, Taipei, Taiwan, NSC 90-2314-
B-037-072
Conflicts of interest: none

\section{Risk of bias}

\begin{tabular}{|c|c|c|}
\hline Bias & Authors' judgement & Support for judgement \\
\hline $\begin{array}{l}\text { Random sequence genera- } \\
\text { tion (selection bias) }\end{array}$ & Low risk & Lot drawing \\
\hline $\begin{array}{l}\text { Allocation concealment } \\
\text { (selection bias) }\end{array}$ & Low risk & Coded balls \\
\hline $\begin{array}{l}\text { Blinding of participants } \\
\text { and personnel (perfor- } \\
\text { mance bias) } \\
\text { All outcomes }\end{array}$ & High risk & $\begin{array}{l}\text { Blinding not attempted although the control group was unaware of the inter- } \\
\text { vention group }\end{array}$ \\
\hline $\begin{array}{l}\text { Blinding of outcome as- } \\
\text { sessment (detection bias) } \\
\text { All outcomes }\end{array}$ & High risk & $\begin{array}{l}\text { Not described but likely to be high as it is difficult to blind this type of interven- } \\
\text { tion }\end{array}$ \\
\hline $\begin{array}{l}\text { Incomplete outcome data } \\
\text { (attrition bias) } \\
\text { All outcomes }\end{array}$ & High risk & $\begin{array}{l}51 \text { initially allocated to each group. } 40 \% \text { loss of data although no difference } \\
\text { between groups. Postrandomisation exclusions: intervention group: pro- } \\
\text { longed labour and caesarean delivery } n=5 \text {, use of epidural } n=15 \\
\text { Control group: prolonged labour and caesarean delivery } n=4 \text {, use of epidural } \\
n=18\end{array}$ \\
\hline $\begin{array}{l}\text { Selective reporting (re- } \\
\text { porting bias) }\end{array}$ & Unclear risk & Study protocol unavailable \\
\hline
\end{tabular}


Liu 2010 (Continued)
Other bias
Unclear risk
No imbalance at randomisation

Moore 1965

\begin{tabular}{|c|c|}
\hline Methods & Parallel, single-blind, RCT of audio-analgesia \\
\hline \multirow[t]{4}{*}{ Participants } & 25 women randomised to the trial \\
\hline & Inclusion criteria: singleton pregnancy in the 1st stage of labour \\
\hline & Exclusion criteria: history of ear disease or vestibular disturbance \\
\hline & The trial was undertaken in England \\
\hline \multirow[t]{3}{*}{ Interventions } & Intervention: women in the experimental arm listened to white sound set at 120 decibels. \\
\hline & $\begin{array}{l}\text { Control: listened to white sound at a maximum } 90 \text { decibels (it was presumed at this level there is no } \\
\text { physiological effect). }\end{array}$ \\
\hline & $\begin{array}{l}\text { The intervention started when the woman was in established labour. If the women became tired the } \\
\text { audio-analgesia was stopped and resumed later. If the midwife considered the pain relief inadequate, } \\
\text { the audio analgesia was stopped and inhalation analgesia started }\end{array}$ \\
\hline Outcomes & Midwife's opinion of pain relief from audio-analgesia, woman's satisfaction with 'sea noise' \\
\hline \multirow[t]{3}{*}{ Notes } & There was no sample-size calculation. No details were provided on baseline characteristics. \\
\hline & Dates of study: not reported \\
\hline & $\begin{array}{l}\text { Funding: not reported } \\
\text { Conflicts of interest: not reported }\end{array}$ \\
\hline
\end{tabular}

\section{Risk of bias}

\begin{tabular}{|c|c|c|}
\hline Bias & Authors' judgement & Support for judgement \\
\hline $\begin{array}{l}\text { Random sequence genera- } \\
\text { tion (selection bias) }\end{array}$ & Unclear risk & Not reported \\
\hline $\begin{array}{l}\text { Allocation concealment } \\
\text { (selection bias) }\end{array}$ & Unclear risk & Not reported \\
\hline $\begin{array}{l}\text { Blinding of participants } \\
\text { and personnel (perfor- } \\
\text { mance bias) } \\
\text { All outcomes }\end{array}$ & Unclear risk & Insufficient details to determine if blinding was undertaken \\
\hline $\begin{array}{l}\text { Blinding of outcome as- } \\
\text { sessment (detection bias) } \\
\text { All outcomes }\end{array}$ & Unclear risk & It was unclear whether the outcome assessor and analyst were blind \\
\hline $\begin{array}{l}\text { Incomplete outcome data } \\
\text { (attrition bias) } \\
\text { All outcomes }\end{array}$ & Low risk & $1(4 \%)$ woman withdrew from the trial \\
\hline $\begin{array}{l}\text { Selective reporting (re- } \\
\text { porting bias) }\end{array}$ & Unclear risk & Study protocol unavailable \\
\hline
\end{tabular}


Moore 1965 (Continued)

Other bias Unclear risk Insufficient reporting

Phumdoung 2007

Methods Randomised factorial design of yoga position + music compared with postural management (5 groups)

Participants

207 women were recruited to the trial from a regional hospital in Southern Thailand.

Inclusion criteria: primiparous women, aged 18-35 years, in latent phase for no more than $10 \mathrm{~h}$, single fetus

Exclusion criteria: received analgesics before the starting the study, induced labour, SROM > than 20 $\mathrm{h}$ previously, history of psychiatric problems, hearing difficulty, asthma, infection, negative reactions whilst listening to music, cephalic presentation, 38-42 weeks' gestation, estimated fetal weight $2.5 \mathrm{~kg}-4$ $\mathrm{kg}$

Interventions

Intervention: yoga + music

The PSU Cat is the position whereby women lean on the inclined $\left(30^{\circ}-45^{\circ}\right)$ head of the bed and the knee is bent on the bed. The head of the woman is placed on the raised head of the bed.

Mechanism of the PSU Cat position: when the mother in a prone position is allowed to lean her body forward on the bed, then the weight of the infant will be put onto the abdomen and this position will relieve back pain. Leaning forward stops the abdominal muscle suppressing the uterus, thus making the uterus extend over a longer area which facilitates fetal axis pressure leading to an increase of oxytocin.

Being in the PSU Cat position means the uterus does not compress the blood vessel in the pelvic area so that the blood can be sent to the uterus without the obstruction of the blood vessel supplying the uterus. When the fetal axis pressure makes flexion of the fetus rapid this leads to easier internal rotation. Gravity then helps the fetus to descend faster. This helps to fix the unstable ilium and sacrum bones in the changing of the sacroiliac ligament, thus reducing labour pain. When the muscles relax for longer periods of time this helps to reduce the labour pains.

Intervention for the 5 experimental groups from cervical dilation of 3-4 cm until cervical dilation of 10 $\mathrm{cm}$ or at least $4 \mathrm{~h}$ were as follows.

1. Women in the PSU Cat alternate with high head group were put in the PSU Cat position for $30 \mathrm{~min}$, and the high head position for $30 \mathrm{~min}$, alternating each position for $30 \mathrm{~min}$, and listening to music without earphones all the time. The instrumental music (without lyrics) played in the study period used synthesizers, harps, pianos, orchestras and jazz

2. Women in the PSU Cat alternate with high head group were put in the PSU Cat for $30 \mathrm{~min}$ and the high head position for $30 \mathrm{~min}$ alternatively, each for $30 \mathrm{~min}$

3. Women in the PSU Cat alternate with supine group were put in the PSU Cat for 30 min, and supine position for $30 \mathrm{~min}$ alternatively

4. Women in the high head group were assigned to lie in the bed with a $45^{\circ}$ lift

5. A group of women also took up a supine position

Outcomes

1. Sensory pain measured by self-report using VA Sensory Pain Scale (0-100)

2. Affective pain reported distress measured by self-reported VA Distress Pain Scale (0-100). Measured at beginning of study period before Rx started, then measured every 30 min during study for a period of $4 \mathrm{~h}$

3. Time in active phase $(3-4 \mathrm{~cm}$ dilation until $10 \mathrm{~cm})$

NOTE not all raw data were reported, results presented graphically 
Phumdoung 2007 (Continued)

Funding: Prince of Songkla University Grant

Conflicts of interest: not reported

\section{Risk of bias}

\begin{tabular}{|c|c|c|}
\hline Bias & Authors' judgement & Support for judgement \\
\hline $\begin{array}{l}\text { Random sequence genera- } \\
\text { tion (selection bias) }\end{array}$ & Low risk & Computer-generated \\
\hline $\begin{array}{l}\text { Allocation concealment } \\
\text { (selection bias) }\end{array}$ & Unclear risk & Unable to obtain details from study author \\
\hline $\begin{array}{l}\text { Blinding of participants } \\
\text { and personnel (perfor- } \\
\text { mance bias) } \\
\text { All outcomes }\end{array}$ & High risk & The participants and clinicians were not blind \\
\hline $\begin{array}{l}\text { Blinding of outcome as- } \\
\text { sessment (detection bias) } \\
\text { All outcomes }\end{array}$ & Unclear risk & Insufficient reporting \\
\hline $\begin{array}{l}\text { Incomplete outcome data } \\
\text { (attrition bias) } \\
\text { All outcomes }\end{array}$ & Low risk & Data were complete \\
\hline $\begin{array}{l}\text { Selective reporting (re- } \\
\text { porting bias) }\end{array}$ & Unclear risk & Study protocol unavailable \\
\hline Other bias & Low risk & There were no differences in baseline characteristics \\
\hline
\end{tabular}

Simavli 2014

\begin{tabular}{|c|c|}
\hline Methods & RCT comparing music to usual care on labour pain \\
\hline \multirow[t]{3}{*}{ Participants } & $\begin{array}{l}161 \text { women attending for antenatal care at the study hospital in Turkey between September } 2011 \text { and } \\
\text { September } 2012 \text {. }\end{array}$ \\
\hline & $\begin{array}{l}\text { Inclusion criteria: primiparous, aged } 18-35 \text { years, } 37-41 \text { weeks' gestation, singleton pregnancy with } \\
\text { cephalic presentation, expected to have normal birthweight baby and vaginal birth. }\end{array}$ \\
\hline & $\begin{array}{l}\text { Exclusion criteria: hypertensive disorders, diabetes, IUGR, PROM, treatment with analgesics or an- } \\
\text { tipsychotic medication, hearing difficulties, chronic pain, severe dysmenorrhoea, fetal death, cardio- } \\
\text { vascular or other fetal anomaly, inability to understand VAS }\end{array}$ \\
\hline
\end{tabular}

Interventions Intervention: music therapy. 1 of 5 types of music (by choice via headphones) classical music, Turkish art or folk music or Turkish classical music or popular music. The intervention started at $2 \mathrm{~cm}$ cervical dilatation, later in labour more rhythmic music was introduced by the midwife, music continued until the end of the third stage

Control: used a blank CD

\section{Outcomes}

Primary outcome VAS pain score $(0-10 \mathrm{~cm})$; anxiety (VAS), maternal blood pressure, and fetal movements and heart rate

\section{Notes}


Simavli 2014 (Continued)

Dates of study: 2011-2012

Funding: none

Conflicts of interest: none

\section{Risk of bias}

\begin{tabular}{lll}
\hline Bias & Authors' judgement & Support for judgement \\
\hline $\begin{array}{l}\text { Random sequence genera- } \\
\text { tion (selection bias) }\end{array}$ & Low risk & Computer-generated randomisation sequence \\
\hline $\begin{array}{l}\text { Allocation concealment } \\
\text { (selection bias) }\end{array}$ & Unclear risk & Not described \\
\hline $\begin{array}{l}\text { Blinding of participants } \\
\text { and personnel (perfor- } \\
\text { mance bias) } \\
\text { All outcomes }\end{array}$ & High risk & Women would have known of their group status \\
\hline
\end{tabular}

\begin{tabular}{lll}
\hline $\begin{array}{l}\text { Blinding of outcome as- } \\
\text { sessment (detection bias) } \\
\text { All outcomes }\end{array}$ & High risk & Not reported although measurement was by staff providing care \\
\hline $\begin{array}{l}\text { Incomplete outcome data } \\
\text { (attrition bias) } \\
\text { All outcomes }\end{array}$ & High risk & $\begin{array}{l}\text { 24 women were postrandomisation exclusions. Reasons for exclusion included } \\
\text { caesarean section, cervical dilatation }>3 \text { and forgetting their group allocation }\end{array}$ \\
\hline $\begin{array}{l}\text { Selective reporting (re- } \\
\text { porting bias) }\end{array}$ & High risk & $\begin{array}{l}\text { Discrepency in 2 similar papers describing the power calculation, denomina- } \\
\text { tors and outcomes collected }\end{array}$ \\
\hline Other bias & Unclear risk & Baseline characteristics between groups are similar \\
\hline
\end{tabular}

\section{Yildirim 2004}

\begin{tabular}{ll}
\hline Methods & Parallel RCT of breathing compared with usual care \\
\hline Participants & 40 women were recruited from SKK Bakirkoy Hospital, Istanbul, Turkey \\
& Inclusion criteria: primiparous, 38-42 weeks pregnant, at low risk, expecting normal vaginal delivery \\
& Exclusion criteria: not stated
\end{tabular}

Interventions

Intervention: investigators provided information about labour, breathing techniques and massage in the latent phase of labour, and accompanied these women during labour. The women received nurseadministered massage and were encouraged to perform breathing exercises and self-administered massage. They were also instructed to change their positions and to relax. Slow, deep inhalations were encouraged in the latent phase and rapid, shallow breathing was encouraged in the active phase. The pant-blow abdominal breathing technique was applied in the $2^{\text {nd }}$ stage of labour. Plus lower and upper back massages were administered by a nurse. Women were also instructed to give themselves a soft massage in the abdominal area using their fingers.

Control: women were monitored routinely in the labour room and did not receive education or supportive nursing care

Outcomes

Pain assessment conducted at $2 \mathrm{~cm}, 4 \mathrm{~cm}, 6 \mathrm{~cm}, 8 \mathrm{~cm}$ and $10 \mathrm{~cm}$ along a VAS. Behaviour was observed and classified by the study investigator. Postnatal interview $2 \mathrm{~h}$ after delivery. 
Yildirim 2004 (Continued)

$\begin{array}{ll}\text { Notes } & \text { Dates of study: Recruitment } 1 \text { January 2000-1 September } 2000 \\ & \text { Funding: not reported } \\ \text { Conflicts of interest: not reported }\end{array}$

\section{Risk of bias}

\begin{tabular}{|c|c|c|}
\hline Bias & Authors' judgement & Support for judgement \\
\hline $\begin{array}{l}\text { Random sequence genera- } \\
\text { tion (selection bias) }\end{array}$ & Unclear risk & $\begin{array}{l}\text { Not reported and no additional details could be obtained from the study au- } \\
\text { thor }\end{array}$ \\
\hline $\begin{array}{l}\text { Allocation concealment } \\
\text { (selection bias) }\end{array}$ & Unclear risk & $\begin{array}{l}\text { Not reported and no additional details could be obtained from the study au- } \\
\text { thor }\end{array}$ \\
\hline $\begin{array}{l}\text { Blinding of participants } \\
\text { and personnel (perfor- } \\
\text { mance bias) } \\
\text { All outcomes }\end{array}$ & High risk & Women and care providers were not blind to the intervention \\
\hline $\begin{array}{l}\text { Blinding of outcome as- } \\
\text { sessment (detection bias) } \\
\text { All outcomes }\end{array}$ & High risk & $\begin{array}{l}\text { Not described but likely to be high as it is difficult to blind this type of interven- } \\
\text { tion }\end{array}$ \\
\hline $\begin{array}{l}\text { Incomplete outcome data } \\
\text { (attrition bias) } \\
\text { All outcomes }\end{array}$ & Low risk & $\begin{array}{l}\text { Not explicitly discussed although data appear complete from all study partici- } \\
\text { pants randomised to the trial }\end{array}$ \\
\hline $\begin{array}{l}\text { Selective reporting (re- } \\
\text { porting bias) }\end{array}$ & Unclear risk & Study protocol unavailable \\
\hline Other bias & Low risk & $\begin{array}{l}\text { Slight imbalance in randomisation of gravida at baseline, higher gravida in the } \\
\text { control group }\end{array}$ \\
\hline
\end{tabular}

IUGR: intrauterine growth restriction

NRS: numerical rating scale

PROM: premature rupture of membranes

$\mathrm{RCT}$ : randomised controlled trial

RAT: respiratory autogenic training

SROM: spontaneous rupture of membranes

STAI: State-Trait Anxiety Inventory

VAS: visual analogue scale

Characteristics of excluded studies [ordered by study ID]

\begin{tabular}{ll}
\hline Study & Reason for exclusion \\
\hline Ahmadi 2017 & $\begin{array}{l}\text { This study delivered a breathing techniques intervention, with the control group Valsalva maneu- } \\
\text { ver. This is not a relevant comparison for this review. }\end{array}$ \\
\hline Ahmadian 2009 & $\begin{array}{l}\text { This study evaluated the role of antenatal education on anxiety and women's emotions during } \\
\text { labour and birthing. Publication was by abstract from conference proceedings only and we have } \\
\text { not been able to obtain further study details from the authors. }\end{array}$ \\
\hline Barbieri 2013 & $\begin{array}{l}\text { The intervention was a birth ball. This intervention does not meet the criteria for a relaxation tech- } \\
\text { nique. }\end{array}$ \\
\hline
\end{tabular}




\begin{tabular}{ll}
\hline Study & Reason for exclusion \\
\hline Bastani 2006 & $\begin{array}{l}\text { This trial delivered a relaxation intervention for women with anxiety, it was not designed to reduce } \\
\text { pain in labour. }\end{array}$ \\
\hline Browning 2000 & $\begin{array}{l}\text { In this qualitative study, } 11 \text { women attending childbirth education classes volunteered to partic- } \\
\text { ipate in a study examining the effect of music during labour. The participants were randomly as- } \\
\text { signed to receive music use and labour support or labour support alone (control group) during } \\
\text { labour. The participants selected the music; they were instructed to listen to some music daily dur- } \\
\text { ing their pregnancy and to play the music during labour. The paper reports on a qualitative analysis } \\
\text { of interviews conducted with the participants within } 72 \text { hours of delivery. }\end{array}$ \\
\hline
\end{tabular}

\begin{tabular}{ll} 
Buxton 1973 & This trial examined the effect of maternal respiration in labour, and was not relevant to this review. \\
\hline Chuang 2012 & This relaxation intervention was not designed to reduce pain in labour. \\
\hline Dehcheshmeh 2015 & $\begin{array}{l}\text { The methods used in this study were not clear. Author correspondence reports that allocation to } \\
\text { groups was matched. }\end{array}$
\end{tabular}
Delgado-Garcia $2012 \quad$ Intervention was birth ball; this intervention is not a relaxation technique and does not fit the re- view's inclusion criteria.

\begin{tabular}{ll}
\hline Drzymalski 2017 & The music intervention was delivered only at the time of the placement of the epidural. \\
\hline Escott 2005 & Intervention in this study was not a relaxation technique. \\
\hline Field 1999 & $\begin{array}{l}\text { The comparison group in this study received massage; this comparison does not meet the eligibili- } \\
\text { ty criteria. }\end{array}$
\end{tabular}

\begin{tabular}{ll}
\hline Firouzbakht 2014 & Not a RCT \\
\hline Gau 2011 & $\begin{array}{l}\text { Intervention was birth ball; this is not a relaxation technique and does not fit the review's inclusion } \\
\text { criteria. }\end{array}$ \\
\hline Geden 1989 & $\begin{array}{l}\text { This paper reported on } 2 \text { studies that examined the effects of music on analogued labour pain; the } \\
\text { first involving music, the second using a combination of imagery and music. } 20 \text { women were in- } \\
\text { cluded in this study which was undertaken in the USA. This study was not conducted on women } \\
\text { during labour and therefore did not meet the inclusion criteria for this review. }\end{array}$
\end{tabular}

\begin{tabular}{ll}
\hline Hao 1997 & $\begin{array}{l}\text { The trial evaluates a psychological suggestion therapy intervention rather than a relaxation thera- } \\
\text { py. }\end{array}$ \\
\hline Huang 2015 & $\begin{array}{l}\text { Relaxation was } 1 \text { component of an intervention to reduce anxiety and depression and reduce the } \\
\text { rate of caesarean section. }\end{array}$ \\
\hline Jain 2015 & The intervention was antenatal exercises. this does not fit review's inclusion criteria. \\
\hline Janke 1999 & Relaxation intervention designed to prolong duration of pregnancy for women in preterm labour. \\
\hline Kamalifard 2012 & Massage was used as the control and this comparison does not meet the eligibility criteria. \\
\hline Korol 1992 & $\begin{array}{l}\text { This intervention not designed to reduce pain and does not meet the inclusion criteria of the re- } \\
\text { view. }\end{array}$ \\
\hline Levett 2016b & $\begin{array}{l}\text { This complex intervention was not primarily relaxation focused and will be included in a related re- } \\
\text { view examining massage for pain relief in labour. }\end{array}$ \\
\hline
\end{tabular}




\begin{tabular}{|c|c|}
\hline Study & Reason for exclusion \\
\hline Mathew 2012 & $\begin{array}{l}\text { Ambulation and birthing ball therapy in first stage of labour do not meet our criteria for the inter- } \\
\text { vention. }\end{array}$ \\
\hline Miquelutti 2015 & $\begin{array}{l}\text { The intervention was not designed to reduce pain in labour. The study addressed reducing back } \\
\text { pain in pregnancy, preventing urinary incontinence and reducing anxiety. }\end{array}$ \\
\hline Mirzakhani 2015 & Intervention was birth ball, this intervention does not fit the review's inclusion criteria. \\
\hline Musa 2011 & In this study the intervention was exercise; this intervention did not meet our inclusion criteria. \\
\hline Narendran 2005 & This was not a RCT \\
\hline NCT01389128 & Not a relaxation intervention \\
\hline NCT01601860 & The intervention in this study was not a relaxation technique. \\
\hline NCT02190591 & $\begin{array}{l}\text { Intervention was birth ball; this intervention is not a relaxation technique and does not fit the re- } \\
\text { view's inclusion criteria. }\end{array}$ \\
\hline Phumdoung 2003 & $\begin{array}{l}\text { Information on methods and outcomes were not clear and clarification could not be obtained from } \\
\text { the study author. }\end{array}$ \\
\hline Phumdoung 2010 & Intervention was position in labour and not a relaxation intervention. \\
\hline Podder 2007 & $\begin{array}{l}\text { There was limited information on methods and we were unable to ascertain from the author de- } \\
\text { tails of randomisation and to obtain raw data. }\end{array}$ \\
\hline Ran 2005 & $\begin{array}{l}\text { The trial evaluates a psychological suggestion therapy intervention rather than a relaxation thera- } \\
\text { py. }\end{array}$ \\
\hline Roth 2016 & Intervention was a peanut ball and not a relevant intervention for this review. \\
\hline Sammons 1984 & $\begin{array}{l}\text { This trial randomised } 30 \text { women to a non-music control group and } 24 \text { to a music group; it was not } \\
\text { clear that the intervention was to reduce pain in labour. }\end{array}$ \\
\hline Schorn 2009 & $\begin{array}{l}\text { This trial evaluated the role of guided imagery on blood loss during labour and was not designed to } \\
\text { reduce pain. }\end{array}$ \\
\hline Shim 2012 & Not a RCT \\
\hline Sun 2010 & Not a RCT \\
\hline Taavoni 2016 & Birth ball and not a relevant intervention for this review. \\
\hline Taghavi 2009 & $\begin{array}{l}\text { This study evaluated an antenatal education to perform respiration and relaxation techniques dur- } \\
\text { ing labour. Publication is by abstract from conference proceedings only and we have not been able } \\
\text { to obtain further study details from the study authors. }\end{array}$ \\
\hline Taghinejad 2010 & $\begin{array}{l}\text { In this study the control group received a massage intervention which is not a relevant comparison } \\
\text { for this review. }\end{array}$ \\
\hline Tragea 2014 & Stress management course and intervention not used in labour. \\
\hline Tussey 2015 & Birth ball and not a relevant intervention for this review. \\
\hline Zilcha-Mano 2016 & The study was not designed to reduce pain in labour. \\
\hline
\end{tabular}


$\mathrm{RCT}$ : randomised controlled trial

Characteristics of studies awaiting assessment [ordered by study ID]

Jahdi 2017

Methods Clinical trial comparing antenatal yoga vs usual care on labour pain and delivery outcomes

Participants

60 primiparous women, aged 18-35 years old presenting to Mirza Koochak Khan hospital in Tehran, Iran from March 2013 to Jun 2014.

Inclusion criteria: no serious illness or high-risk complications during pregnancy and delivery, BMI between 19.8 or 26 respectively, non-elective caesarean, never having a previous experience with yoga and other exercise such as Pilates or Tai Chi, absence of fetal abnormalities or fetal growth retardation (IUGR) which was confirmed by ultrasonography

Interventions

Intervention: yoga. 5 components of yoga practice including yoga asanas, chanting om, breathing awareness, yoga Nidra, Dhyana were taught to women who had not practiced yoga or other exercise such as Pilates or Tai Chi.

Participants in the intervention group were asked to perform yoga exercises daily starting at the 26 th and continuing until the end of their 37 th week of gestation. This consisted of a 60 -min yoga work out a 3 times a week. All experimental participants joined supervised yoga classes provided by a yoga expert to ensure correct form and safety. A booklet and yoga training DVD were provided for each woman containing principles and benefits of each yoga posture, as well as demonstrating the proper technique.

Control: routine midwifery care through scheduled hospital visits

Outcomes

Labour pain was assessed by the VAS $(0=$ no pain and $10=$ most severe pain woman had experienced). Pain scores were measured in both groups when cervical dilatation researched $3-4 \mathrm{~cm}$ and then $2 \mathrm{~h}$ after the first and $2 \mathrm{~h}$ after second measurements. Labour outcomes included duration of first, second and third stage, induction, birth mode, analgesia consumption, newborn baby, birth and Apgar scores

Notes Randomisation method unclear - contacted study authors 19 June 2017 to clarify

Salem 2004

Methods We have been unable to obtain the thesis. No details available

\section{Participants}

Interventions

\section{Outcomes}

Notes

Shafai 2013

\begin{tabular}{ll}
\hline Methods & Reported to be a randomised trial \\
\hline Participants & Nulliparous women in labour
\end{tabular}


Shafai 2013 (Continued)

Physiological delivery versus a complex intervention including aromatherapy, pelvic exercises with
ball, back and stomach massage during contraction using Lavandula oil, and an accompanying
person in active phase

\begin{tabular}{ll}
\hline Outcomes & Unclear \\
\hline Notes & Assessment from brief abstract. Attempting to obtain a translation of the study report \\
\hline
\end{tabular}

\section{Tehrani 2006}

\begin{tabular}{ll}
\hline Methods & Unclear - clinical trial comparing relaxation and meditation versus an unknown control \\
\hline Participants & 90 primiparous women presenting to Fatemah hospital clinic \\
\hline Interventions & $\begin{array}{l}\text { Intervention: relaxation and meditation techniques were taught during the third trimester (28-30 } \\
\text { weeks) } \\
\text { Control: unclear }\end{array}$ \\
\hline Outcomes & Pain scores during labour \\
\hline Notes & Awaiting translation - data from English abstract only \\
\hline
\end{tabular}

BMI; body mass index

VAS: visual analogue scale

Characteristics of ongoing studies [ordered by study ID]

\section{NCT00917332}

\begin{tabular}{ll}
\hline Trial name or title & Effects of relaxation and guided imagery training on pain at childbirth \\
\hline Methods & RCT \\
\hline Participants & $\begin{array}{l}\text { Inclusion criteria: } 110 \text { primiparous women, who speak Hebrew } \\
\text { Exclusion criteria: obstetric complications, planning an elective caesarean section, medical com- } \\
\text { plications (high blood pressure, diabetes), history of mental illness }\end{array}$
\end{tabular}

Interventions

Intervention: relaxation using breathing and muscle relaxation and guided imagery (safe place)

Control: supportive care

\begin{tabular}{ll}
\hline Outcomes & Pain intensity, use of epidurals \\
\hline Starting date & August 2009 \\
\hline Contact information & Efrat Esterkin, MA, efratkin@gmail.com \\
\hline Notes & \\
\hline
\end{tabular}


NCT03066973

\begin{tabular}{|c|c|}
\hline Trial name or title & Breathing exercises for labour pain and duration \\
\hline Methods & $\mathrm{RCT}$ \\
\hline Participants & $\begin{array}{l}\text { Inclusion criteria: } 250 \text { nulliparous women between } 37-42 \text { weeks of gestation Exclusion criteria: } \\
\text { analgesic use, clinical instability and psychiatric disorders }\end{array}$ \\
\hline \multirow[t]{2}{*}{ Interventions } & Intervention: breathing exercises at the first stage of labour \\
\hline & Control: routine care services \\
\hline Outcomes & $\begin{array}{l}\text { VAS to identify perception of pain during the second stage of labour. Duration of the second stage } \\
\text { of labour and Apgar scores for newborns }\end{array}$ \\
\hline Starting date & May 2016 \\
\hline Contact information & Yasemin Cayir, Ataturk University \\
\hline Notes & $\begin{array}{l}\text { Study was conducted at Nenehatun Obstetric and Gynecology Hospital between May-June 2016, in } \\
\text { Erzurum, Turkey. Currently not recruiting }\end{array}$ \\
\hline
\end{tabular}

$\mathrm{RCT}$ : randomised controlled trial

VAS: visual analogue scale

\section{DATA AND ANALYSES}

\section{Comparison 1. Relaxation versus usual care}

\begin{tabular}{|c|c|c|c|c|}
\hline Outcome or subgroup title & No. of studies & $\begin{array}{l}\text { No. of partici- } \\
\text { pants }\end{array}$ & Statistical method & Effect size \\
\hline 1 Pain intensity & 4 & & $\begin{array}{l}\text { Mean Difference (IV, Random, 95\% } \\
\mathrm{CI})\end{array}$ & Subtotals only \\
\hline 1.1 Latent phase & 1 & 40 & $\begin{array}{l}\text { Mean Difference (IV, Random, 95\% } \\
\mathrm{CI})\end{array}$ & $-1.25[-1.97,-0.53]$ \\
\hline 1.2 Active phase & 4 & 271 & $\begin{array}{l}\text { Mean Difference (IV, Random, 95\% } \\
\mathrm{CI})\end{array}$ & $-1.08[-2.57,0.41]$ \\
\hline 1.3 Transition & 1 & 40 & $\begin{array}{l}\text { Mean Difference (IV, Random, 95\% } \\
\text { CI) }\end{array}$ & $0.0[0.0,0.0]$ \\
\hline 2 Pain intensity & 1 & 977 & Mean Difference (IV, Fixed, 95\% CI) & $0.0[-0.23,0.23]$ \\
\hline $\begin{array}{l}3 \text { Satisfaction with pain re- } \\
\text { lief }\end{array}$ & 1 & 40 & Risk Ratio (M-H, Fixed, 95\% Cl) & $8.0[1.10,58.19]$ \\
\hline $\begin{array}{l}4 \text { Satisfaction with child- } \\
\text { birth experience }\end{array}$ & 3 & 1176 & $\begin{array}{l}\text { Std. Mean Difference (IV, Random, } \\
95 \% \mathrm{CI} \text { ) }\end{array}$ & $-0.03[-0.37,0.31]$ \\
\hline 5 Assisted vaginal birth & 4 & 1122 & Risk Ratio (M-H, Random, 95\% Cl) & $0.61[0.20,1.84]$ \\
\hline 6 Caesarean section & 4 & 1122 & Risk Ratio (M-H, Random, 95\% Cl) & $0.73[0.26,2.01]$ \\
\hline
\end{tabular}




\begin{tabular}{|c|c|c|c|c|}
\hline Outcome or subgroup title & No. of studies & $\begin{array}{l}\text { No. of partici- } \\
\text { pants }\end{array}$ & Statistical method & Effect size \\
\hline $\begin{array}{l}7 \text { Admission to special care } \\
\text { nursery }\end{array}$ & 1 & 59 & Risk Ratio (M-H, Fixed, 95\% Cl) & $1.03[0.07,15.77]$ \\
\hline $\begin{array}{l}8 \text { Low Apgar score }<7 \text { at } 5 \\
\text { minutes }\end{array}$ & 1 & 34 & Risk Ratio (M-H, Fixed, 95\% Cl) & $0.47[0.02,10.69]$ \\
\hline $\begin{array}{l}9 \text { Use of pharmacological } \\
\text { pain relief }\end{array}$ & 2 & 1036 & Risk Ratio (M-H, Fixed, 95\% Cl) & $0.99[0.88,1.11]$ \\
\hline 9.1 Epidural & 1 & 977 & Risk Ratio (M-H, Fixed, 95\% Cl) & $1.00[0.88,1.13]$ \\
\hline $\begin{array}{l}\text { 9.2 Any additional pharma- } \\
\text { cological intervention }\end{array}$ & 1 & 59 & Risk Ratio (M-H, Fixed, 95\% Cl) & $0.89[0.61,1.28]$ \\
\hline 10 Length of labour & 3 & 224 & $\begin{array}{l}\text { Mean Difference (IV, Random, 95\% } \\
\mathrm{CI})\end{array}$ & $39.30[-41.34,119.93]$ \\
\hline $\begin{array}{l}11 \text { Need for augmentation } \\
\text { with oxytocin }\end{array}$ & 1 & 34 & Risk Ratio (M-H, Fixed, 95\% Cl) & $1.14[0.82,1.59]$ \\
\hline 12 Anxiety & 1 & 140 & Mean Difference (IV, Fixed, 95\% CI) & $0.30[-4.15,4.75]$ \\
\hline 13 Non-prespecified: vitality & 1 & 117 & Mean Difference (IV, Fixed, 95\% CI) & $13.10[10.58,15.62]$ \\
\hline $\begin{array}{l}14 \text { Non-prespecified: fatigue } \\
\text { in labour }\end{array}$ & 1 & 140 & Mean Difference (IV, Fixed, 95\% CI) & $0.5[-1.44,2.44]$ \\
\hline
\end{tabular}

Analysis 1.1. Comparison 1 Relaxation versus usual care, Outcome 1 Pain intensity.

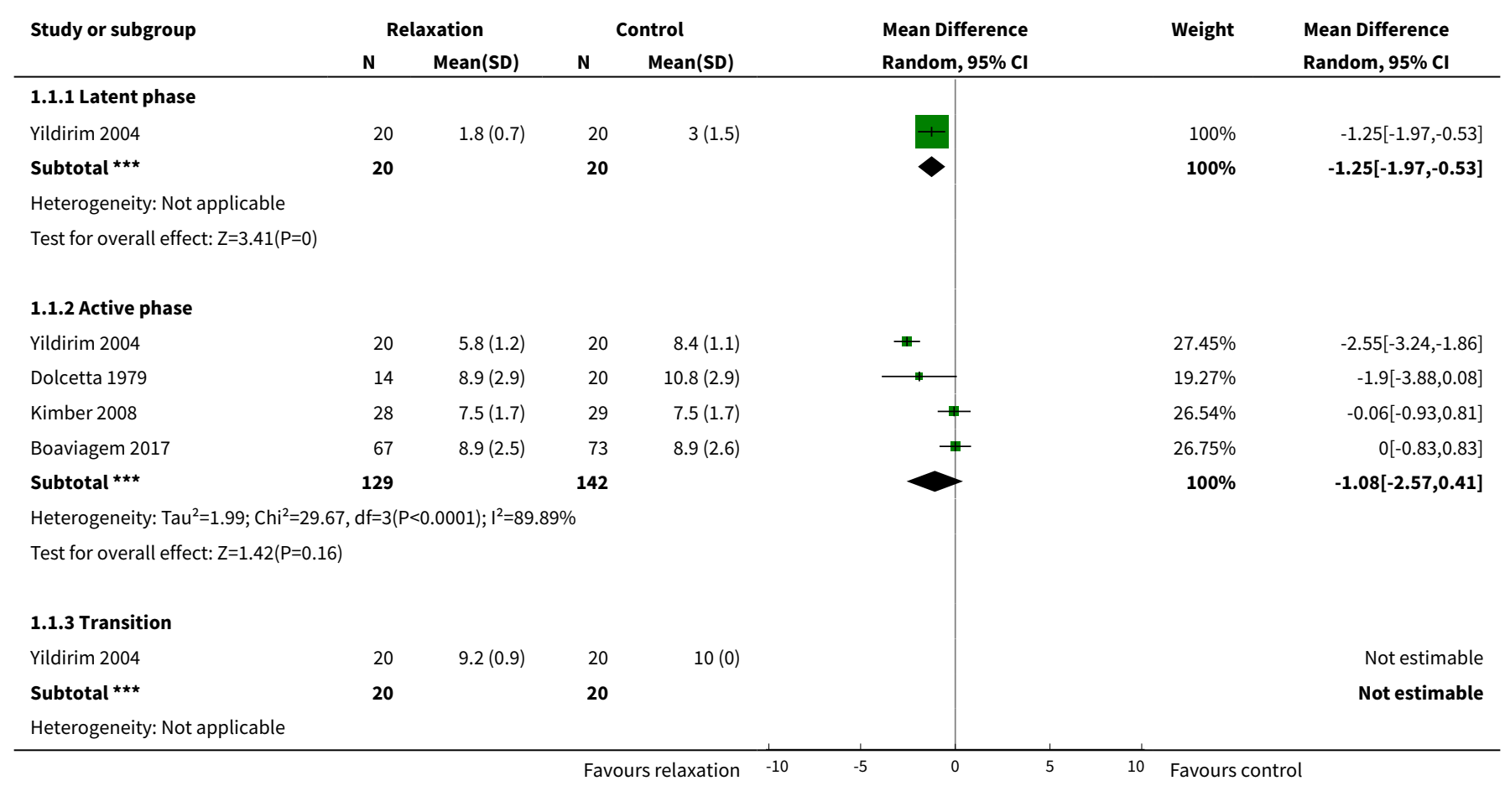




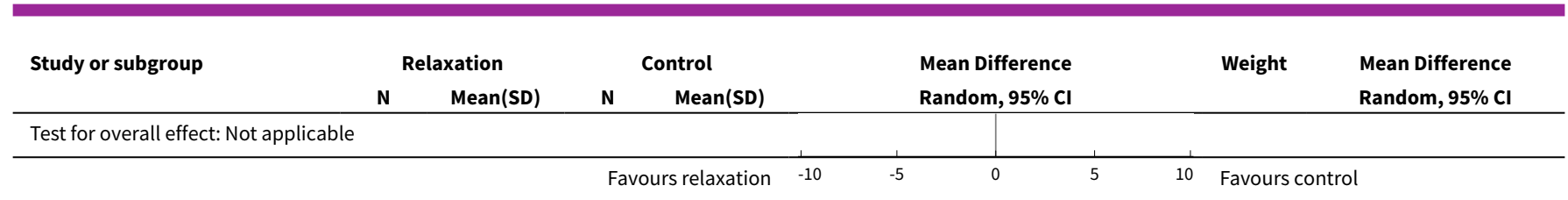

Analysis 1.2. Comparison 1 Relaxation versus usual care, Outcome 2 Pain intensity.

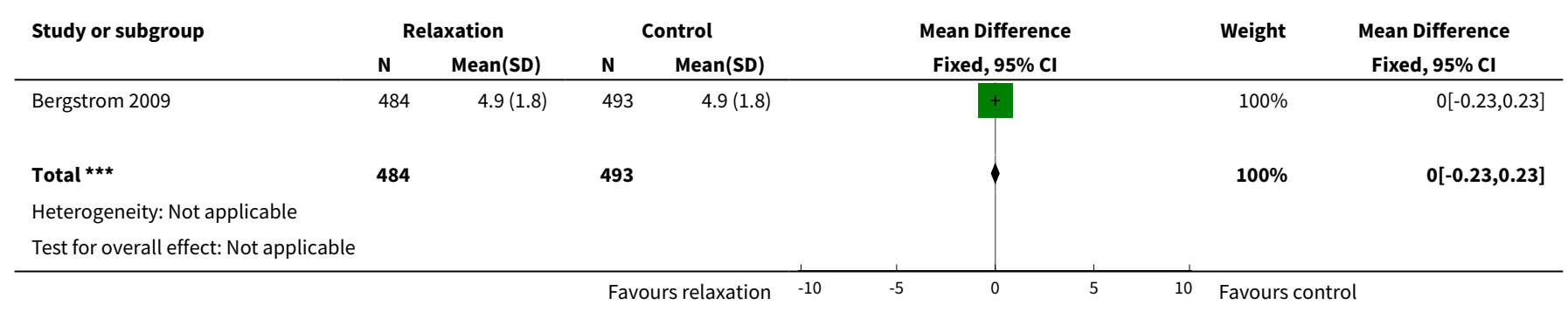

\section{Analysis 1.3. Comparison 1 Relaxation versus usual care, Outcome 3 Satisfaction with pain relief.}

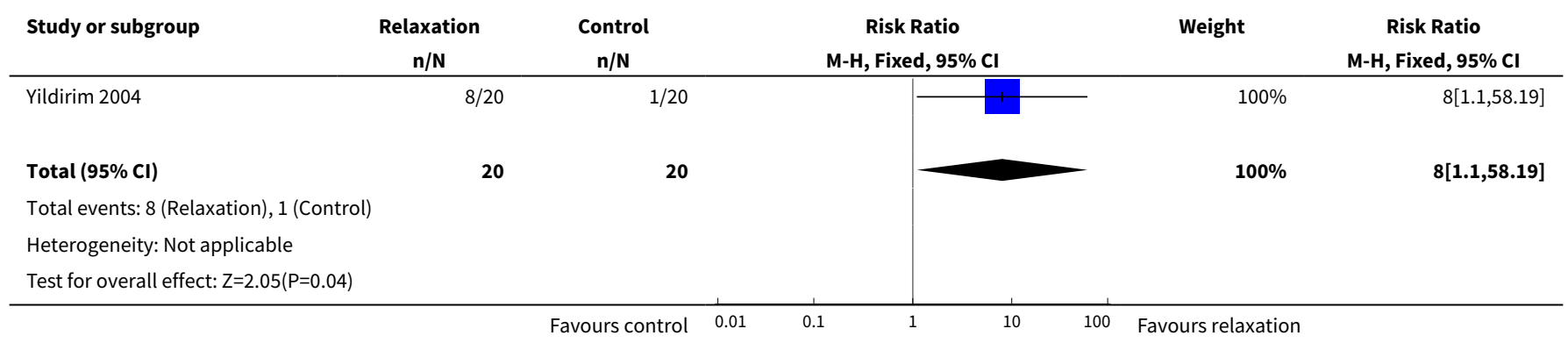

Analysis 1.4. Comparison 1 Relaxation versus usual care, Outcome 4 Satisfaction with childbirth experience.

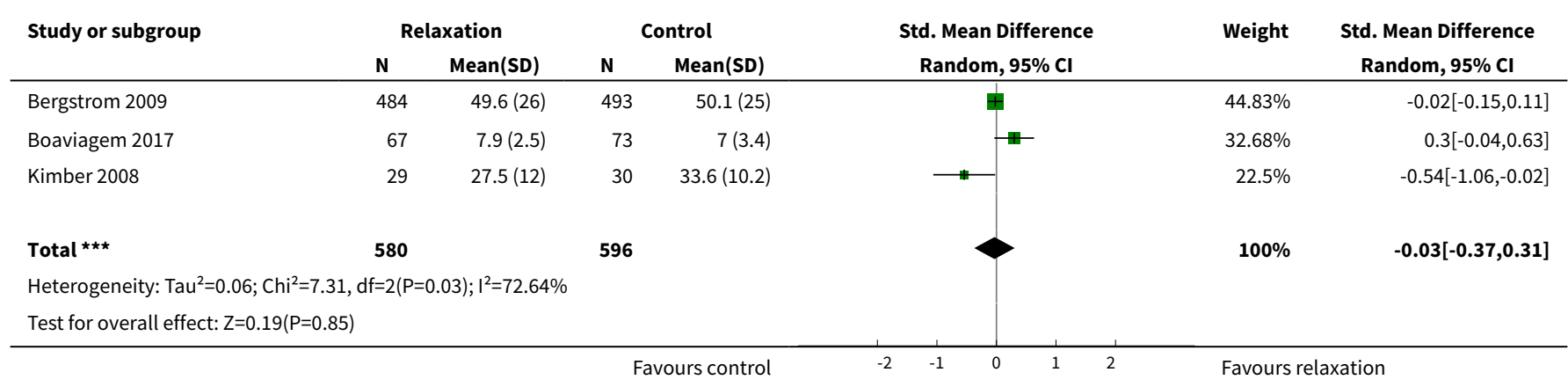


Analysis 1.5. Comparison 1 Relaxation versus usual care, Outcome 5 Assisted vaginal birth.

\begin{tabular}{|c|c|c|c|c|c|}
\hline Study or subgroup & $\begin{array}{c}\text { Relaxation } \\
\mathbf{n} / \mathbf{N} \\
\end{array}$ & $\begin{array}{c}\text { Control } \\
\mathrm{n} / \mathrm{N}\end{array}$ & $\begin{array}{c}\text { Risk Ratio } \\
\text { M-H, Random, } 95 \% \text { CI } \\
\end{array}$ & Weight & $\begin{array}{c}\text { Risk Ratio } \\
\text { M-H, Random, } 95 \% \mathrm{CI} \\
\end{array}$ \\
\hline Bergstrom 2009 & $67 / 484$ & $60 / 493$ & 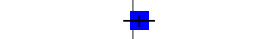 & $43.41 \%$ & $1.14[0.82,1.57]$ \\
\hline Dolcetta 1979 & $0 / 14$ & $4 / 20$ & & $11.27 \%$ & $0.16[0.01,2.68]$ \\
\hline Gatelli 2000 & $0 / 26$ & $15 / 26$ & & $11.76 \%$ & $0.03[0,0.51]$ \\
\hline Kimber 2008 & $7 / 29$ & $6 / 30$ & 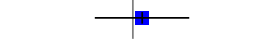 & $33.56 \%$ & $1.21[0.46,3.16]$ \\
\hline \multicolumn{6}{|c|}{ Total events: 74 (Relaxation), 85 (Control) } \\
\hline \multicolumn{6}{|c|}{ Heterogeneity: $\operatorname{Tau}^{2}=0.7 ; \mathrm{Chi}^{2}=9.44, \mathrm{df}=3(\mathrm{P}=0.02) ; \mathrm{I}^{2}=68.22 \%$} \\
\hline \multicolumn{6}{|c|}{ Test for overall effect: $Z=0.88(P=0.38)$} \\
\hline
\end{tabular}

Analysis 1.6. Comparison 1 Relaxation versus usual care, Outcome 6 Caesarean section.

\begin{tabular}{|c|c|c|c|c|c|}
\hline Study or subgroup & $\begin{array}{c}\text { Relaxation } \\
\mathrm{n} / \mathrm{N} \\
\end{array}$ & $\begin{array}{c}\text { Control } \\
\mathrm{n} / \mathrm{N}\end{array}$ & $\begin{array}{c}\text { Risk Ratio } \\
\text { M-H, Random, 95\% Cl }\end{array}$ & Weight & $\begin{array}{c}\text { Risk Ratio } \\
\text { M-H, Random, } 95 \% \text { CI } \\
\end{array}$ \\
\hline Bergstrom 2009 & $96 / 484$ & $106 / 493$ & 典 & $42.41 \%$ & $0.92[0.72,1.18]$ \\
\hline Dolcetta 1979 & $4 / 14$ & $1 / 20$ & 1 & $15.35 \%$ & $5.71[0.71,45.84]$ \\
\hline Gatelli 2000 & $1 / 26$ & $8 / 26$ & & $16.09 \%$ & $0.13[0.02,0.93]$ \\
\hline Kimber 2008 & $3 / 29$ & $7 / 30$ & $\longrightarrow$ & $26.15 \%$ & $0.44[0.13,1.55]$ \\
\hline \multicolumn{6}{|c|}{ Total events: 104 (Relaxation), 122 (Control) } \\
\hline \multicolumn{6}{|c|}{ Heterogeneity: $\mathrm{Tau}^{2}=0.62 ; \mathrm{Chi}^{2}=8.04, \mathrm{df}=3(\mathrm{P}=0.05) ; \mathrm{I}^{2}=62.7 \%$} \\
\hline \multicolumn{6}{|c|}{ Test for overall effect: $Z=0.61(P=0.54)$} \\
\hline
\end{tabular}

Analysis 1.7. Comparison 1 Relaxation versus usual care, Outcome 7 Admission to special care nursery.

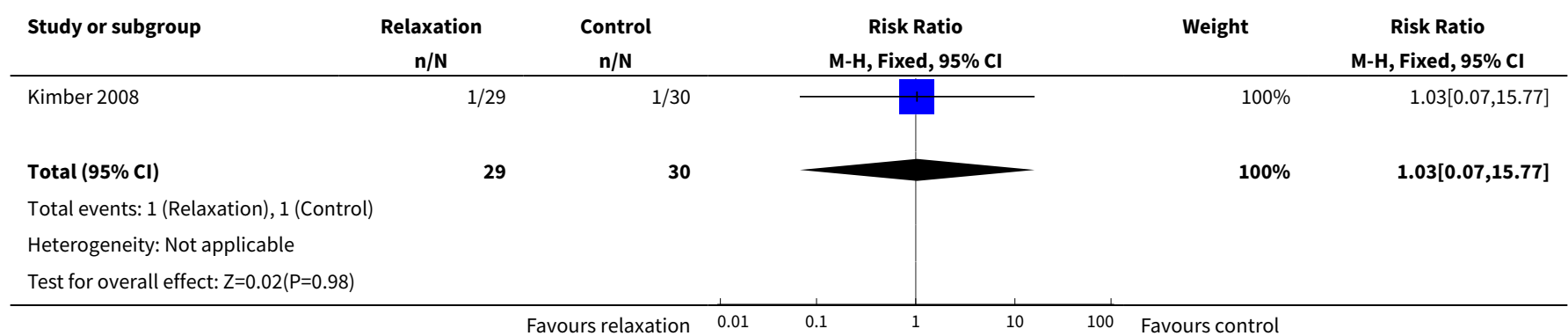

Analysis 1.8. Comparison 1 Relaxation versus usual care, Outcome 8 Low Apgar score $<7$ at 5 minutes.

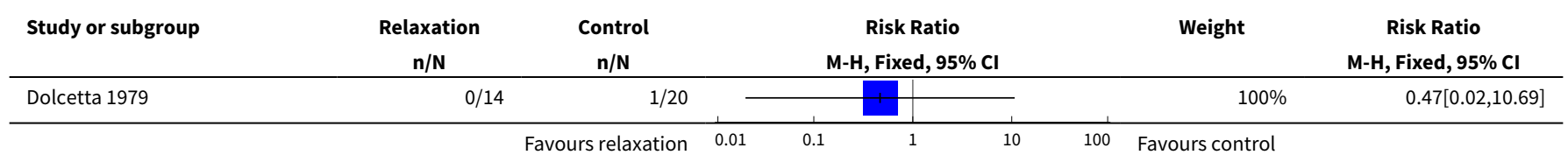




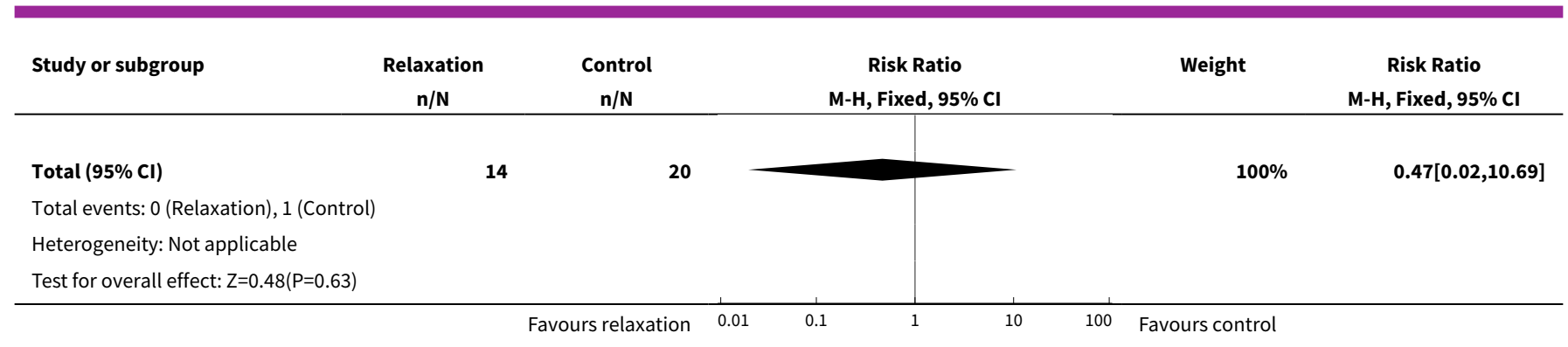

\section{Analysis 1.9. Comparison 1 Relaxation versus usual care, Outcome 9 Use of pharmacological pain relief.}

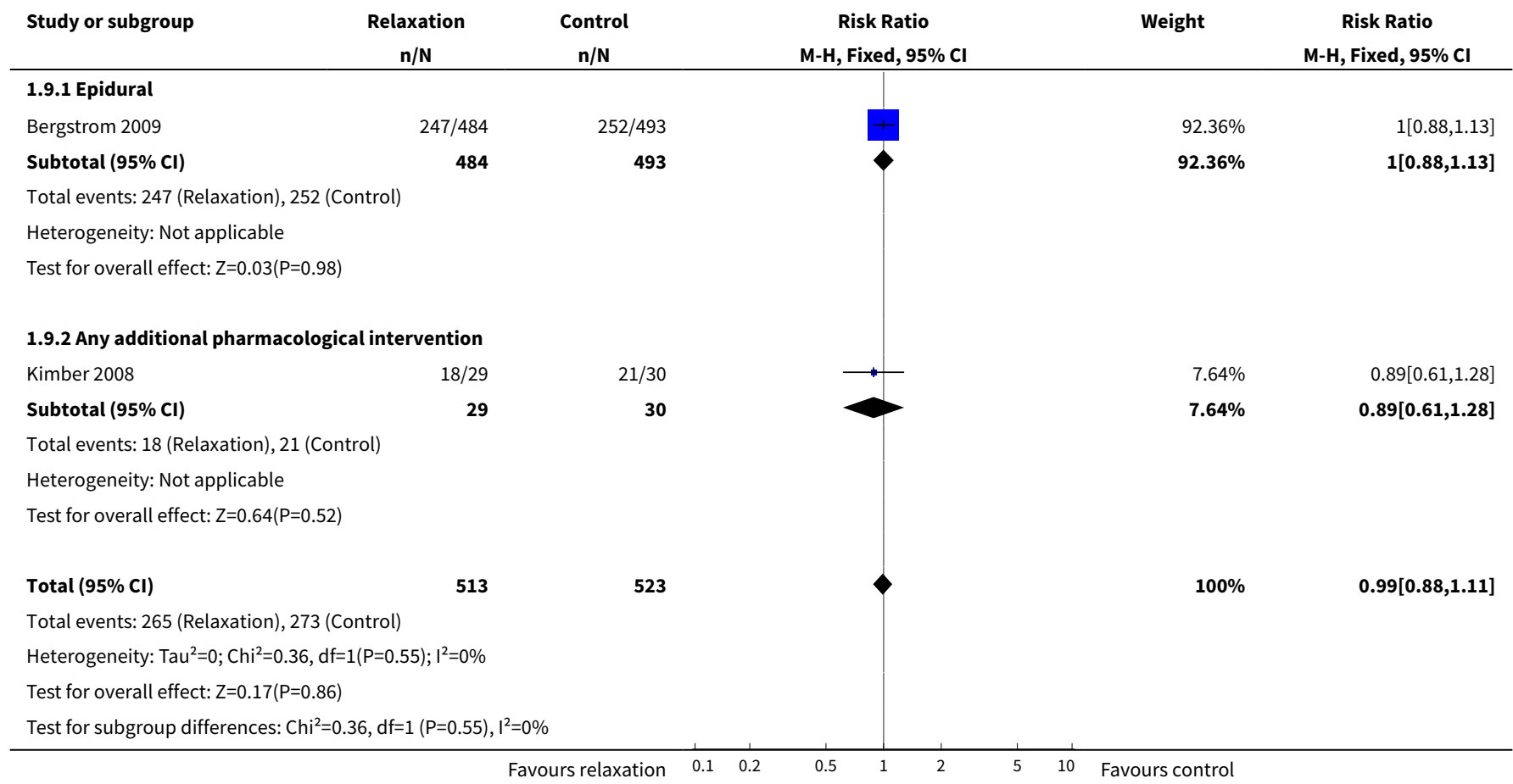

Analysis 1.10. Comparison 1 Relaxation versus usual care, Outcome 10 Length of labour.

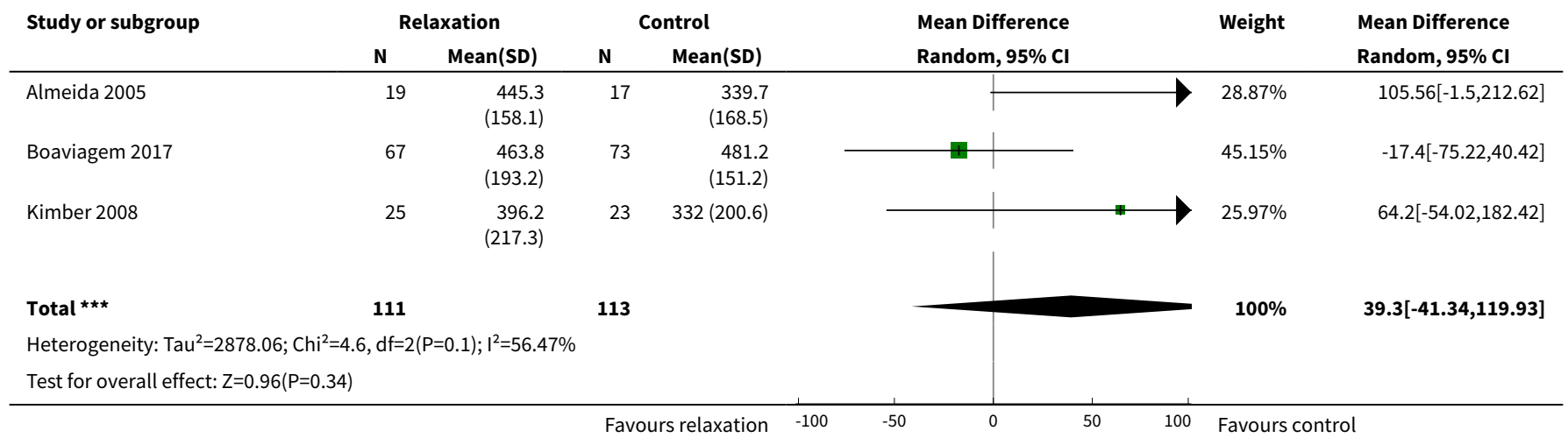




\section{Analysis 1.11. Comparison 1 Relaxation versus usual care, Outcome 11 Need for augmentation with oxytocin.}

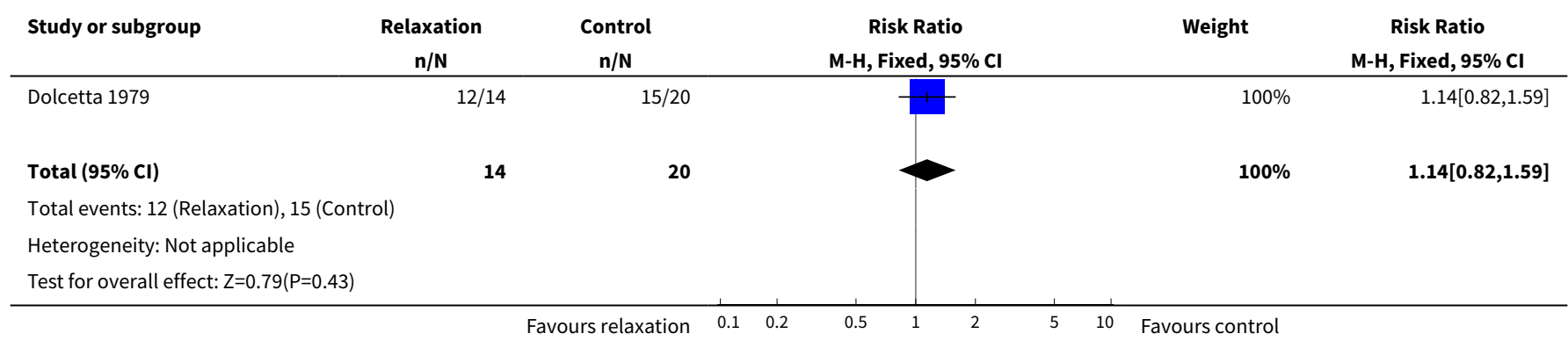

Analysis 1.12. Comparison 1 Relaxation versus usual care, Outcome 12 Anxiety.

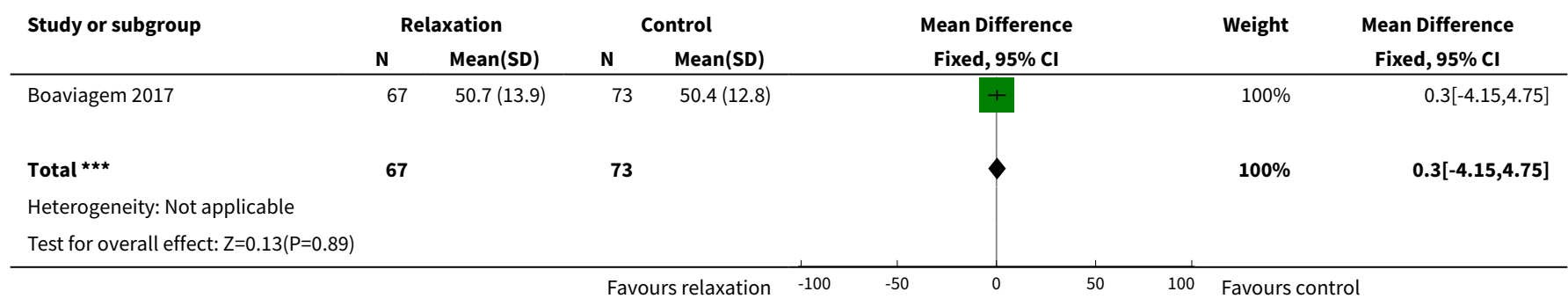

Analysis 1.13. Comparison 1 Relaxation versus usual care, Outcome 13 Non-prespecified: vitality.

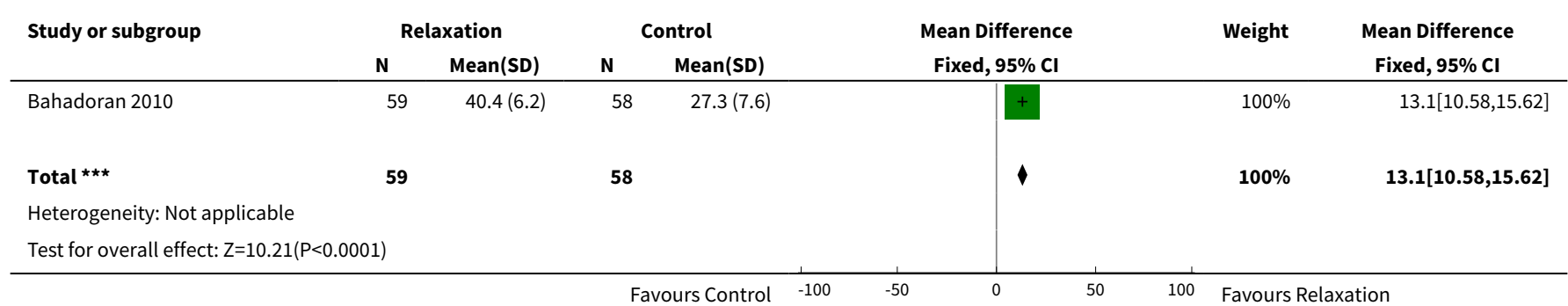

Analysis 1.14. Comparison 1 Relaxation versus usual care, Outcome 14 Non-prespecified: fatigue in labour.

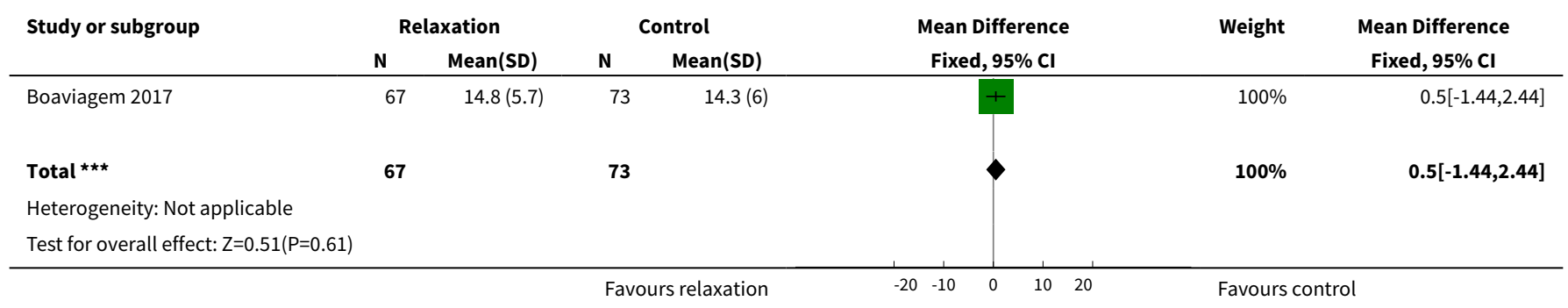


Comparison 2. Yoga versus control

\begin{tabular}{|c|c|c|c|c|}
\hline $\begin{array}{l}\text { Outcome or subgroup ti- } \\
\text { tle }\end{array}$ & No. of studies & $\begin{array}{l}\text { No. of partici- } \\
\text { pants }\end{array}$ & Statistical method & Effect size \\
\hline 1 Pain intensity & 1 & 66 & Mean Difference (IV, Fixed, 95\% Cl) & $-6.12[-11.77,-0.47]$ \\
\hline 1.1 Latent phase & 1 & 66 & Mean Difference (IV, Fixed, 95\% CI) & $-6.12[-11.77,-0.47]$ \\
\hline $\begin{array}{l}2 \text { Satisfaction with pain re- } \\
\text { lief }\end{array}$ & 1 & 66 & Mean Difference (IV, Fixed, 95\% CI) & $7.88[1.51,14.25]$ \\
\hline 2.1 Latent phase & 1 & 66 & Mean Difference (IV, Fixed, 95\% CI) & $7.88[1.51,14.25]$ \\
\hline $\begin{array}{l}3 \text { Satisfaction with child- } \\
\text { birth experience }\end{array}$ & 1 & 66 & Mean Difference (IV, Fixed, 95\% CI) & $6.34[0.26,12.42]$ \\
\hline $\begin{array}{l}4 \text { Low Apgar score }<7 \text { at } 5 \\
\text { minutes }\end{array}$ & 1 & 66 & Risk Ratio (M-H, Fixed, 95\% Cl) & $0.0[0.0,0.0]$ \\
\hline $\begin{array}{l}5 \text { Use of pharmacological } \\
\text { pain relief }\end{array}$ & 2 & & Risk Ratio (M-H, Fixed, 95\% Cl) & Subtotals only \\
\hline 5.1 Usual care & 1 & 66 & Risk Ratio (M-H, Fixed, 95\% Cl) & $0.82[0.49,1.38]$ \\
\hline 5.2 Supine position & 1 & 83 & Risk Ratio (M-H, Fixed, 95\% Cl) & $0.05[0.01,0.35]$ \\
\hline 6 Length of labour & 2 & & Mean Difference (IV, Fixed, 95\% CI) & Subtotals only \\
\hline 6.1 Usual care & 1 & 66 & Mean Difference (IV, Fixed, 95\% CI) & $\begin{array}{l}-139.91[-252.50 \\
-27.32]\end{array}$ \\
\hline 6.2 Supine position & 1 & 83 & Mean Difference (IV, Fixed, 95\% CI) & $\begin{array}{l}-191.34[-243.72 \\
-138.96]\end{array}$ \\
\hline $\begin{array}{l}7 \text { Need for augmentation } \\
\text { with oxytocin }\end{array}$ & 1 & 66 & Risk Ratio (M-H, Fixed, 95\% Cl) & $0.76[0.45,1.31]$ \\
\hline
\end{tabular}

Analysis 2.1. Comparison 2 Yoga versus control, Outcome 1 Pain intensity.

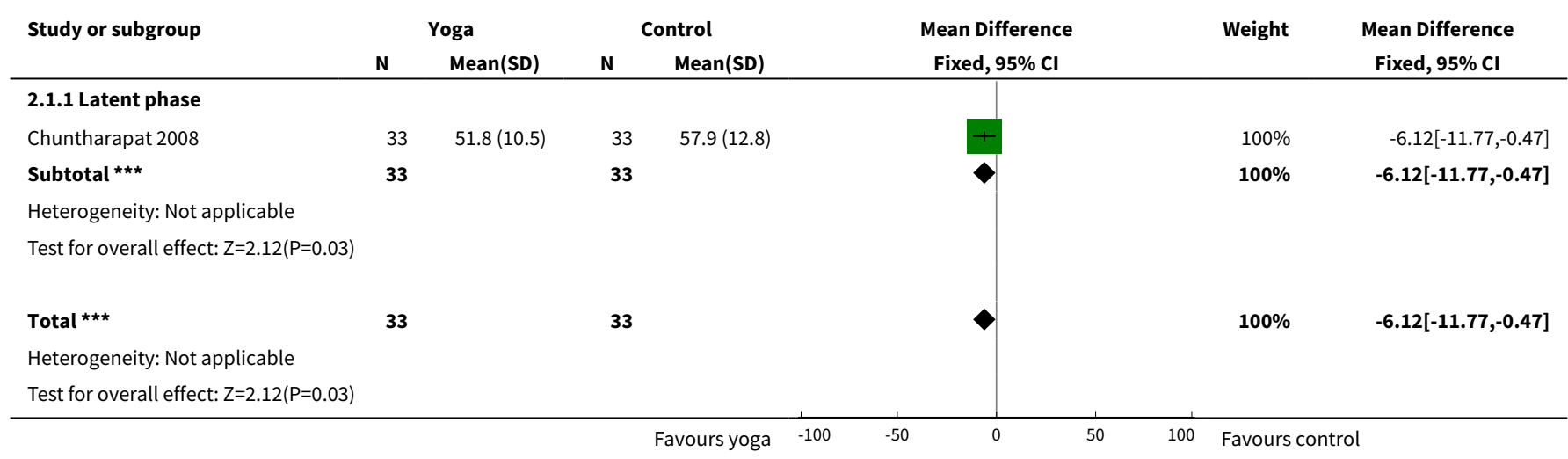


Analysis 2.2. Comparison 2 Yoga versus control, Outcome 2 Satisfaction with pain relief.

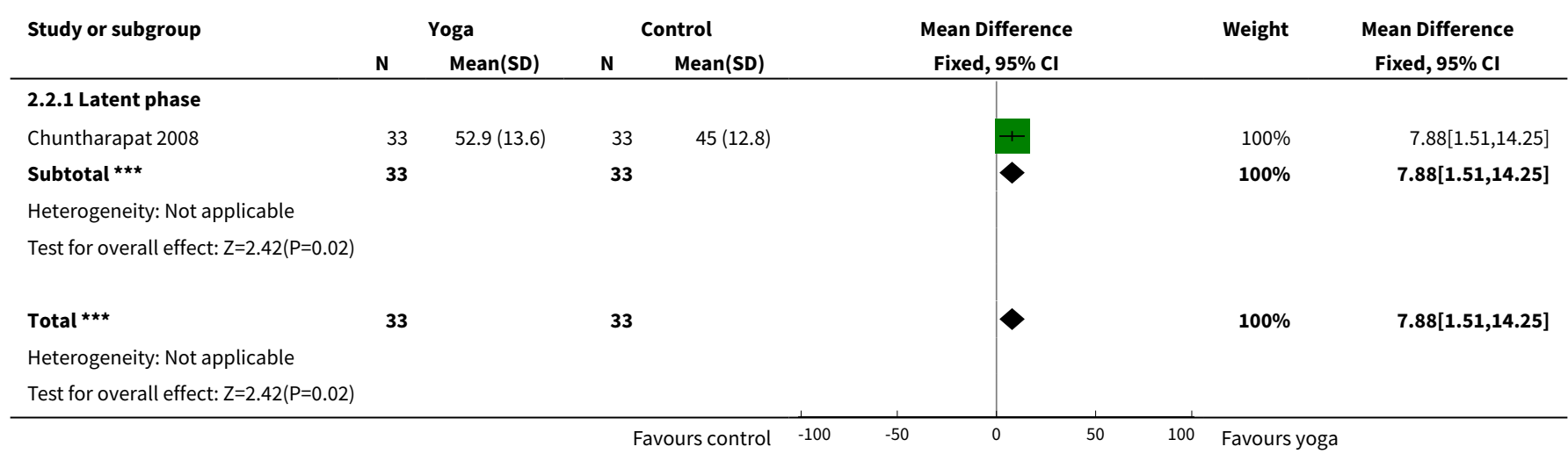

Analysis 2.3. Comparison 2 Yoga versus control, Outcome 3 Satisfaction with childbirth experience.

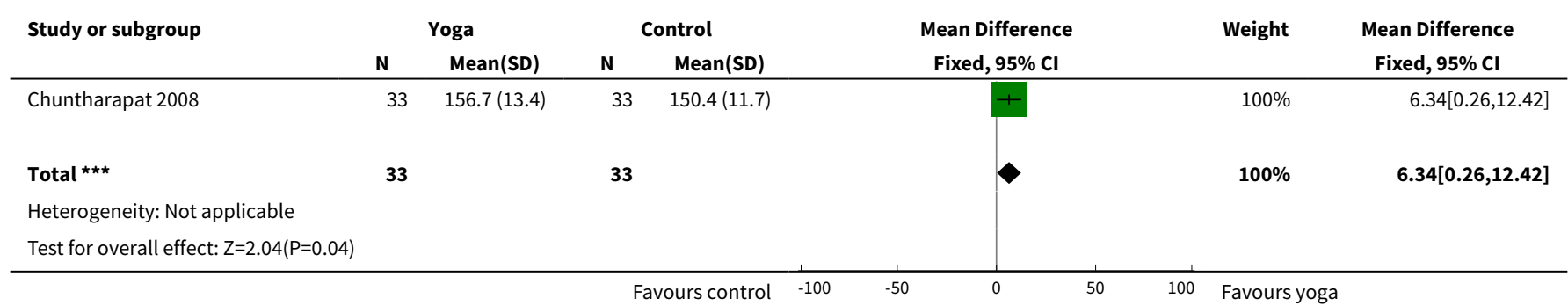

Analysis 2.4. Comparison 2 Yoga versus control, Outcome 4 Low Apgar score $<7$ at 5 minutes.

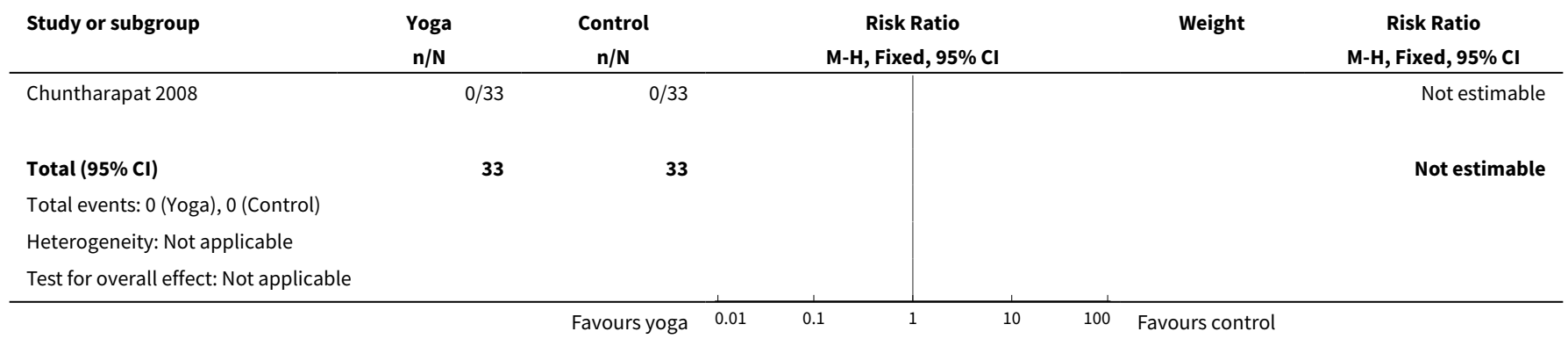

Analysis 2.5. Comparison 2 Yoga versus control, Outcome 5 Use of pharmacological pain relief.

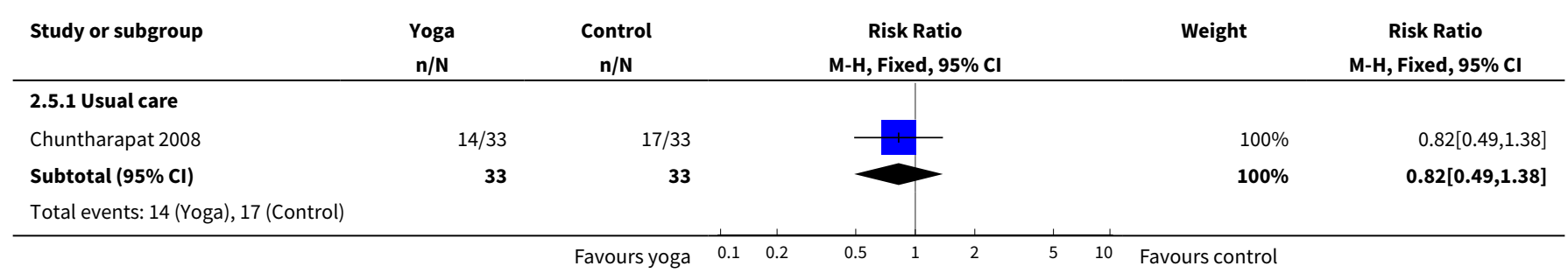




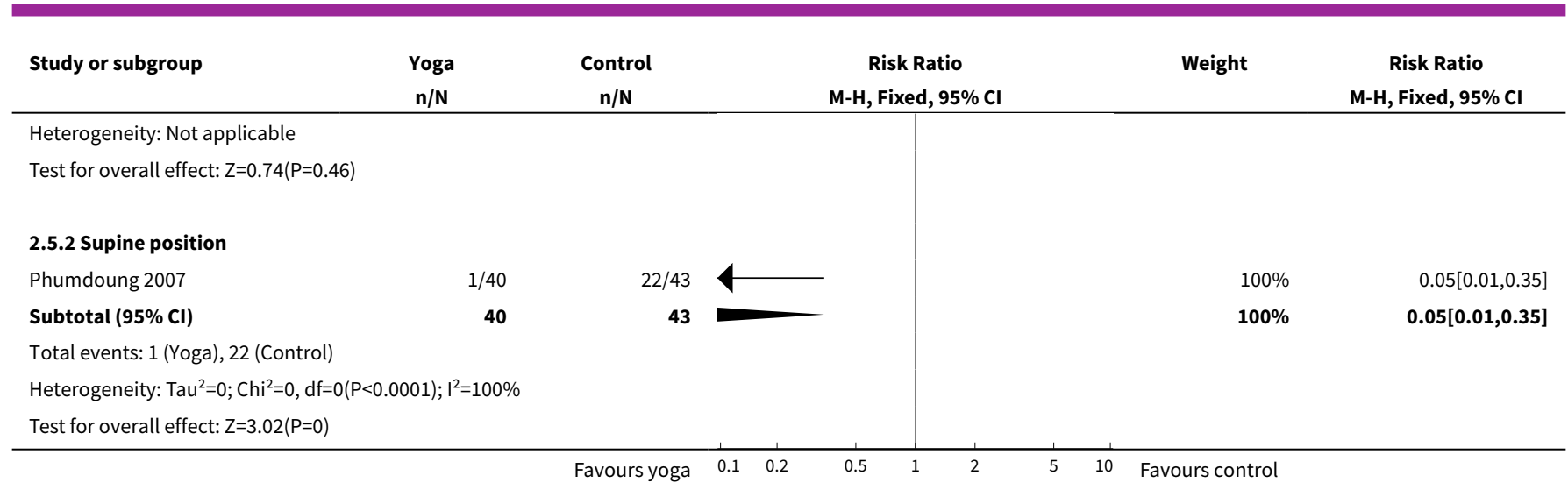

Analysis 2.6. Comparison 2 Yoga versus control, Outcome 6 Length of labour.

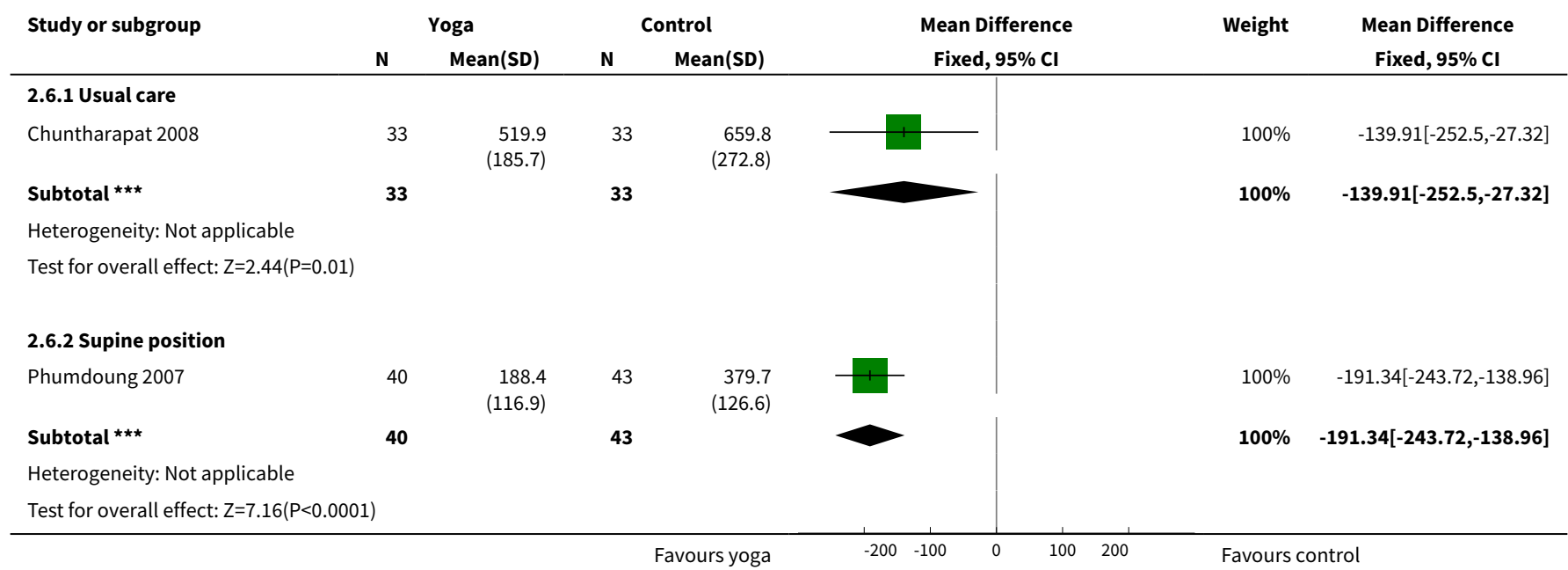

Analysis 2.7. Comparison 2 Yoga versus control, Outcome 7 Need for augmentation with oxytocin.

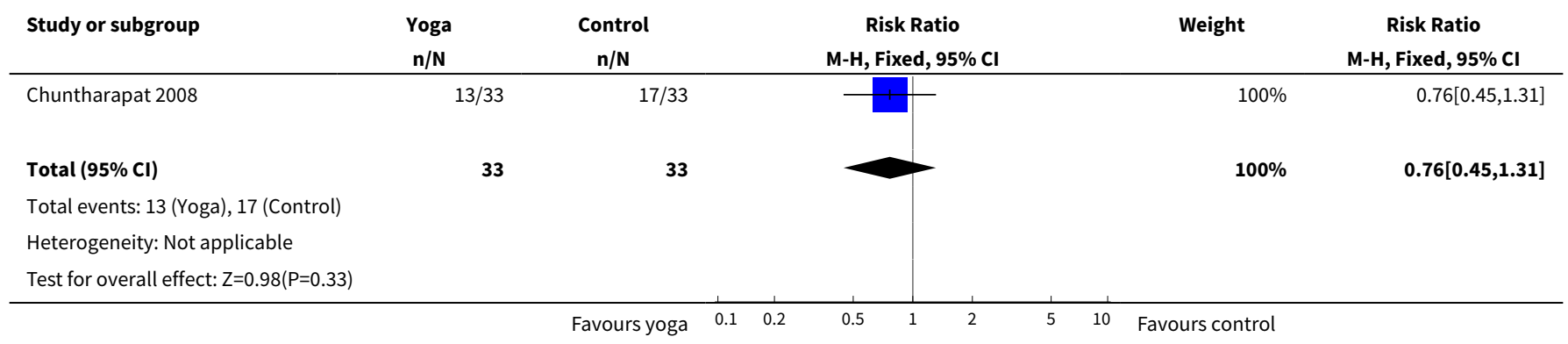


Comparison 3. Music versus control

\begin{tabular}{|c|c|c|c|c|}
\hline $\begin{array}{l}\text { Outcome or subgroup } \\
\text { title }\end{array}$ & No. of studies & $\begin{array}{l}\text { No. of partici- } \\
\text { pants }\end{array}$ & Statistical method & Effect size \\
\hline 1 Pain intensity & 3 & & Mean Difference (IV, Random, 95\% CI) & Subtotals only \\
\hline 1.1 Latent phase & 2 & 192 & Mean Difference (IV, Random, 95\% CI) & $-0.73[-1.01,-0.45]$ \\
\hline 1.2 Active phase & 3 & 217 & Mean Difference (IV, Random, 95\% CI) & $-0.51[-1.10,0.07]$ \\
\hline 1.3 Transition & 1 & 132 & Mean Difference (IV, Random, 95\% CI) & $-0.70[-0.86,-0.54]$ \\
\hline 2 Assisted vaginal birth & 1 & 156 & Risk Ratio (M-H, Fixed, 95\% Cl) & $0.41[0.08,2.05]$ \\
\hline 3 Caesarean section & 2 & 216 & Risk Ratio (M-H, Fixed, 95\% Cl) & $0.78[0.36,1.70]$ \\
\hline $\begin{array}{l}4 \text { Admission to special } \\
\text { care nursery }\end{array}$ & 1 & 155 & Risk Ratio (M-H, Fixed, 95\% Cl) & $0.23[0.05,1.01]$ \\
\hline $\begin{array}{l}5 \text { Use of pharmacologi- } \\
\text { cal pain relief }\end{array}$ & 1 & 60 & Risk Ratio (M-H, Fixed, 95\% Cl) & $0.83[0.53,1.32]$ \\
\hline 6 Length of labour & 1 & 60 & Mean Difference (IV, Fixed, 95\% CI) & $-2.60[-11.58,6.38]$ \\
\hline 6.1 Second stage & 1 & 60 & Mean Difference (IV, Fixed, 95\% CI) & $-2.60[-11.58,6.38]$ \\
\hline 7 Anxiety & 2 & & Mean Difference (IV, Random, 95\% CI) & Subtotals only \\
\hline 7.1 Latent phase & 2 & 192 & Mean Difference (IV, Random, 95\% CI) & $0.08[-1.86,2.02]$ \\
\hline 7.2 Active phase & 2 & 192 & Mean Difference (IV, Random, 95\% CI) & $-0.30[-1.74,1.13]$ \\
\hline 7.3 Transition & 1 & 132 & Mean Difference (IV, Random, 95\% CI) & $-0.66[-0.82,-0.50]$ \\
\hline
\end{tabular}

Analysis 3.1. Comparison 3 Music versus control, Outcome 1 Pain intensity.

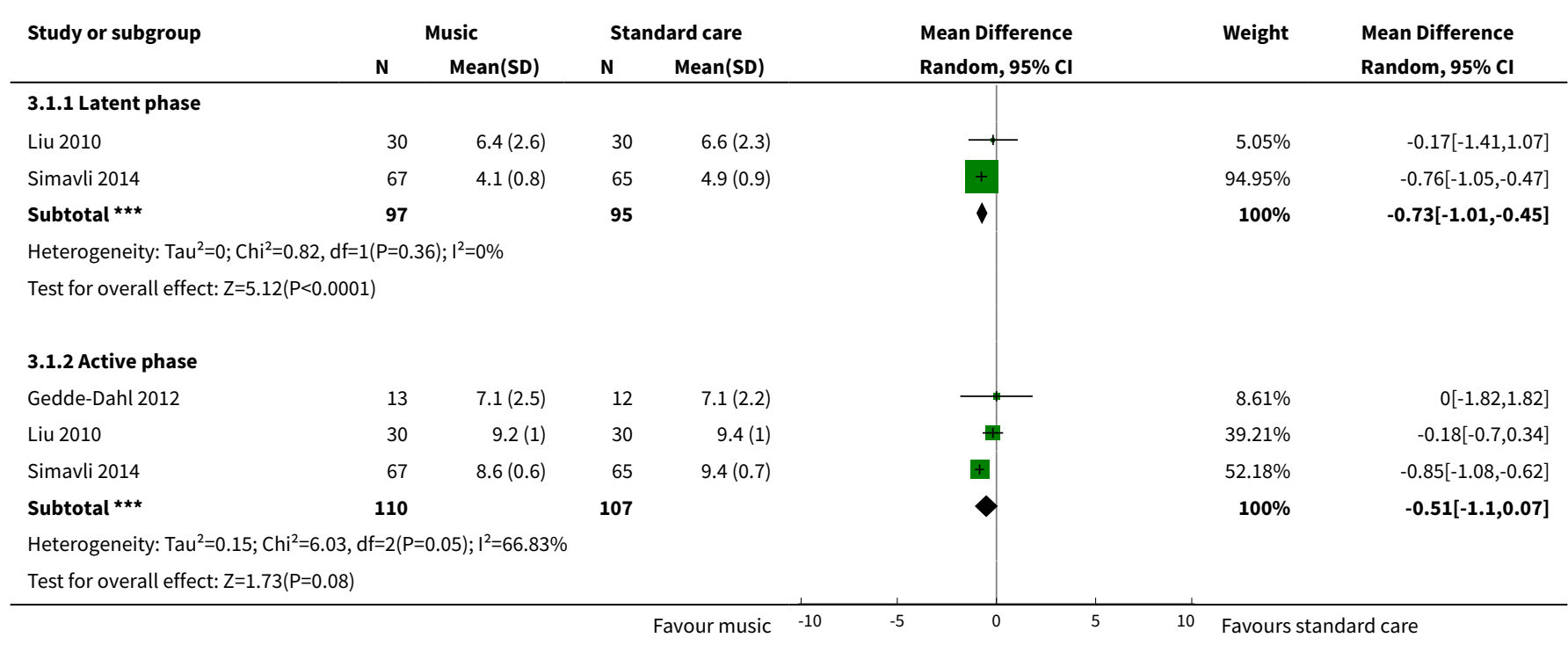




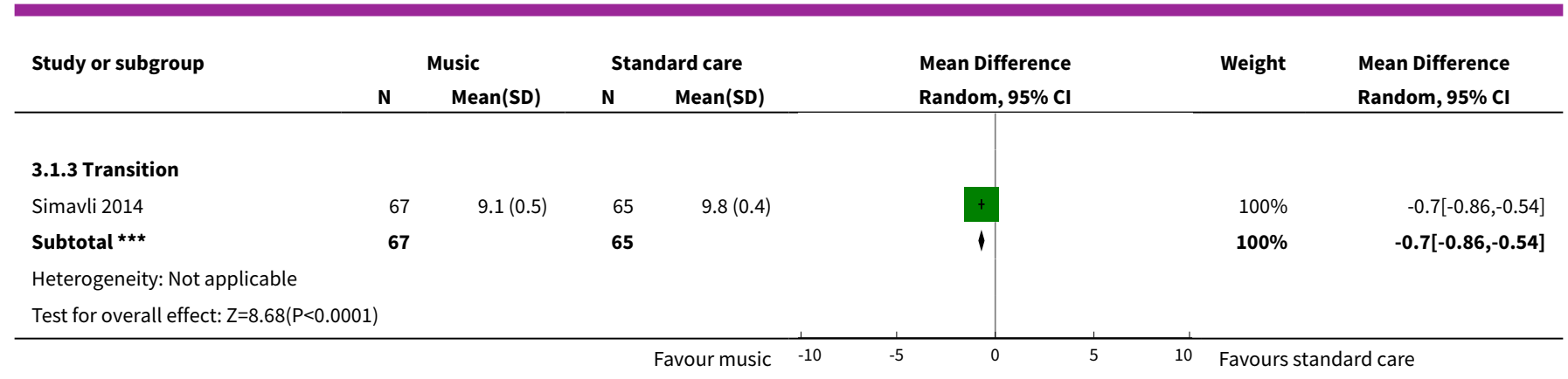

Analysis 3.2. Comparison 3 Music versus control, Outcome 2 Assisted vaginal birth.

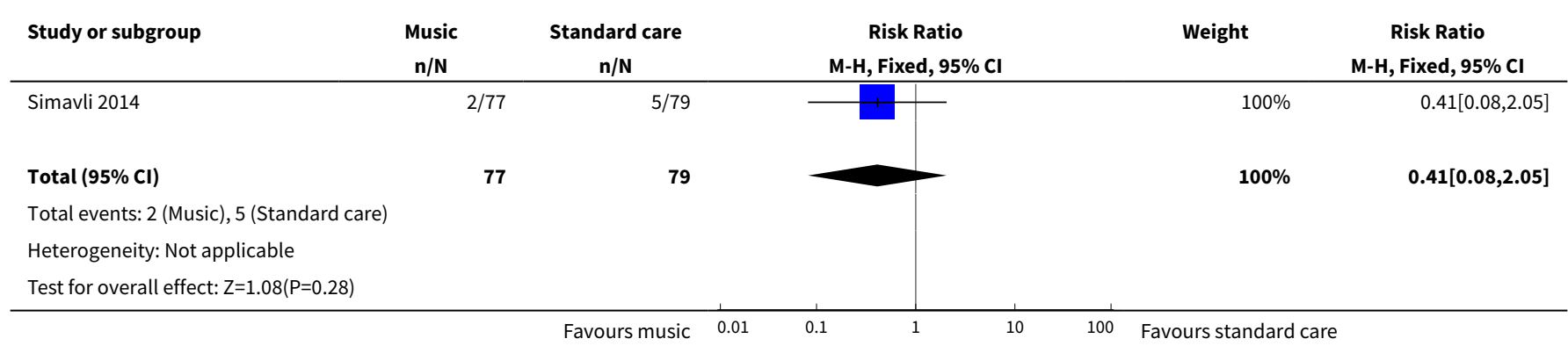

Analysis 3.3. Comparison 3 Music versus control, Outcome 3 Caesarean section.

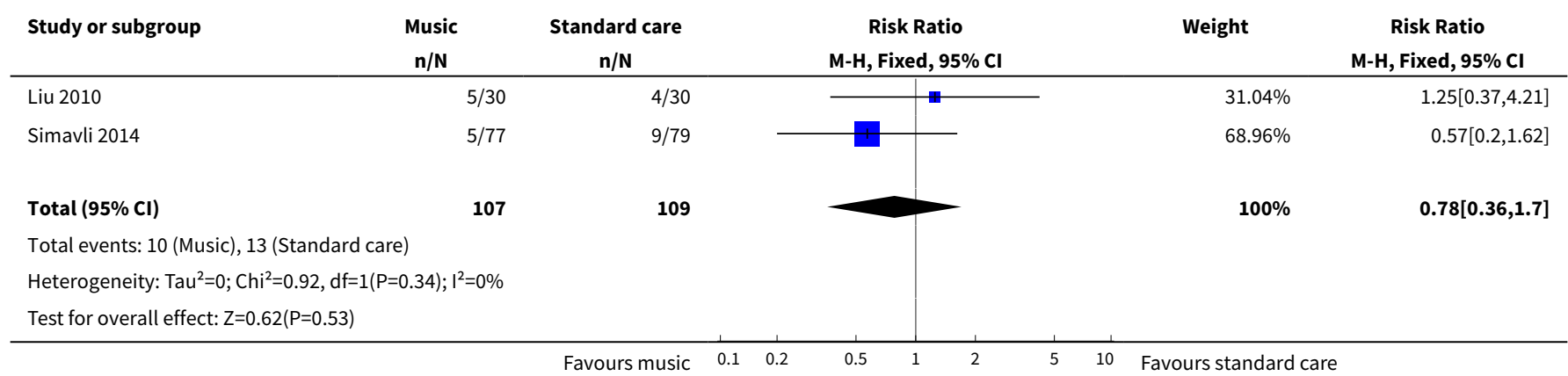

Analysis 3.4. Comparison 3 Music versus control, Outcome 4 Admission to special care nursery.

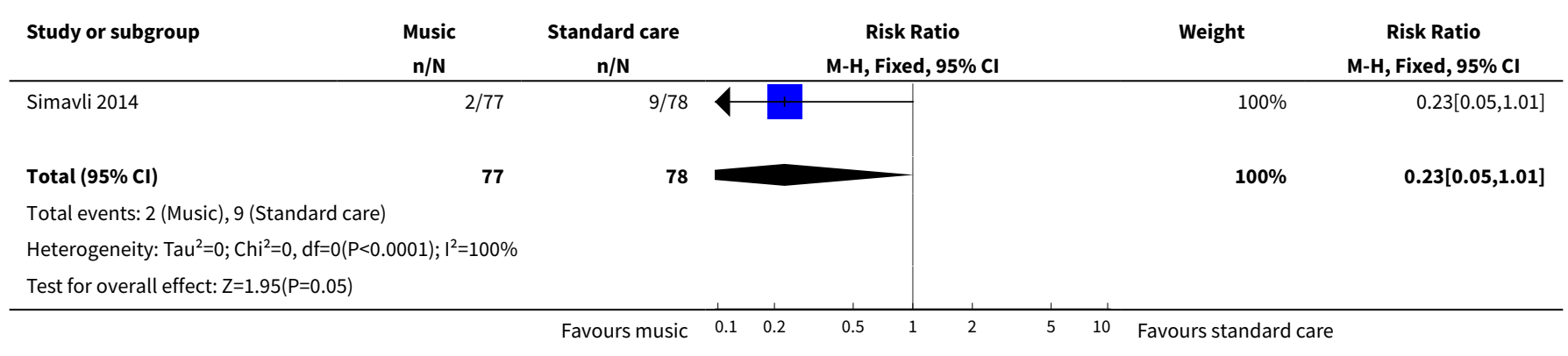


Analysis 3.5. Comparison 3 Music versus control, Outcome 5 Use of pharmacological pain relief.

\begin{tabular}{|c|c|c|c|c|c|}
\hline Study or subgroup & $\begin{array}{c}\text { Music } \\
n / N\end{array}$ & $\begin{array}{c}\text { Standard care } \\
n / N\end{array}$ & $\begin{array}{c}\text { Risk Ratio } \\
\text { M-H, Fixed, } 95 \% \mathrm{Cl}\end{array}$ & Weight & $\begin{array}{c}\text { Risk Ratio } \\
\text { M-H, Fixed, } 95 \% \text { Cl }\end{array}$ \\
\hline Liu 2010 & $15 / 30$ & $18 / 30$ & - & $100 \%$ & $0.83[0.53,1.32]$ \\
\hline Total $(95 \% \mathrm{Cl})$ & 30 & 30 & 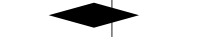 & $100 \%$ & $0.83[0.53,1.32]$ \\
\hline \multicolumn{6}{|c|}{ Total events: 15 (Music), 18 (Standard care) } \\
\hline \multicolumn{6}{|c|}{ Heterogeneity: Not applicable } \\
\hline Test for overall effec & & & & & \\
\hline
\end{tabular}

Analysis 3.6. Comparison 3 Music versus control, Outcome 6 Length of labour.

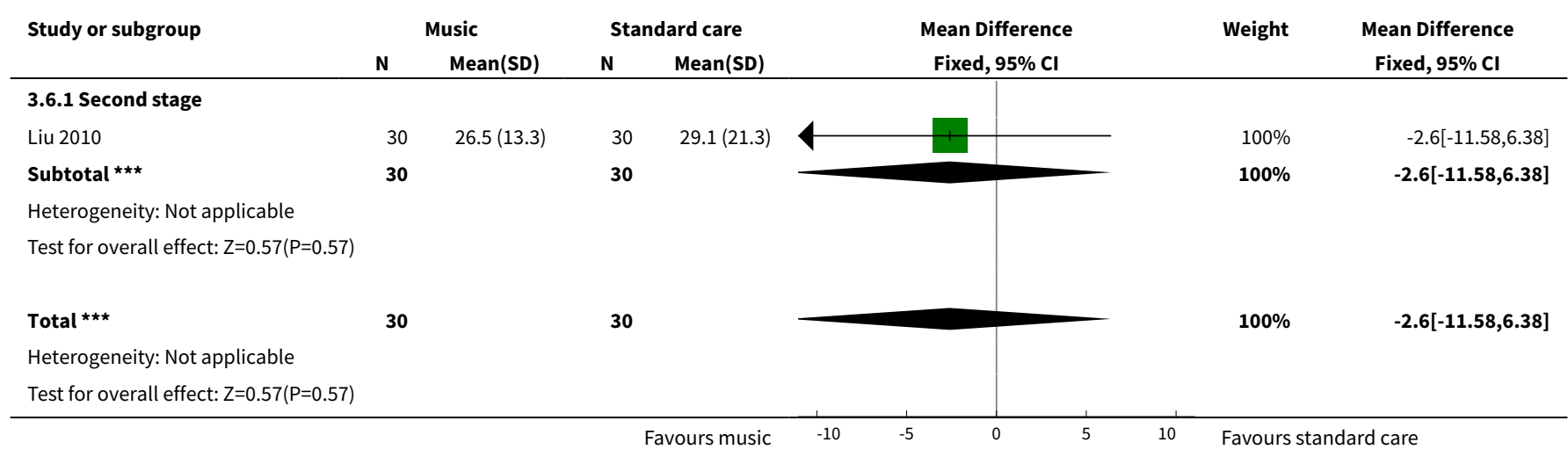

Analysis 3.7. Comparison 3 Music versus control, Outcome 7 Anxiety.

\begin{tabular}{|c|c|c|c|c|c|c|c|}
\hline \multirow{2}{*}{ Study or subgroup } & \multicolumn{2}{|c|}{ Music } & \multicolumn{2}{|c|}{ Standard care } & \multirow{2}{*}{$\begin{array}{l}\text { Mean Difference } \\
\text { Random, } 95 \% \mathrm{CI}\end{array}$} & \multirow[t]{2}{*}{ Weight } & \multirow{2}{*}{$\begin{array}{l}\text { Mean Difference } \\
\text { Random, } 95 \% \mathrm{Cl}\end{array}$} \\
\hline & $\mathbf{N}$ & Mean(SD) & $\mathbf{N}$ & $\operatorname{Mean}(\mathrm{SD})$ & & & \\
\hline \multicolumn{8}{|l|}{ 3.7.1 Latent phase } \\
\hline Liu 2010 & 30 & $6.4(3)$ & 30 & $5.2(2.2)$ & + & $44.58 \%$ & $1.18[-0.13,2.49]$ \\
\hline Simavli 2014 & 67 & $4.3(0.8)$ & 65 & $5.1(0.9)$ & + & $55.42 \%$ & $-0.81[-1.09,-0.53]$ \\
\hline Subtotal $\star \star \star \star$ & 97 & & 95 & & & $100 \%$ & $0.08[-1.86,2.02]$ \\
\hline \multicolumn{8}{|c|}{ Heterogeneity: $\operatorname{Tau}^{2}=1.74 ; \mathrm{Chi}^{2}=8.41, \mathrm{df}=1(\mathrm{P}=0) ; \mathrm{I}^{2}=88.11 \%$} \\
\hline \multicolumn{8}{|c|}{ Test for overall effect: $Z=0.08(P=0.94)$} \\
\hline \multicolumn{8}{|l|}{ 3.7.2 Active phase } \\
\hline Liu 2010 & 30 & $8.2(2.3)$ & 30 & $7.7(2.1)$ & & $43.08 \%$ & $0.54[-0.56,1.64]$ \\
\hline Simavli 2014 & 67 & $8.5(0.7)$ & 65 & $9.4(0.7)$ & 7 & $56.92 \%$ & $-0.94[-1.17,-0.71]$ \\
\hline Subtotal $\star \star \star$ & 97 & & 95 & & & $100 \%$ & $-0.3[-1.74,1.13]$ \\
\hline \multicolumn{8}{|c|}{ Heterogeneity: $\operatorname{Tau}^{2}=0.93 ; \mathrm{Chi}^{2}=6.61, \mathrm{df}=1(\mathrm{P}=0.01) ; \mathrm{I}^{2}=84.87 \%$} \\
\hline \multicolumn{8}{|c|}{ Test for overall effect: $Z=0.41(P=0.68)$} \\
\hline \multicolumn{8}{|l|}{ 3.7.3 Transition } \\
\hline Simavli 2014 & 67 & $9.1(0.6)$ & 65 & $9.8(0.4)$ & + & $100 \%$ & $-0.66[-0.82,-0.5]$ \\
\hline
\end{tabular}




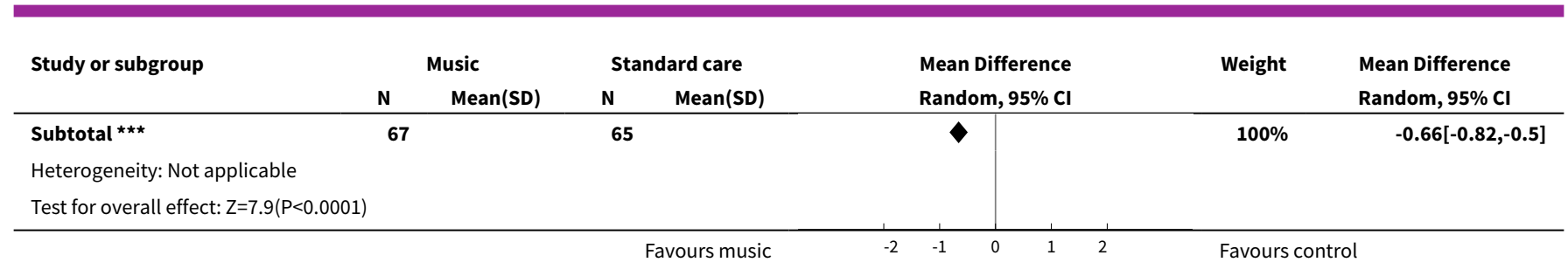

\section{Comparison 4. Audio-analgesia versus control}

\begin{tabular}{lllll}
\hline Outcome or subgroup title & No. of studies & $\begin{array}{l}\text { No. of partici- } \\
\text { pants }\end{array}$ & Statistical method & Effect size \\
\hline 1 Satisfaction with pain relief & 1 & 24 & Risk Ratio (M-H, Fixed, 95\% Cl) & $2.0[0.82,4.89]$ \\
\hline
\end{tabular}

Analysis 4.1. Comparison 4 Audio-analgesia versus control, Outcome 1 Satisfaction with pain relief.

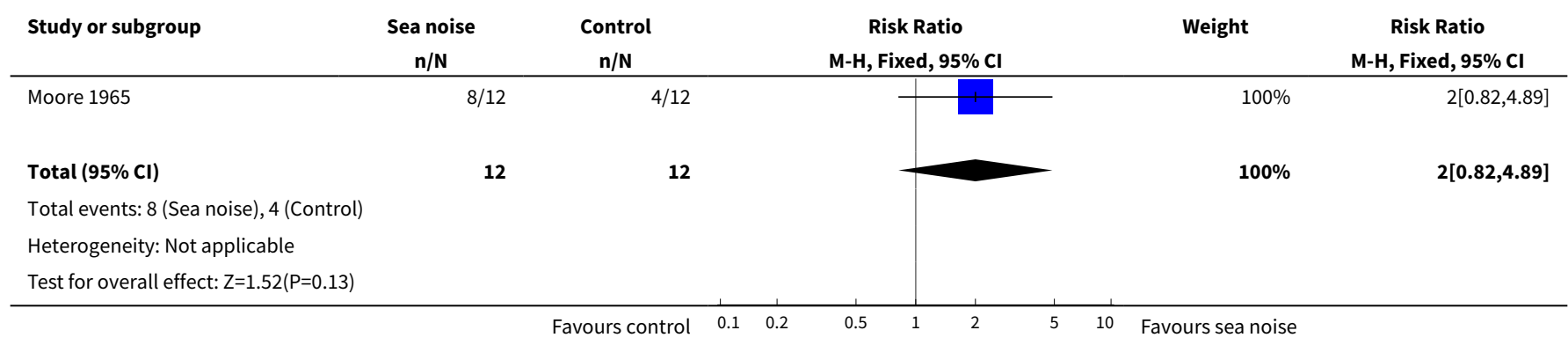

\section{Comparison 5. Mindfulness training versus usual care}

\begin{tabular}{llllll}
\hline Outcome or subgroup title & No. of studies & $\begin{array}{l}\text { No. of partici- } \\
\text { pants }\end{array}$ & Statistical method & Effect size \\
\hline 1 Sense of control in labour & 1 & 26 & Mean Difference (IV, Fixed, 95\% Cl) & $31.30[1.61,60.99]$ \\
\hline 2 Satisfaction with childbirth & 1 & 26 & Mean Difference (IV, Fixed, 95\% Cl) & $-4.5[-17.61,8.61]$ \\
\hline 3 Assisted vaginal birth & 1 & 29 & Risk Ratio (M-H, Fixed, 95\% Cl) & $0.31[0.01,7.09]$ \\
\hline 4 Caesarean section & 1 & 29 & Risk Ratio (M-H, Fixed, 95\% Cl) & $0.93[0.15,5.76]$ \\
\hline $\begin{array}{l}5 \text { Need for pharmacological } \\
\text { pain relief }\end{array}$ & 1 & 26 & Risk Ratio (M-H, Fixed, 95\% Cl) & $0.5[0.20,1.26]$ \\
\hline
\end{tabular}


Analysis 5.1. Comparison 5 Mindfulness training versus usual care, Outcome 1 Sense of control in labour.

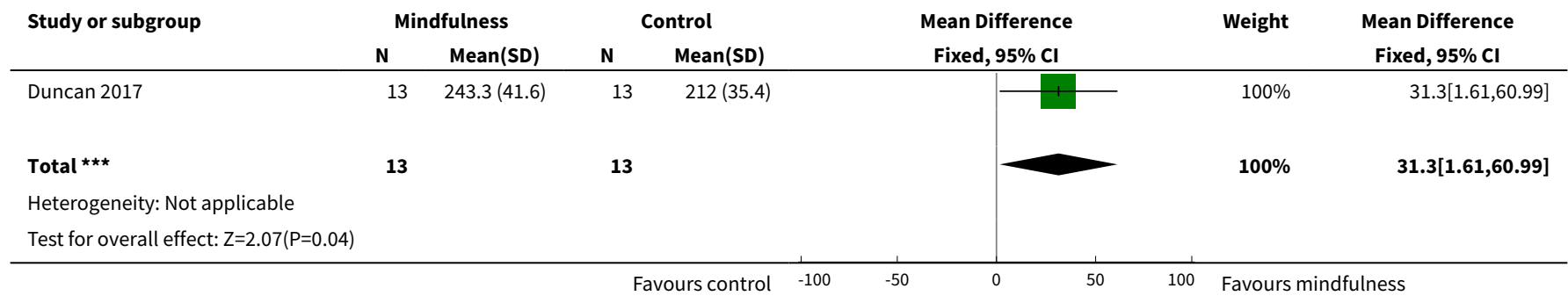

Analysis 5.2. Comparison 5 Mindfulness training versus usual care, Outcome 2 Satisfaction with childbirth.

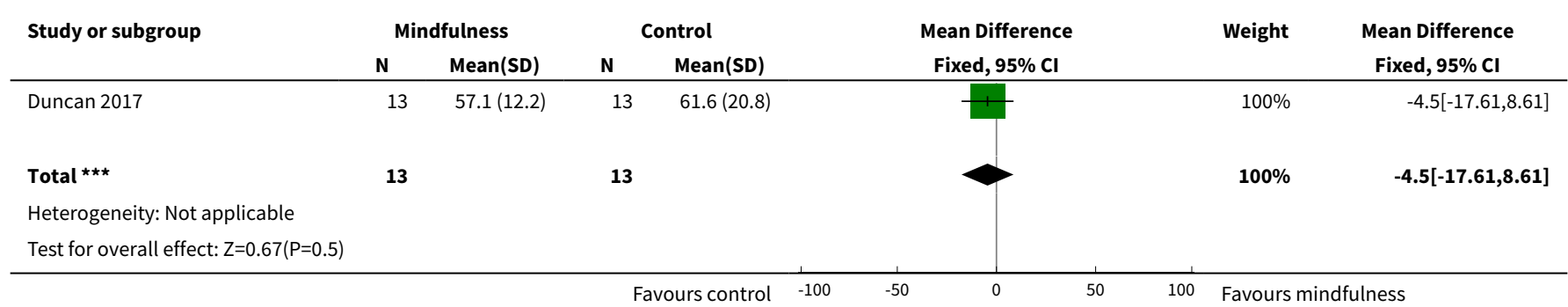

Analysis 5.3. Comparison 5 Mindfulness training versus usual care, Outcome 3 Assisted vaginal birth.

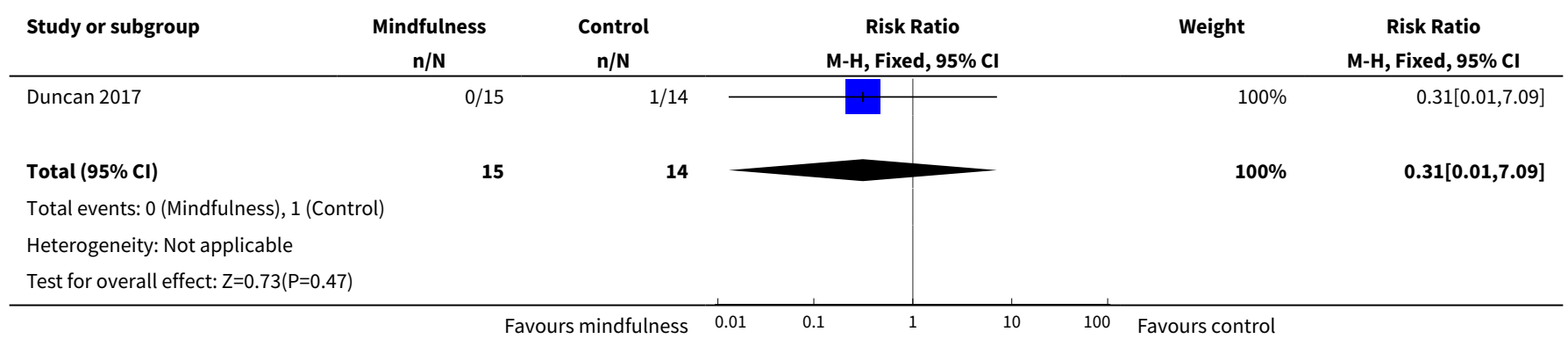

Analysis 5.4. Comparison 5 Mindfulness training versus usual care, Outcome 4 Caesarean section.

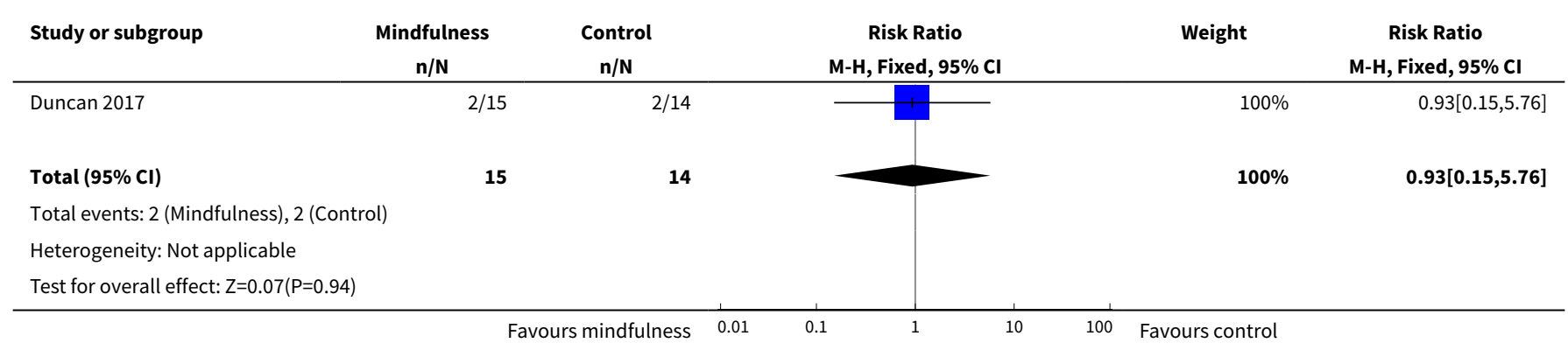


Analysis 5.5. Comparison 5 Mindfulness training versus usual care, Outcome 5 Need for pharmacological pain relief.

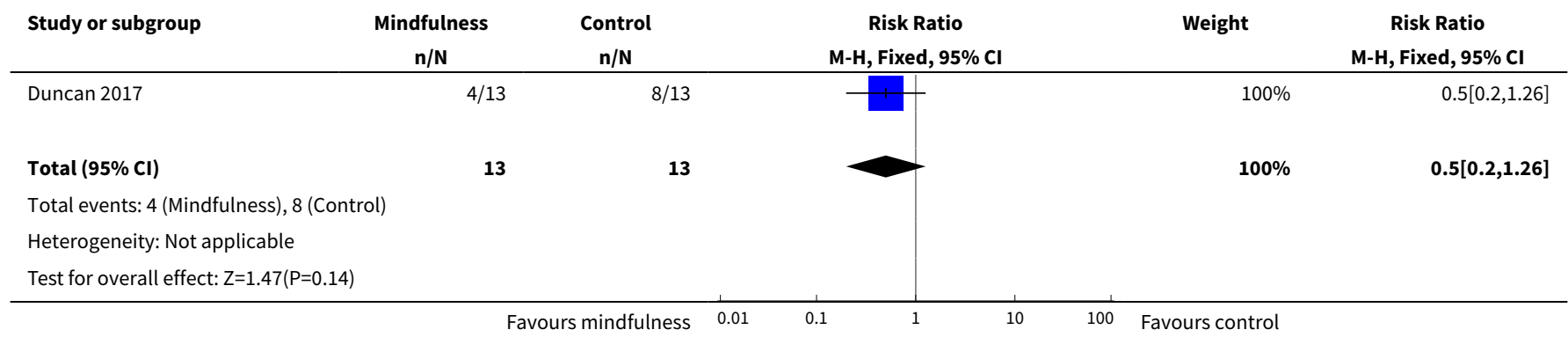

\section{APPEN DICES}

\section{Appendix 1. CENTRAL search strategy}

(Written and run by review authors)

\#1 (labor or labour):ti,ab,kw

\#2 Labo*r

\#3 (childbirth or child-birth or child birth) in Clinical Trials

\#4 midwife*in Clinical Trial

\#5 obstetric* in Clinical Trials*

\#6 labo*r pain in Clinical Trials

\#7 pain*labo*r in Clinical Trials

\#8 contraction* in Clinical trials

\#9 Pain management in Clinical Trials

\#10 pain* manage* in Clinical Trials

\#11 (\#1 OR \#2 OR \#3 OR \#4 OR \#5 \#6 OR \#7 OR \#8 OR \#9 OR \#10)

\#12 MeSH descriptor Relaxation explode all trees

\#13 yoga in Clinical Trials

\#14 meditation in Clinical Trials

\#15 imagery in Clinical trials

\#16 visuali*ation in Clinical Trials

\#17 breathing exercises in Clinical Trials

\#18 music in Clinical Trials

\#19 (\#12 OR \#13 OR \#14 OR \#15 OR \#16 OR \#17 OR \#18)

\#20 (\#11 AND \#19)

\section{Appendix 2. MEDLINE search strategy}

(Written and run by review authors) 
1. yoga.mp. or exp Yoga/

2. meditation.mp. or exp Meditation/

3. imagery.mp. or exp "Imagery (Psychotherapy)"/

4. visualisation.mp.

5. 3 or 4

6. exp Relaxation/ or relaxation.mp.

7. breathing exercises.mp. or exp Breathing Exercises/

8. exp Music/ or music.mp.

9. 1 or 2 or 5 or 6 or 7 or 8

10. exp Labor, Obstetric/ or exp Labor Presentation/ or exp Labor, Induced/ or exp Labor Pain/ or labo*r.mp. or exp Labor Onset/ or exp Labor Stage, First/

11. (childbirth or child birth or child-birth).tw.

12. (labour or labor).ab.

13. pain\$.mp.

14. pain manag\$.mp. or exp Pain/

15. exp Labor, Obstetric/ or labo*r.mp.

16. or/10-154

17. 9 and 16

18. randomi ${ }^{\star}$ ed controlled trial.pt.

19. controlled clinical trial.pt.

20. (randomised or randomised).ab.

21. placebo.ab.

22. drug therapy.fs.

23. randomly.ab.

24. trial.ab.

25. groups.ab.

26. or $/ 18-25$

27. (animals not (humans and animals)).sh.

28. 26 not 27

29. 17 and 28

\section{Appendix 3. CINAHL search strategy}

(Written and run by review authors)

S28. S25 and S26 and S27

$\mathrm{S} 27 . \mathrm{S} 7$ or $\mathrm{S} 8$ or $\mathrm{S} 9$ or $\mathrm{S} 10$ or $\mathrm{S} 11$ or $\mathrm{S} 12$ or $\mathrm{S} 13$ or $\mathrm{S} 14$ or $\mathrm{S} 15$ or $\mathrm{S} 16$ or $\mathrm{S} 17$

$\mathrm{S} 26 . \mathrm{S} 1$ or S2 or S3 or S4 or S5 or S6

Relaxation techniques for pain management in labour (Review) 
$\mathrm{S} 25 . \mathrm{S} 18$ or $\mathrm{S} 19$ or $\mathrm{S} 20$ or S21 or S22 or S23 or S24

S24. clinical trials

S23. Randomi ${ }^{\star}$ ed control\# trial\#

S22. random assignment

S21. random\# allocation

S20. placebo\#

S19. placebos/

S18. quantitative studies/

S17. AB(labo*r pain)

$\mathrm{S} 16 . \mathrm{AB}$ (pain or labo* ${ }^{\star}$ pain)

S15. AB pain\# manage\#

S14. AB pain\#

S13. AB midwife\#

S12. AB midwi\#

S11. AB obstetric\#

S10. AB (childbirth or child birth or child-birth)

S9. AB labor or labour

S8. MW labor or labour

S7. labor or labour

S6. MW music

S5. MW breathing exercises

S4. MW relaxation

S3. MW imagery or MW visuali*ation

S2. MW meditation\#

S1. MW yoga

\section{Appendix 4. Clinical Trials Registry searches}

(Written and run by review authors)

We used the following search terms: obstetrics; labor; labour; birth; pain each combined with the terms yoga; meditation; imagery; visualisation; relaxation; breathing exercises; music, using the Boolean operator AND

\section{WHAT'S NEW}

Date Event Description

9 May $2017 \quad$ New search has been performed

Search updated. Eight new studies have been included in this update (Bahadoran 2010; Boaviagem 2017; Dizavandi 2012; Duncan 2017; Gedde-Dahl 2012; Hosseini 2013; Kimber 2008; Simavli 2014). Three 'Summary of findings' tables have been incorporated. 


\begin{tabular}{lll}
\hline Date & Event & Description \\
\hline 9 May 2017 & $\begin{array}{l}\text { New citation required but conclusions } \\
\text { have not changed }\end{array}$ & Relaxation therapies may be helpful, further trials are needed \\
\hline
\end{tabular}

\section{CONTRIBUTIONS OF AUTHORS}

Caroline Smith and Carmel Collins conceptualised and wrote the protocol, reviewed trials, performed data extraction and jointly wrote the review and its update.

Kate Levett reviewed trials, performed data extraction and jointly wrote the review and its update.

Mike Armour undertook additional searches, data extraction, reviewed trials, prepared the 'Summary of findings' tables and commented on the draft of the paper.

Machiko Suganuma, reviewed trials and commented on the draft.

Hannah Dahlen contributed to the discussion and conclusion.

Caroline Smith is the guarantor of the review.

\section{DECLARATIONS OF INTEREST}

Caroline A Smith: as a medical research institute, National Institute of Complementary Medicine (NICM) receives research grants and donations from foundations, universities, government agencies and industry. Sponsors and donors provide untied and tied funding for work to advance the vision and mission of the Institute. This systematic review was not specifically supported by donor or sponsor funding to NICM.

Kate M Levett: is employed at The University of Notre Dame, School of Medicine, and as a medical school receives research grants and donations from Foundations, Government agencies and industry. Kate Levett offers private acupressure for labour and birth education classes in Sydney Australia, these classes include complementary therapy strategies, such as relaxation and massage, for pain relief in labour.

Carmel T Collins: none known.

Mike Armour: is an acupuncturist, not current in clinical practice and until recently was a director of an acupuncture and physiotherapy clinic. As a medical research institute, National Institute of Complementary Medicine (NICM) receives research grants and donations from foundations, universities, government agencies and industry. Sponsors and donors provide untied and tied funding for work to advance the vision and mission of the Institute. This systematic review was not specifically supported by donor or sponsor funding to NICM.

Hannah G Dahlen: none known

Machiko Suganuma: none known.

\section{SOURCES OF SUPPORT}

\section{Internal sources}

- NICM, Western Sydney University, Australia.

- Women's and Children's Health Research Institute, Flinders Medical Centre South Australia, Australia.

- Children, Youth and Women's Health Services, Adelaide, Australia.

- The University of Adelaide, Adelaide, Australia.

\section{External sources}

- WHO UNDP-UNFPA-UNICEF-WHO-World Bank Special Programme of Research, Development and Research Training in Human Reproduction (HRP), Department of Reproductive Health and Research (RHR), World Health Organization, Switzerland.

\section{DIFFERENCES BETWEEN PROTOCOL AND REVIEW}

This updated review differs from the previously published Cochrane Review 'Complementary and alternative therapies for pain management in labour' (Smith 2006), which has now been revised to three separate reviews. 
In this update, 2017, we have incorporated three 'Summary of findings' tables.

\section{NOTES}

This new review is one of three which, collectively, update the previous review on a range of complementary therapies (Smith 2006). This review includes only trials of relaxation techniques.

\section{INDEX TERMS}

\section{Medical Subject Headings (MeSH)}

Analgesia, Obstetrical [ ${ }^{\star}$ methods]; Cesarean Section [statistics \& numerical data]; Labor Pain [ ${ }^{\star}$ therapy]; Mindfulness; Music Therapy; Pain Management [ ${ }^{\star}$ methods]; Pain Measurement; Patient Satisfaction; Randomized Controlled Trials as Topic; Relaxation Therapy [*methods]; Supine Position; Yoga

\section{MeSH check words}

Female; Humans; Pregnancy 